\title{
Alternative Development Practice: The Role of Personal Conceptions of
}

\section{Development and Self-Understanding}

A thesis submitted to Victoria University of Wellington in partial fulfilment of requirements for the degree of Master of Development Studies

By

Dan Harris

School of Geography, Environment and Earth Sciences

Victoria University of Wellington 


\section{ABSTRACT}

It seems to be a favourite past time of development studies lecturers to begin their courses with the question: "What is development?" This old chestnut invariably serves its purpose of challenging and complicating our understandings of development and stimulating a good deal of debate. It is rare however, if this question is ever followed by any real guidance on how to answer it or consideration of what the answer might mean for one's practice. For those seeking an alternative development practice in the context of a 'development' that grows ever more theoretically complex and morally ambiguous, I argue that engaging with and answering this question at a personal level is of vital importance.

Within development studies, debate continues to grow over the definition of development's ends and means, and over who controls it, defines it and benefits from it. In particular, alternative development approaches originating from Another Development thinkers of the 1970 s are concerned with challenging the conceptualisation of development by opening its interpretation to multiple value systems and realities. At the same time there is an increasing awareness of the 'primacy of the personal' (Chambers, 1994 p3) through the implication of personal ethics and awareness in development practice. I argue that the combination of these factors gives rise to a personal challenge for alternative development practitioners to engage with and understand their own conceptions of development. A challenge that practitioners are not equipped to meet as they lack the conceptual and methodological tools required to move from abstract development theory to concrete practice.

In response to these challenges my research draws on my personal experience as an intern in Latin America and employs an innovative auto-ethnographic methodology to examine the potential of development 'theorias' for orientating alternative development practice. Theorias are personal conceptions of development that allow 
practitioners to work with their own understandings of good change and structure these in relation to development and development practice. Employing reflective practice methods, I draw on my own experience as a novice development practitioner to investigate the elaboration of development theorias and their consequences for alternative development practice. The results suggest that theorias could provide practitioners with appropriate 'tools' with which to reflect upon, work through and explore personal conceptions of development as the basis for alternative development practice. My research indicates that theorias could also form the basis of an 'alignment based approach' to alternative development that facilitates cooperative processes aimed at co-creating and working towards new conceptualisations of development. The overall result is a unique contribution to the field of development studies which provides an example of reflective processes and conceptual tools for practitioners to constructively engage with the central questions of development's ends and means from within the context of their own practice. The lack of literature regarding reflective engagement with practitioner conceptions of development highlights the importance of this research and its potential to contribute to alternative development practice and theory. 


\section{ACKNOWLEDGEMENTS}

Carrying out this research was not an easy journey and I give thanks to all those who helped me along the way. First and foremost to my friends and family at home and overseas who kept me sane and gave me strength. In particular I thank Chelsea for being by my side while I was overseas; our memories will always stay with me.

I also want to acknowledge the generous support and encouragement of my supervisor Sara Kindon who was a friend as well as a guide. Thank you for challenging me, for appreciating my ideas and for offering me yours.

I offer my sincere appreciation to the directors and staff of the NGO that I interned with during my research and to the community members that I got to meet and who were kind enough to participate in my research. To the NGO members in particular I offer my apologies if the results of my research appear critical and I want you to know that I deeply respect you as friends and colleagues. I wish you well and I hope you can bring about the changes that you are looking for.

To the administrators of the SYLFF fellowship I express my heartfelt appreciation for the funds provided to me through the SYLFF scholarship without which I would have been unable to carry out this research. In particular I thank Naomi for her continuous assistance and quick response during the administration of the scholarship.

Last but not least I would like give thanks to all those other spiritual teachers and seekers who have inspired me. Even when not cited directly, their teachings and ideas have helped me to trust in my own spiritual experiences and to shape and express my 
own conceptions of spirituality. So among many and with no assigned order I give thanks to:

Marcus Aurelius - For his teachings on acceptance and Tao and the joy we can take from being good people.

Lao Tzu - For giving a name to Tao and the inspiration to trust in life.

The Dalai Lama - For his teachings on the power and centrality of love and compassion.

* Krishnamurti - For helping of me to understand the pervasiveness of the ego and the true meaning of freedom.

Geofrey Gore - For sharing the teaching of the Baha'i faith with me and the mirror of our heart.

* Theodore Roszak - For letting me know that I am not alone in this yearning and that it is good.

Herman Hesse - For opening my heart and providing a mirror for my life.

* The unknown Imam - For helping me take the first step. 


\section{DEDICATION}

I dedicate this work to the memory of Corey Amohanga.

A big brother, a true friend and a good man.

Wish you were here. 


\section{TABLE OF CONTENTS}

ABSTRACT

ACKNOWLEDGEMENTS

DEDICATION V v

TABLE OF CONTENTS Vi

LIST OF BOXES $\quad x$

LIST OF TABLES

LIST OF FIGURES Xii

INTRODUCTION

SECTION A: RESEARCH CONTEXT 8

$\begin{array}{ll}\text { Chapter 1: Theoretical Research Context } & 8\end{array}$

1.1 Introduction 8

1.2 Key Research Concepts in Relation to Development 9

$\begin{array}{ll}1.3 \text { Alternative Development } & 14\end{array}$

1.4 The Personal Challenge of Alternative Development 20

Practice

1.5 The Personal Challenges of Participatory Methodologies, 23

Post-Development and Complicity

1.6 Self Understanding and Spiritual Approaches to Alternative 30

Development

1.7 Summary: The Centrality of Personal Conceptions of 36

Development in Alternative Development Practice

Chapter 2: Practice Research Context 38

2.1 Introduction 38

2.2 Absence of the Personal in Practice Literature 39 
2.3 Personal Practice Theories of Development

2.4 Reflective Practice and Personal Development Theorias 44

2.5 Challenges and Limits to Reflection 48

2.5.1 Relational Domains of Reflection 49

2.5.2 Power and Reflection $\quad 50$

2.5.3 Reflection and Limits to Learning 52

2.6 Summary: Reflective Practice for Developing an 54

Alternative Development Practice

Chapter 3: Personal Research Context 57

3.1 Introduction $\quad 57$

3.2 My Journey So Far 57

$\begin{array}{ll}\text { SECTION B: RESEARCH APPROACH } & 60\end{array}$

$\begin{array}{ll}\text { Chapter 4: Research Process and Methodology } & 60\end{array}$

4.1 Introduction $\quad 60$

$\begin{array}{ll}\text { 4.2 The Research Process } & 61\end{array}$

$\begin{array}{ll}4.3 \text { Research Epistemology } & 66\end{array}$

4.4 Research Methodology 68

$\begin{array}{ll}4.5 \text { Methods and Techniques } & 70\end{array}$

$\begin{array}{ll}\text { 4.5.1 Data Analysis Methods } & 73\end{array}$

4.6 Strengths and Weaknesses of my Research Approach 75

4.7 Summary: A Subjective and Reflective Approach to 77

Researching Theorias

$\begin{array}{ll}\text { SECTION C: RESULTS AND ANALYSIS } & 79\end{array}$

Chapter 5: Constructing a Personal Theoria of Development 79

$\begin{array}{ll}5.1 \text { Introduction } & 79\end{array}$

$\begin{array}{ll}\text { 5.2 Description of the Research Process } & 79\end{array}$ 
5.2.1 First Reflective Phase

5.2.2 Second Reflective Phase $\quad 84$

$\begin{array}{ll}\text { 5.2.3 Third Reflective Phase } & 87\end{array}$

5.3 Presentation of Results, Discussion and Critique 89

5.3.1 The Process $\quad 89$

$\begin{array}{ll}\text { 5.3.2 Observations } & 91\end{array}$

$\begin{array}{ll}\text { 5.3.3 Critical Reflection } & 93\end{array}$

5.3.4. My Theoria 95

$\begin{array}{ll}\text { 5.3.5 Observations } & 97\end{array}$

$\begin{array}{ll}\text { 5.3.6 Critical Reflection } & 98\end{array}$

5.4 Summary: Processes for Constructing Personal Theorias of 100

Development

Chapter 6: The Role of Development Theorias in Personal 101

Practice

$\begin{array}{ll}6.1 \text { Introduction } & 101\end{array}$

$\begin{array}{ll}\text { 6.2 Description of the Research Process } & 101\end{array}$

$\begin{array}{ll}\text { 6.2.1 Overview of the Critical Incident Analysis } & 101\end{array}$

$\begin{array}{ll}\text { 6.2.2 Description } & 102\end{array}$

$\begin{array}{ll}6.2 .3 \text { Judgement } & 103\end{array}$

$\begin{array}{ll}\text { 6.2.4 Analysis } & 104\end{array}$

6.3 Presentation of Results, Discussion and Critique 107

$\begin{array}{ll}\text { 6.3.1 Critical Incident Analysis Results } & 107\end{array}$

6.3.2 Observations 112

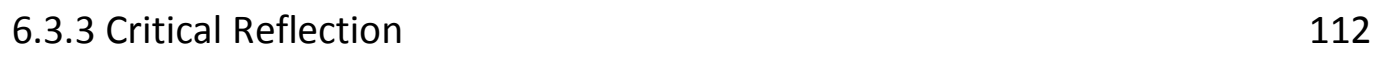

6.4 Summary: Development Theorias and Personal Practice 114

Chapter 7: The Significance of Actor Theorias in Development 115

Processes

$\begin{array}{ll}7.1 \text { Introduction } & 115\end{array}$

$\begin{array}{ll}\text { 7.2 Description of the Research Process } & 115\end{array}$ 
7.3 Presentation of Results, Discussion and Critique

7.3.1 Context and Actors

7.3.2 Interpretation of Actor Theorias of the Community Conservation Area

7.3.3 Observations 136

7.3.4 Critical Reflection

7.4 Summary: Theorias and Alternative Development Initiatives

SECTION D: FINAL REFLECTIONS

Chapter 8: Reflecting on Research Implications

8.1 Introduction 142

8.2 Personal Implications of the Research 142

8.3 Implications for Alternative Development Practice

8.4 Implications for Alternative Development Theory 147

8.5 Concluding Reflections 


\section{LIST OF BOXES}

Box 1. Definitions of Spirituality 4

Box 2. Self-Understanding in Definitions of Spirituality 31

Box 3. Broad View of Reflective Practice Resulting from the 47

Influence of Critical Reflection

Box 4.Reflective Practice Approaches Relevant to the

Construction of Theoria

Box 5. Conceptual Framework for my Theory of Development

with Reflective Questions

Box 6. Conceptual Framework for my Practice Theory of 88

Development with Reflective

Box 7. Reflective Process for Developing a Personal Development

Theoria based on Self-Understanding

Box 8. Critical Incident Description 103

$\begin{array}{ll}\text { Box 9. Results of the Critical Incident Analysis } & 107\end{array}$

Box 10. Interpretive Structure for Actor CCA Theorias 116 


\section{LIST OF TABLES}

Table 1. Summary of Alternative Development in relation to

Dominant Development

Table 2. Original Themes and Categories for Reflection

Table 3. Revised Themes and Categories for Reflection

Table 4. List of Values

Table 5. New List of Values 85

Table 6. My Conceptions of Good Change in Relation to Myself and Others 
LIST OF FIGURES

Fig 1. My Personal Theoria of Development 95

Fig 2. Official CCA Theoria of the NGO 123

Fig 3. Director Theorias of the CCA 125

Fig 4. Donor Theorias of the CCA 128

$\begin{array}{ll}\text { Fig 5. Field Worker Theorias of the CCA } & 130\end{array}$

Fig 6. CCA Member Theorias of the CCA 133 


\section{INTRODUCTION}

"What is development?" The question is a favourite of development studies lecturers seeking to stimulate debate and complicate their students' understanding of development. It is rare however, if this challenge is ever followed by guidance regarding how to answer the question or a consideration of what the answer might mean for one's practice. For those seeking an alternative development practice in the context of a 'development' that grows ever more theoretically complex and morally ambiguous, I argue that engaging with, and answering this question at a personal level is of vital importance. Unlike more conventional associations with participatory or sustainable development, my use of 'alternative development' traces its genealogy to the Another Development movement of the 1970s. This more radical understanding of alternative development challenges the ends of development along with the interpretation of the concept itself, an approach that has most recently resurfaced in the form of 'alternatives-to-development' (Escobar, 1995b) within post-development theory. It is towards these kinds of alternative development approaches (discussed in greater detail in Chapter 2) and the challenge that their ambiguous conception of development presents for development practitioners that my research is orientated. In addition to the challenge of conceptual ambiguity, there is also a an increasing awareness of the 'primacy of the personal' (Chambers, 1995 p3) in alternative development practice with a growing implication of personal ethics and awareness in development practice. The result is that alternative development practitioners are currently faced with a practice context that is personally challenging and morally and conceptually ambiguous while receiving little guidance with which to navigate it.

My thesis argues that this ambiguous context presents a personal challenge to development practitioners to define their own conceptions of development as a means of orienting their practice. In relation to this challenge, I argue that alternative development practitioners are often not equipped with the conceptual and methodological 'tools' they need to move from abstract development theory to 
concrete practice. From idealist assumptions and theories to the messy, complex and very human reality of the development arena (Long, 2003). As a result, my research examines the potential of development 'theorias' for orientating alternative development practice. Theorias are personal conceptions of development that allow practitioners to work with their own understandings of good change and structure these in relation to concepts of development and development practice. In exploring the role of these personal conceptions of development my research focuses on the questions:

a) How can practitioners construct personal conceptions of development to guide their alternative development practice?

b) What is the significance of an engagement with personal development theorias for one's practice?

c) What is the significance of interactions between different actor theorias of development for development initiatives, processes and outcomes?

In investigating my research questions I have employed an innovative autoethnographic methodology grounded in a constructivist epistemology. This autoethnographic methodology focuses on my experience as an intern in Latin American NGO involved in alternative development projects. The methodology draws on my experience to outline a process for developing practitioner theorias and explore the consequence of these theorias for individual practice and for alternative development processes. In doing so the methodology draws on reflective practice and moves through three iterative cycles of reflection that employ different reflective lenses including appreciative reflection, critical reflection and an actor-orientated lens.

While being an auto-ethnographic approach my research does not engage with my personal theoria of development in isolation but uses it as a reference point for reflecting on the development conceptions of other actors. In particular I examine how the power relations in which different development actors are entangled shape their 
conceptions of development and the interaction and manifestation of different theorias of development in practice. I also examine how the personal theorias of different actors shape broader development processes including the outcomes of alternative development initiatives.

As an auto-ethnographic and highly reflexive research approach it is important that I begin my thesis with an exploration of my researcher positionality. My research has primarily been carried out from the position of a novice development practitioner and I consciously adopt a practitioner perspective throughout the research. In doing so, I recognize that my practitioner 'gaze' (England, 1994) is one of a relatively privileged minority world development practitioner whose interest lies in working with actors in majority world countries. I interpret my privilege in terms of the relatively high degree of economic, political and socio-cultural (existence of familial and social ties and responsibilities) freedom that I possess and recognise that a large part this freedom derives from my relationship with powerful development discourses (Kapoor, 2004). In presenting my research I employ a constructivist epistemology that sees the information provided here, including my descriptions of others, as based on my own subjective interpretations. As a result, my thesis includes substantial background information regarding the personal context of my research (Chapters $3 \& 4$ ) in order to contextualise my interpretations and highlight the positionalities that underpin them.

In addition to my subjective practitioner perspective, I engage with my research as a spiritual person drawn to understanding myself and my place in the world. Throughout my research I frequently reference the spiritual in relation to development approaches, self-understanding and hopeful onotologies. Subsequently, it is important to provide an explanation of how I will be using the concept of spirituality throughout my thesis. From my own perspective I see spirituality as both a personal experience and a journey that involves cultivating understanding, developing connection with oneself, others and the cosmos and cultivating one's higher qualities of being - one's spiritual values and virtues. This personal interpretation forms the basis for my 
research engagement with spirituality and throughout my thesis I have drawn on the work of development theorists and practitioners who share a similar interpretation (See Box 1).

Box 1. Descriptions of Spirituality from Development Literature

Spirituality is:

- Our inner world, our inner space.

- Our sense of connection and relationship with ourselves, others and the divine.

- An inner and outer journey of exploring ourselves and our personal meaning as well as our connection and inter-relationship with others.

- The search for fulfilling relationships with ourselves, others and the divine.

- The working out of the morals, values and relationships that guide our lives.

- A sense of connection of belonging and wholeness.

- Our struggle to understand ourselves and the world around us.

- Knowing ourselves while continuing to act for and as part of the whole.

- Our felt experience of the supernatural and divine realms.

- Our search for personal meaning and fulfilment.

- Involves the relationship between the individual, the collective and the universe

- Is the inner self who defines who we are

- Is based on the actual experiences of the divine dimensions of reality

- Peoples' search for meaning that becomes embedded in their ways of life

- The personal beliefs by which an individual relates to and experiences the supernatural realm

- A personal relationship with the supernatural or spiritual realm that provides meaning and a basis for personal and communal reflection, decision and actions

(Ver Beek 2000; Chile \& Simpson, 2004; Sanderson, 2007; Singh, 2007; Lunn, 2009)

In particular I have focused on the spiritual aspects of self-understanding and personal meaning making with a focus on the role of personal beliefs and values regarding one's life and the world. In doing so I see spirituality as concerned with one's inner space, with our 'selves' as a realm for exploration, understanding, reflection and creativity. In line with Singh (2007), I also believe that this search for meaning is not carried out in isolation but is based on one's profound connection or relationship with others and the visible and invisible/felt dimensions of the world. 
In engaging with spirituality it is also important to explain how I distinguish spirituality from religion. For me religion is the institutionalised and collective expression of individuals' unique and subjective spiritual experiences:

While religion is generally considered an institutionalised set of beliefs and practices regarding the spiritual realm, spirituality describes the personal and relational side of those beliefs, which shape daily life. So while one could be spiritual without being religious or vice versa, in practice the two are commonly intertwined as people experience and describe their spirituality through a religious perspective.

(Ver Beek, 2000 p32)

As a result, spirituality and religion are often intertwined and while religions may be different, it is often possible to establish connections and dialogue between them based on shared spiritual values and beliefs (Agnivesh, 2003). Personally I do not consider myself religious as I do not identify with any particular religion but am instead drawn to the shared wisdom, values and teachings found in multiple religions.

One final point I wish to clarify regarding my use of spirituality is that while I engage with my research as a spiritual person, my thesis is not aimed at promoting a spiritual approach to development. Nor is spirituality a central axis of my research focus and instead my focus is on alternative development approaches and practices capable of engaging with multiple conceptions of development including spiritual conceptions among others. I engage with spiritual approaches to self-understanding because of my identification with them but acknowledge that equally profound engagements with self-understanding have been proposed by thinkers who would not consider themselves spiritual including the work of secular philosophers. 
With these understandings regarding my research focus, approach and positionality clarified, I will now provide a brief outline of my thesis structure and my target audiences. My thesis consists of four main parts including:

- Section A: Research context

- Section B: Research approach

- Section C: Results and analysis

- Section D: Final Reflections

Section A involves a description of the research context in terms of its theoretical (Chapter 1), practice (Chapter 2) and personal groundings (Chapter 3). The section frames my research in relation to the central challenge faced by alternative development practitioners in terms of the tension that exists between alternative development's ambiguity and the need to define it. In doing so, the context section highlights how this tension underpins the need for personal conceptions of development based on self-understanding and explores approaches and tools for developing these.

Section B involves a description of the research approach including a subjective account of the research process (4.2) followed by a more detailed description of the research epistemology, methodology and methods employed (4.3-4.5). In outlining my research approach this section highlights the subjective and practitioner orientated nature of the research and addresses some of the strengths and weaknesses of the approach.

Section $\mathrm{C}$ of my thesis presents and analyses the results emerging from my investigation. The section is divided according to the three cycles of reflection that took place in my research (Chapters 5, 6 \& 7) with each providing a detailed description of the research process along with a presentation of the results and their 
analysis in the form of observations and critical reflections. Insights emerging from the analysis illustrate how personal theorias of development could be constructed by practitioners and the role that such theorias play in individual practice as well in broader development processes and outcomes.

Section $\mathrm{D}$ concludes the thesis by presenting final reflections on the results and analysis outlined earlier drawing out key conclusions in relation to the three main audiences for my research:

- Myself and the practice and career that I am cultivating.

- Alternative development practitioners who are seeking to navigate the challenges of alternative development and engage with their personal conceptions of development in practice.

- Academic writers engaged with alternative development theory and critical approaches to alternative development in particular.

In doing so the final section of my thesis concludes with explorations of the role of alignment in individual practice and as a broader approach within alternative development. 


\section{SECTION A: RESEARCH CONTEXT}

\section{Chapter 1: Theoretical Research Context}

\subsection{Introduction}

In the following chapter I ground the focus of my research in the personal challenges of alternative development practice. I define alternative development as concerned with diversifying and reinterpreting the concept of development itself so that it more clearly reflects the values, beliefs and aspirations of the different peoples undertaking and experiencing it. While I argue that alternative development offers a promising approach for re-imagining development, it also presents practitioners with a range of intellectual, ethical and practical challenges. Principal among these is the need to engage with the ambiguous, critical and contested nature of development itself (Thomas, 2004). As a result, this chapter will outline the personal nature of this challenge beginning with a clarification of key theoretical concepts including my understanding of alternative development and the intellectual genealogy underpinning it. Following on from this, I examine the central challenge posed by alternative development's ambiguous nature and its need for definition, and how this tension creates a challenge for practitioners at a personal level. I outline the role that personal conceptions of development could play in addressing this challenge, and how dominant critical approaches within alternative development limit a creative engagement with such a solution. The chapter concludes with a focus on spiritual approaches to alternative development and the role that self-understanding and hopeful onotologies could play in engaging with personal conceptions of development. 


\subsection{Key Research Concepts in Relation to Development}

In order to lay a firm theoretical foundation for my research it is important to clarify the key concepts that underpin it including my understandings of development, dominant development, institutionalised development and the development practitioner. I believe that one of the main reasons for the confusion caused by the question "What is development?" is because it addresses development as a single phenomenon. In contrast, and throughout my study, I will engage with development as a multiplicity of both normative conceptions and socio-historical change processes related to the pursuit of the good life (Goulet, 1997). For me, development's normative nature is concerned with the pursuit of collective good change (Chambers, 1997), a pursuit common to all humans throughout history. At the same time, the normative nature of development means that multiple conceptions of development must exist due to different interpretations of 'the good life' along with the possibility that one group's conception of good change may be considered bad change or "antidevelopment" by another (Goulet, 1975). At the same time the socio-historical processes that emerge in the pursuit of development may or may not result in good change depending on who experiences it, who benefits from it and whether it 'works' or not. While good change may have historically gone by many names before, I argue that the world is witnessing an unprecedented phenomenon in the spread of 'dominant development' as a hegemonic conception of good change.

As a normative concept, I associate 'dominant development' with a universalised conception of good change promulgated by the industrialised economic powers which emerged towards the end of the Second World War (Latouche, 1992; Ziai, 2007). Related to terms such as economic development (Escobar, 1995) or mainstream development (Pieterse, 1998), this conception of good change divided the world into developed and underdeveloped countries with the good life being equated with the lives of the former. These developed countries were considered the nations of Western Europe and North America as well as their white settler ex-colonies and 
Russia (Nabudere, 1997). According to the dominant development concept, good change simply involves becoming like the developed countries and copying their economic, social and political systems (Mehmet, 1996).

This division between the developed and underdeveloped can be traced back to earlier dichotomies of civilised/uncivilised peoples that facilitated the expansion of European colonialism (Kothari, 2006) and further back to the Hellene/Barbarian dichotomy prevalent in the Greek and Roman Empires (Lepenies, 2008). Assertions of cultural superiority or autocentricism (Shahid Alam, 2003) are obviously not unique to Western empires and are notable in Mesopotamian, Egyptian, Chinese, and the Islamic civilisations (Muzhou, 2005; Shahid Alam, 2003). However, what makes Western autocentricism unprecedented is its ability to project its cultural superiority on a global scale and to eclipse all other conceptions of civilisation (Mehmet, 1996). This hegemony is due to the former reach of the European colonial empires and the subsequent hegemony of American power, both united in the concept of civilisation as modernity (Lushaba, 2009). As a result the image of the good life and good change presented by dominant development is one of progress leading to modernity (ibid) and the attainment of a modern life characterised by ease, comfort and material wealth (Norberg-Hodge, 1992).

Since its inception in the 1940s, the concept of dominant development has been implemented in practice through institutionalised development. Institutionalised development is a form of pursuing good change whose practice is professionalised and realised through an established industry of development organisations and institutions (Flora \& Flora, 2006). These organisations largely derive their theories and procedures from the economically wealthy and powerful industrialised nations while their activities are primarily orientated to improving the lives of those in poor underdeveloped countries (Escobar, 1995). As a result, dominant development has led to the emergence of a unique practice of good change that is a highly professionalised and primarily orientated to one set of peoples - the underdeveloped nations. 
In practice, dominant development has meant that the developed countries keep doing what they are doing while underdeveloped countries have to catch up through institutionalised development programs (Flora \& Flora, 2006). However, while dominant development continues to be its main discourse (Agostino, 2007), institutionalised development has expanded to incorporate and support alternative development approaches that employ different means and conceptions of "good change" (Kiely, 1999). Notable examples include the emergence of the Another Development movement from within development policy circles (Freidman, 1992), the growth of post-development thinking from within academic disciplines associated with institutionalised development, and the institutional support for a wide range of NGOs working with alternative approaches to development (Korten, 1990). Consequently the practice of institutionalised development is far more complex than the simple implementation of dominant development and includes streams of resistance and reworking across multiple scales (Lewis et al in Lie, 2008).

Finally, with the advent of institutionalised development and the subsequent establishment of academic development studies programmes a professional class of development practitioners has come into existence. For this study I define development practitioners as those professionals dedicated to collective social change processes, motivated by the achievement of good change and who work with or within the context of institutionalised development. It is from a development practitioner perspective that my study will engage with the challenge of alternative development theory and practice.

In line with post-development critiques, I believe that dominant development as a normative concept promotes a largely harmful form of good change. I base my judgement on dominant development's promotion of homogeneity, oppression and harmful living patterns. In the first instance dominant development can be seen as 
promoting a homogenous modern and economic way of life based on "high levels of industrialization and urbanization, technicalization of agriculture, rapid growth of material production and living standards, and the widespread adoption of modern education and cultural values" (Escobar, 1995 p5).

Consequently, the dominance of dominant development negates or devalues other ways of living, other conceptions and practice of the good life and destroys diversity (Agostino, 2007). Related to this first point is the oppressive tendency of dominant development. While dominant development is harmful to many ways of life, it is obviously considered as good change by the few and the powerful who pursue it as a global agenda. As a result dominant development as a discourse can also be considered a form of oppression, the imposition of a conception of good change that benefits powerful elites while failing to deliver a good life or resulting in antidevelopment for the majority of peoples (Ziai, 2007). When implemented through institutionalised development it can lead to attempts to control and re-organise others' lives and societies based on external agendas and rationalities (ibid). Finally, many critics have pointed out that the dominance of dominant development leads to harmful patterns of living that are unsustainable and lead to societal and ecological breakdown (Kapra, 1982; Norberg-Hodge, 1992; Shiva, 1993; Rist, 2007).

These critiques of development as homogenous, oppressive and damaging are equally valid for the supposedly developed countries and not just the less industrialised nations. Little attention is given to the effect of being on the other side of the underdeveloped/developed dichotomy. I believe however, that being considered 'developed' equally restricts peoples ways of life and compels the 'developed' to maintain patterns of development that are harmful to themselves, others and the environment (Joans, 2000). 
It is at this point that I will cease to use the developed/underdeveloped dichotomy that unrealistically divides the peoples of the world along with its insinuation of superiority and inferiority. Instead I will employ the more nuanced terminology of minority and majority world peoples (Doyle, 2005). Minority world peoples are who are relatively privileged in economic and political terms and whose distribution is largely in the materially rich and politically powerful countries of the OECD. Minority world peoples tend to have a degree of power or authority vested in their identities due to their relationship with the discourse of dominant development and their being considered 'developed' and 'modern' (Kapoor, 2004). At the same time minority and majority 'worlds' are not constrained by bounded geo-political territories but are diffuse and composite. Minority world peoples for example can be found in majority world countries in the form of local elites while majority world peoples can be found in minority countries in the form of the marginalized (Doyle, 2005). The difference between majority and minority world peoples is further complicated by my definition of oppression derived from Freire's Pedagogy of the Oppressed (2005 p55) where "Any situation in which ' $A$ ' objectively exploits ' $B$ ' or hinders his pursuit of self-affirmation is one of oppression". As a result, I doubt that there are many people living in the global context of dominant development that could consider themselves completely liberated or non-oppressed. At the same time, I acknowledge that the oppression of majority world peoples (wherever they may be) is more severe due to the lack of resources (economic and political) available to them to resist or navigate oppression (Mathews, 2004).

Finally, while both majority and minority worlds are subject to the logic of dominant development, I do not believe that dominant development as a normative concept reflects the complex, multiple, and socio-historical 'realities' of the world. While it is important to outline why I believe the concept of dominant development can lead to a harmful way of life it is also important to emphasise that I consider these to be tendencies of dominant development and not its inherent outcomes. In minority and majority worlds there are peoples and organisations both inside and outside of institutionalised development that resist and re-work dominant development or 
pursue their own alternatives (Kavanagh \& Mander, 2004; Sen, Anand, Escobar \& Waterman, 2004; Korten, 2007). At the same time I acknowledge that there are those who are attracted to elements of dominant development or what they believe dominant development can provide (De Vries, 2007) and who fight for access to initiatives operating within its logic (Pieterse, 2000). Concrete socio-historical processes will always be the outcome of complex interactions between different conceptions and practices of development across different scales and within and between minority and majority world peoples (Freidman, 1992). In summary then, dominant development remains dominant as a normative concept within institutionalised development and the world at large. At the same time, institutionalised development has diversified and incorporated alternative conceptions and practices of development, while the manifestations of development as sociohistorical processes remain the complex outcome of interactions between different conceptions and practices of development across scales.

\subsection{Alternative Development}

In relation to the understanding of development outlined earlier, my research is grounded in the theoretical context of alternative development. My choice of an alternative development focus stems from my practitioner interest in alternative development practice in relation to dominant approaches to development. Within development studies literature alternative development is often associated with drug eradication programmes (UNOCD, 2005) or with participatory, sustainable or gender sensitive approaches (McGregor, 2009). However, my thesis engages with a different intellectual lineage originating in the Another Development movement of the 1970s and distinguished by a fundamental concern with redefining the ends, purpose and meaning of development itself (Freidman, 1992; Pieterse, 1998). From this alternative development orientation, participatory, gender and sustainability approaches to development would be considered 'alternatives-within-development' as they propose 
a re-working of dominant development's means rather than a challenging of its ends (Latouche in Kippler, 2010).

Alternative development first emerged under the guise of the Another Development movement (ADM) in the 1970s within the context of the 'crisis of development' (DHF, 1975). This crisis of development stemmed from the fact that after 30 years of development programs and in many cases significant economic growth, dominant development had failed to eliminate poverty, human misery or suffering (Freidman, 1992). In response, a movement of like minded thinkers emerged under the banner of the Another Development movement aimed at redefining the whole purpose of development (ibid). The movement and its associated thinkers and organisations were underpinned by a rejection of dominant development as a universal approach to good change arguing that:

What is conventionally termed development - dynamic economic performance, modern institutions, the availability of abundant goods and services - is simply one possibility, among many, of development in a broader, more critical sense.

(Goulet in Goulet, 1980 p482)

In response, Another Development thinkers called for approaches to development that were: “i) need-oriented (but by no means limited to the so-called 'basic needs'); (ii) self-reliant; (iii) endogenous; (iv) in harmony with nature and ecologically sustainable; and $(v)$ going hand in hand with people empowered to make structural transformations" (Nerfin, 1986 p172). One of the central pillars of this alternative development approach was endogenous development or development from within: "Development is endogenous; it springs from the heart of each society which relies first on its own strengths and resources, and defines in sovereignty the vision of its future" (DHF, 1975 p7). 
As a result, $A D M$ thinkers challenged dominant development's monopoly over the conceptualisation of the good life and the practice of good change and opened it up to multiple interpretations. This diversification of development also involved moving beyond the narrow economic focus of dominant development and dependency approaches, arguing that: "Development is a whole, it is an integral, value-loaded, cultural process; it encompasses the natural environment, social relations, education, production, consumption and well-being" (DHF, 1975 p7).

In particular ADM thinkers focused on the human dimension of development and were united by a people centred approach that saw development's ends and means as: "The development of every man and woman, of the whole man and woman and not just the growth of things which are merely means" (DHF, 1975 p7). The result of ADM's approach was an alternative development that rejected universal blueprints and conceptions of good change and argued for multiple conceptions of development that were holistic and human centred. Consequently, the definition of development's ends had to be endogenous and to come from within the societies and nation-states engaged in development.

In 1976 thinkers related to the ADM established the International Association for Development Alternatives (IFAD) whose Third System Project (TSP) championed a popular bottom up approach to development (Freidman, 1992). Launched in 1978 the TSP initiated an ongoing focus on civil society as the driver of alternative development which saw a shift to community level actors based on the argument that "the primary community whether geographical or organisational is the immediate space open to most people and where personal and societal development first and best interact" (IFAD, p11). 
This community level approach led to the emergence of another key dimension of alternative development - a focus on bottom-up participatory process as the means for achieving development (Oakley \& Marsden, 1985). This participatory approach was highly influenced by emerging radical approaches to research, activism and education including feminist empowerment approaches and critical pedagogy (Parpart, 2000). In contrast to later participation-as-means approaches (Parfitt, 2004), early alternative participatory approaches tended to be ends focused and seen as a "strategy for the creation of opportunities to explore new, often open-ended directions with those who were traditionally the objects of development." (Oakley \& Marsden, 1985 p13)

Due to a combination of factors, the Another Development movement began to wane in the 1980s with alternative development thinking becoming eclipsed by the popularity of alternatives-within-development approaches such as PRA based approaches to participatory development (Chambers, 1997), gender and development and sustainable development. However alternative development thinking saw an explosive return in the mid-1990s with the arrival of post-development theory as "a collection of outraged critiques" that once again fundamentally challenged the concept of dominant development (McGregor, 2009 p1).

While many authors disagree, I would consider current post-development a continuation of alternative development thinking. Essentially both post-development and alternative development share the same critiques (Pieterse, 2000) - that dominant development is a failure in its own terms, is harmful and violent, and imposes a Western modernist way of life on others (McGregor, 2009). Post-development initially distinguished itself through equating dominant development with institutionalised development leading to the rejection of both (Kiely, 1999), while alternative development had tended to explore ways that institutionalised development could support alternative conceptions and practices of development (DHF, 1975). However, as post-development thinking has evolved its more constructive forms now engage with institutionalised development and pursue similar solutions to alternative 
development - working with locally based alternatives that challenge the ends and means of dominant development (McGregor, 2009).

What remains distinctive of post-development is its use of a post-modern critique which sees development as an oppressive discourse used to promote Western hegemony over the rest (Kippler, 2010). As a result post-development thinkers tend to reject conceptions of development emerging from within Western scientific and academic traditions and to privilege local and non-western "alternatives-todevelopment" (Escobar, 1995b). Post-development has also contributed to alternative development through creating conceptual space for engaging with alternatives outside of institutionalised development (Radcliffe \& Laurie, 2006). Whereas Another Development thinkers had primarily pursued alternatives from within the context of institutionalised development practice (Freidman, 1992) (often considering themselves its prime architect), post-development thinkers draw attention to popular alternatives that exist outside of, or pre-date institutionalised development (McGregor, 2009).

One of the main criticisms levelled at alternative development is that it does not provide a coherent paradigm or theory of development (Pieterse, 1998). Drawing on the different streams of alternative development identified earlier (including constructive approaches to post-development), I believe it is possible to outline a normative approach to alternative development in contrast to that of dominant development (see Table 1.). The defining feature of such an alternative development approach is its normative and diverse conception of development's ends (Goulet, 1975; Sheth, 1987; Escobar, 1995) which remain open to multiple interpretations and as a result multiple conceptions and practices of good change. As a result, alternative approaches emphasise the agency (IFAD, 1980; Pieterse, 1998; Nerfin, 1986) and creativity (DHF, 1976; Escobar, 1995b; Carmen, 1996) of the actors involved in development and their ability to collectively imagine, design and pursue their own conceptions of development. Bottom-up processes play a key role in this alternative development approach (IFAD, 1980; Pieterse, 1998; Santos, 1999) as the means by 
which development actors can construct and pursue their conceptions of

development. Finally, alternative development approaches tend to focus on local

actors and majority world peoples as the main source of alternatives to development

(Freidman, 1992; McGregor, 1999; Mathews, 2007).

Table 1. Summary of Alternative Development in relation to Dominant Development

\begin{tabular}{|c|c|c|}
\hline & Alternative Development & Dominant Development \\
\hline Ends & $\begin{array}{l}\text { - Human Focused and Diverse e.g. aimed } \\
\text { at human fulfilment and well-being but } \\
\text { with no single formula, blueprint or } \\
\text { definition of the goals of development. } \\
\text { - Holistic e.g. human focused but engaged } \\
\text { with multiple dimensions of human } \\
\text { existence and the satisfaction of multiple } \\
\text { human needs. } \\
\text { - Endogenous e.g. determined according } \\
\text { to the aspirations and beliefs of the } \\
\text { people experiencing and/or undertaking } \\
\text { development processes. }\end{array}$ & $\begin{array}{l}\text { - Economic and Universal e.g. a universally } \\
\text { applicable development goal of material } \\
\text { wealth envisioned as economic } \\
\text { development. } \\
\text { - Reductionist e.g. conceived of as } \\
\text { primarily an economic objective from } \\
\text { which other goals will naturally be } \\
\text { achieved. } \\
\text { - Exogenous e.g. Determined by the } \\
\text { economically rich and powerful and } \\
\text { applied to the economically poor and less } \\
\text { powerful. }\end{array}$ \\
\hline Means & $\begin{array}{l}\text { People Power - Diverse but generally } \\
\text { based on individual and collective } \\
\text { empowerment and capacity building, and } \\
\text { bottom-up processes of change e.g. } \\
\text { decision-making and popular action. }\end{array}$ & $\begin{array}{l}\text { Economic Drivers - Primarily top-down } \\
\text { processes of change, designed and } \\
\text { facilitated by national governments and } \\
\text { institutions and linked to the market } \\
\text { economy and economic growth. }\end{array}$ \\
\hline Main actors & $\begin{array}{l}\text { People Centred - Humanity, individuals, } \\
\text { communities, especially the marginalized, } \\
\text { impoverished and oppressed through } \\
\text { individual and collective popular action } \\
\text { and transformation. }\end{array}$ & $\begin{array}{l}\text { Governments and Economic Institutions - } \\
\text { The nation state and international and } \\
\text { national economic institutions involved in } \\
\text { the design and implementation of } \\
\text { development programs and the } \\
\text { management of the national and } \\
\text { international economies. }\end{array}$ \\
\hline Scope & $\begin{array}{l}\text { Broad and Deep - Development involves } \\
\text { the whole human race and all nations and } \\
\text { due to the holistic and diverse nature of } \\
\text { development it is not possible to divide } \\
\text { the world into developed and } \\
\text { underdeveloped countries or peoples. }\end{array}$ & $\begin{array}{l}\text { Narrow and Linear - The North has } \\
\text { already achieved development and so } \\
\text { development efforts are now primarily } \\
\text { targeted at the South. Development will } \\
\text { be achieved by all when the economic } \\
\text { dynamics of the South reflect those of the } \\
\text { North. }\end{array}$ \\
\hline $\begin{array}{l}\text { Focus of } \\
\text { engagement }\end{array}$ & $\begin{array}{l}\text { Local and Global - Focus on the local } \\
\text { communities and the valuing and } \\
\text { championing of local development } \\
\text { conceptions. Global networks and } \\
\text { alliances of local civil society actors. }\end{array}$ & $\begin{array}{l}\text { National and Global - Focus on the nation- } \\
\text { state, achieving national economic growth } \\
\text { through tapping into global markets and } \\
\text { insertion in the global economy. }\end{array}$ \\
\hline
\end{tabular}


(DHF, 1975; Nerfin, 1986; Korten, 1990; Freidman, 1992; Joy, 1997; Pieterse, 1998)

The result is a broad approach that provides a conceptual and normative framework for the pursuit of multiple theories and paradigms of development. Rather than a single methodology and vision it creates space for diverse alternatives-to-development (Escobar, 1995b) linked by similar features including freedom, diversity, popular action and creativity. Within this framework several groupings of alternative development approaches can be identified including spiritual approaches (Kumar, 2003), cultural approaches (Tauli-Corpuz, Enkiwe-Abayao \& de Chavez, 2010), alternative economic approaches (Schumacher, 1989; Henderson, 1991) and transformative approaches (Rahman, 1993; Friere, 2005) with considerable cross-fertilisation between each. These different approaches both within and outside of institutionalised development present new possibilities for conceptions and practices of good change that aim to be diverse rather than homogenous, liberating rather than oppressive, and fulfilling rather than harmful. At the same time however, working with alternative development presents numerous challenges for development practitioners at a personal level. Challenges that require them to think through and reconceptualise their development practice.

\subsection{The Personal Challenge of Alternative Development Practice}

The main challenge that alternative development approaches pose for development practitioners is the ambiguous conception of development they present. These approaches cannot answer the question "What is development?" and instead emphasise that "no universal formula exists" (DHF, 1975 p7). In contrast dominant development approaches provide coherent, objective and universalised theories and practices that practitioners can work with. Instead alternative development approaches focus on the diversity of endogenous conceptions and processes of development and are unable to provide a guiding conception of development with 
which to orientate one's practice. At the same time, an alternative development practice inherently requires the existence and definition of an alternative conception of development. This is because alternative development is defined by its call for a different understanding of development, while processes or practices that are not guided by such an alternative vision cannot be considered alternative development at all (Pieterse, 1998). As a result, alternative development presents practitioners with an internal tension between the inherent ambiguity of its ends and the inherent need to define them. The pressure on practitioners to resolve this tension is amplified by the strong critiques that underpin most alternative development approaches. These critiques highlight the harmful nature of dominant development and the need to challenge its claim as a provider of generalised happiness (Rist, 2007) or risk becoming entangled in and replicating its harmful power relations (Kapoor, 2004). The result is a strong personal challenge for practitioners to develop an understanding of the alternative development ends and means that they wish to work towards through their practice.

The usual response from within alternative development has been to side-step this personal challenge by focusing on 'the other'. Alternative development's focus on local actors and bottom-up processes has led to an emphasis on supporting majority world peoples' local and endogenous conceptions of development (Escobar, 1995b; Mathews, 2007; McGregor, 2009). Deferring one's conception of development for that of another in development practice is problematic for several reasons, essentially however, such a response does not solve the main challenge of alternative development. Instead this tactic simply replaces one personal challenge "What is development?" with another "Whose development should I support?" Faced with multiple and potentially competing alternative conceptions of development, practitioners are required to choose between them and judge whether the initiatives pursued by local actors constitute good change (Mathews, 2007). As a result, practitioners must once again refer to their own understandings of 'good change' or 'a good way of life' in order to make these decisions. 
So where are practitioners to get their alternative conceptions of development from? If one is to take the alternative development framework as a guide then conceptions of development should be developed from the bottom-up, the foundation of which is always the individual. Such conceptions should be endogenous, should come from within the person, and be based on their beliefs, values and aspirations. This position is emphasised by ADM thinkers who argue that development is primarily "a question of values and human attitudes [and] self-defined goals" (Goulet, 1997 p1161). As a result, alternative development seems to suggest that practitioners should engage with their 'selves' - their own beliefs, values and aspirations - as the foundation for developing an alternative development practice. In other words, that the practitioner's personal conception of development should act as the basis for pursuing and assessing alternatives-to-development. Such a position could easily meet with resistance from within alternative development due to the risk of repeating dominant development's imposition of outside values and beliefs. However as Mathews (2007 p141) has argued: "Our concern not to impose particular values in the way many development initiatives have done in the past cannot lead us to embrace a naive relativistic stance which refuses to favour any group or initiative over another". Cooke (1997 p336) goes further in arguing that:

There are no forms of engagement that are not interventions...and which do not reflect the interventionists norms and values about making things better, not least in the very choice to act in one arena and not another, and to pretend otherwise is dishonest.

As a result, the development practitioner's beliefs and values - his/her conceptions of 'the good' and 'good change' - are already and always at play in development interventions. 
Working with personal conceptions of development suggests a creative engagement with one's personal beliefs and values and their adoption as the foundation of an individual's alternative development practice. Consequently, the central challenge of alternative development - the tension between its inherent ambiguity and its demand for clarity - appears to offer an invitation to personal creativity. A challenge for practitioners to engage with themselves - their beliefs, values and aspirations - in order to answer the question: "What is development for me?" In doing so they have the opportunity to arrive at the personal understanding of development required to guide their practice as well as their engagement with other's alternatives-to-development. Unfortunately such an approach meets with considerable resistance from within alternative development in the form of dominant critical approaches which are not conducive to a constructive engagement with the practitioner's self.

\subsection{The Personal Challenges of Participatory Methodologies, Post-Development and Complicity}

Within development studies literature, ends focused participatory approaches (such as participatory action research) and post-development theory constitute the dominant methodological and theoretical discourses in relation to alternative development. Both participatory methodologies and post-development theory can be considered critical approaches due to their conceptual grounding in a broad family of approaches linked to Critical Theory (Taylor, 2010) and its Marxist critique of society (Poutanen \& Kovalainen, 2009). While diverse, these approaches share a common focus on social justice and challenging the status quo to expose relationships of oppression and discrimination (Deranty, 2010). In challenging injustice, critical approaches emphasise the role of unequal power relations between different social groupings including classes, genders and races (Fasenfest, 2006). While differences clearly exist between participatory and post-development approaches, they generally share a common focus on the existence of unequal power relations, a central concern with social justice and a focus on critiquing the harmful effects and practices of development. In addition they 
also tend to pose similar barriers to practitioner engagement with personal conceptions of development. My reading of the literature associated with these critical approaches indicates a generally unsympathetic engagement with practitioner's selves (their identities, beliefs and values) and practitioner conceptions of development. Instead the literature tends to emphasise the problematic nature of practitioners' beliefs, values and identities for development practice resulting in a predominant 'dono-harm' ethos that focuses on working with and mitigating the harmful potential of practitioners' selves. Rather than a resource, these critical approaches often portray the practitioner's beliefs, values and conceptions of development as harmful influences in development practice.

In the case of participatory methodologies the rejection of the self as a resource is based on a critique of the unequal power relations that exist between practitioners and local actors in development processes. Participatory approaches argue that development initiatives often fail because powerful development practitioners tend to impose their realities on local situations (Chambers, 1997). As a result practitioners privilege their own priorities and understanding of development problems and solutions while ignoring the need for local knowledge, solutions and leadership (ibid). In response, participatory methodologies are aimed at reversing and neutralising the unequal power relations that exist between practitioners and local actors (Kapoor, 2004). The result is a focus on the practitioner as facilitator, acting as the mid-wife for other's development processes. A key part of this facilitation involves neutralizing the practitioner's negative behaviours, attitudes and assumptions (Chambers, 1997). Consequently, participatory approaches tend to portray the practitioner's outsider or "upper" (ibid) conception of development as a negative influence. Engagement with the practitioner's values, beliefs and conceptions of development is then limited to critique and self-effacement (Fetcher, 2012).

Post-development theory deepens the critique of the practitioner's influence through implicating them in the harm caused by dominant development. Employing a post- 
modern (Santos, 1999) or post-structural critique (McGregor, 2009) post-development shows how powerful elites in the minority world employ development as a discourse to maintain and justify their domination over minority world peoples (ibid). In contrast to participatory development, there is no methodological solution to this challenge as development practice itself is considered harmful due to the discourse it is embedded within. As a result, development practitioners are called on to facilitate from a distance by creating intellectual or political 'space' for the emergence of alternatives-todevelopment (Nabudere, 1997; Escobar, 2007; McGregor, 2009). While postdevelopment theorists call for creativity and imagination in the construction of alternatives-to-development this is almost exclusively aimed at local actors and new social movements in the minority world (Habermann \& Ziai, 2007). As a result, practitioners and their conceptions of development are often implicitly portrayed as having little to offer (Esteva \& Prakash, 1996) or seen as potentially harmful due to their association with dominant development (Kapoor, 2004).

While post-development theory has received criticism for its lack of engagement with the micro-politics of development practice (Kippler, 2010) several authors have sought to extend its critique through an engagement with the concept of 'complicity' (Spivak, 1988; Kapoor, 2004; Kindon, 2012). The original Spivakian/Kapoorian approach to complicity presents the world as a generally oppressive system dominated by Western hegemony which devalues other cultures and maintains its own dominance through powerful discourses (Kapoor, 2004). All those benefiting from these discourses are inherently complicit in them and tend to reproduce them through their words, actions and inactions (ibid). Critiquing both participatory methodologies and postdevelopment, Kapoor (2004) illustrates how the geo-political determinants of practitioner's identities easily leave them both blind (ibid p630) and deaf (ibid p639) to the agendas of the subaltern. At the same time their interaction with the subaltern results in silencing and appropriating marginalized voices in a way that serves powerful agendas and oppressive discourses (ibid). As a result, Spivak and Kapoor's approach to complicity poses perhaps the greatest personal challenge for alternative development 
practitioners who are implicated in the oppression of less powerful others not only through their direct association with development but through their very identities.

Authors working with complicity reject the possibility of self-effacement or the ability to disassociate oneself from development which in turn renders facilitation and representation deeply problematic (Kindon, 2012). In response, practitioners are called on to practice hyper-self-reflexivity in order to confront their complicities and create the context for an ethical encounter with the subaltern (Kapoor, 2004). In the Spivakian/Kapoorian approach this involves thorough self-critique and the confession of one's arrogance, prejudices and implications in oppressive power relations (Kapoor, 2004). This approach to complicity sees the practitioner's self as a generally harmful influence and their conceptions of development as inherently "contaminated" (Kapoor, 2004 p641) by oppressive discourses.

As outlined above, dominant critical approaches within alternative development limit a constructive engagement with practitioner's personal conceptions of development by portraying practitioner's beliefs, values and identities as generally harmful influences. My argument is that these critical approaches fail to significantly engage with the positive potential of practitioner conceptions of development due to the critical ontology that underpins them. Rooted in a Marxist philosophy these critical approaches tend to view the world and the relationships between humans through the lens of power, struggle, oppression and injustice. The result is a critical ontology which sets up a series of powerful dichotomies that tend to cast practitioners and their selves as potentially harmful influences. This same ontology also tends to ignore the practitioner's creativity and downplays their ability to extract themselves from harmful relationships and to imagine new possibilities for their conception and practice of development. 
At the heart of the critical ontology underpinning participatory, post-development and complicity lies a predisposition to viewing power and the powerful as harmful. Such thinking can be traced to the Marxist roots of critical approaches and their focus on oppression, class struggle, and idealisation of the oppressed masses (Mathews, 2007). This focus on power as used to oppress sets up a series of dichotomies that construct practitioners as inherently or potentially harmful and predisposed to oppression in comparison to local actors who are powerless, harmless and the source of creativity, imagination and alternatives (Pieterse, 1998). Such naive dichotomies tend to ignore the agency of local actors and their capacity to avoid harm and to cause harm as well. As Habermann \& Ziai (2007) have pointed out, there is no reason to assume that local actors and activists are ethically pure or devoid of harmful power relations.

Within critical approaches these simplistic dichotomies and the focus on the powerful as harmful leads to an engagement with the practitioner's self within a predominant 'do-no-harm' ethos. This do-no-harm ethos privileges critique over creativity and leads to a focus on value free facilitation, creating space for other's alternatives-todevelopment or the working through of complicities. In practice, the do-no-harm ethos tends to orientate practitioners towards 'undoing-harm' rather than seeking to understand or enact 'the good'. An example is the focus of many critical approaches on ending oppression, while largely ignoring questions such as emancipation for what? or freedom for what? The result is that practitioners find themselves distanced from the local actors they would seek to partner with as well as from their own personal creativity in conceptualising their development practice.

Finally, the critical focus on power and its ability to oppress, control and constrain tends towards a devaluing of practitioner agency. Both structuralist and poststructuralist critical approaches privilege the framing (e.g. power structures, dominant discourses) over the individual in ways that potentially disregard the individual's agency. For example, simplistic interpretations of Foucauldian discourse within postdevelopment tend to undermine practitioners' abilities to do, be and imagine in non- 
harmful ways (Lie, 2008; Kippler, 2010). Based on the argument that it is impossible to be outside of discourse, these interpretations portray practitioners as bearers of discourse who "reproduce the very discourse by which they are shaped" (Lie, 2008, p122). Such a position ignores the fact that just as it is impossible to be outside of discourse, it is equally impossible for discourse to be outside of us (Long, 2003). That it is people who give meaning to discourse and who interpret, misinterpret or reinterpret it (Lie, 2008). Meanwhile, the influence of more simplistic uses of discourse means that the practitioner's values, beliefs and conceptions of development are not considered a resource for re-imagining development as they remain contaminated by the oppressive discourses in which practitioners are embedded.

Recently there have been moves from within critical approaches to more constructively engage with the roles of power, practitioners and possibility in development processes. Hickey and Mohan (2004) have argued for the transformative potential of participatory development in pursuing empowerment while postdevelopment authors have begun to experiment with a more engaged approach to practice (Gibson-Graham, 2005). In addition, post-development theorists are increasingly calling for the use of creativity, imagination and possibility in the search for alternatives-to-development (Escobar, 1995; Santos, 2004; McGregor, 2009). Within complicity thinking, Gunaratnam (2003) and Kindon (2012) have sought to work with the ambivalent and constructive dimensions of complicity showing how forms of complicity are necessary for confronting and challenging unjust power relations.

Within wider critical approaches to alternative development an awakening to the world as a place of possibility and hope as well as of oppression and injustice appears to be taking place. However these more constructive approaches remain limited by the critical ontology which underpins them leading to contradictions. For example, while participatory approaches have moved from a means to an ends focus and employed a more sophisticated use of power (Kesby, 2007), practitioners are still called upon to use their power to facilitate the development processes of others from which they are 
separate. Within post-development, Gibson-Graham's (2005) example of a practice that 'dares to intervene' illustrates a constructive new approach while being indicative of the resistance that many in post-development still experience when directly engaging in the practice and envisioning of alternative development processes. Despite many post-development thinkers calling for an ontology of possibility (McGregor, 2004), the imagining of possibilities still remains largely reserved for local actors with Escobar ironically be-moaning the lack of imagination of European thinkers (Escobar, 2004 p225) while in the same article implicitly excluding them from the business of alternatives (ibid p207). While Kapoor critiques this essentialising and romanticizing of local actors and the use of 'us and them' thinking he also inevitably falls back on an oppressor/oppressed dichotomy when referring to the subaltern and "Western" development practitioners (Kappor, 2004). Meanwhile, more constructive approaches to complicity still remain grounded in a do-no-harm ethos while at the same time pointing towards new directions capable of moving beyond it (Kindon, 2012).

Alternative development requires an ontology of possibility, an ontology of hope. As an approach, alternative development is predicated on a faith in the existence of multiple endogenous conceptions of the good life and good change, and the possibility these offer for a different world. While more constructive critical approaches also call for an ontology of possibility and hope (McGregor, 2009) it is a hope that is placed explicitly in other's alternatives to development. This may be great for others but in the context of institutionalised alternative development practice what is also required is an ontology for practitioners. A hopeful ontology that constructively engages with practitioners' roles in alternative development, with practitioners' selves and with practitioners' conceptions of development. A do-no-harm ethos is not enough for alternative development practice, practitioners need their own understandings of the possibilities they are pursuing. In doing so, who the poor and marginalized are and what the poor and marginalized do is not sufficient. What alternative development practice requires is an ontology of possibility that validates the practitioner's agency and their ability to create their own vision of what they are for, who they support and why. Such a vision would be the basis for an ethos of "doing good" and not just "doing 
no harm". These conceptions of development would not be totalising discourses but individual endogenous conceptions based on the practitioner's own culture, values, and beliefs and drawn from their relationships with others and the world around them. In order to engage with such personal conceptions of development, an ontology of possibility would require a balanced approach to the practitioner's self. An approach that sees the practitioner's self as a resource and acknowledges the helpful as well as the harmful dimensions of practitioners' identities, beliefs and values. I believe the basis for such an approach would involve working with self-understanding, a concept effectively ignored in most critical approaches but evident in spiritual approaches to alternative development.

\subsection{Self Understanding and Spiritual Approaches to Alternative Development}

Spiritual approaches to alternative-development interpret the ends and means of development according to spiritual conceptions and place a strong emphasis on the spiritual and moral development of human beings as the foundation of development processes (Goulet, 1980; BIC, 1998; Kumar, 2003). Consequently, they constitute an important space for considering alternative approaches to the self and the personal in alternative development practice. Whereas critical approaches typically portray the self as an identity positioned in a web of power relations, spiritual approaches focus on the self as a conscious spiritual and moral being. The self is essentially not an outer construct but an inner space to be explored and cultivated through self-understanding. The focus on self-understanding within the spiritual approaches to alternative development that I engage with in my research is indicated below in Box 2 . 
Spirituality is:

- An inner and outer journey of exploring ourselves and our personal meaning as well as our connection and inter-relationship with others.

- The working out of the morals, values and relationships that guide our lives.

- Our struggle to understand ourselves and the world around us.

- Right living - how to live our day to day lives in the right way and according to the right values and principles.

- Knowing ourselves while continuing to act for and as part of the whole.

- Our search for personal meaning and fulfilment.

(Ver Beek 2000; Chile \& Simpson, 2004; Sanderson, 2007; Singh, 2007; Lunn, 2009)

These descriptions highlight the role of self-understanding in the working out of one's personal values, morals and beliefs. At the same time, they illustrate how selfunderstanding is not purely introspective but involves understanding one's relationships with others and the world. An understanding of ourselves so that we might know how to live in an ethical and fulfilling way (Fortin, 2002). As a result, critical and spiritual approaches are not incompatible and have at times been combined (Alkire, 2006) most notably in Freire's use of liberation theology to develop his critical pedagogy (Stenberg, 2006). What spiritual approaches require however is an emphasis on the practitioner as the subjective experiencer of reality, the conscious interpreter and re-creator of discourse and the active negotiator and mediator of power relations. The practitioner as a conscious self, capable of generating and drawing on their own experiences, beliefs and values in order to question and shape their understandings and actions.

One of the foundations of personal agency related to spiritual descriptions of the self is the human capacity for self-understanding. I define self-understanding as knowledge of the self - one's beliefs, values, relationships, meanings, identities, patterns, 
assumptions, faults, biases and prejudices - cultivated in order to live well by developing ones positive attributes and guarding against one's harmful ones in relation to others and the world. I contrast self-understanding with dominant types of selfanalysis carried out in critical approaches which are aimed at self-effacement (Fetcher, 2012) or self-transformation (Kapoor, 2004) through self-critique. Within spiritual approaches self-understanding can be seen as contributing to development practice through a) self-transformation, b) orientating practice, and c) engaging with others.

\section{a) Self-Understanding for Transformation}

In contrast to dominant critical approaches which often regard the self as a harmful influence, spiritual approaches generally take a more optimistic if ambivalent approach. Spiritual approaches begin from a conception of human beings as inherently flawed and imperfect, complex and conflicted but possessed of the potential to be and to live better (Hope \& Timmel, 2003; Loy, 2003; Alkire, 2006; Mesbahuddin, 2010). Consequently practitioner's selves are seen as a domain for developing their positive potential through cultivating self-understanding and being the change they want to see in the world (Ghandi in Cohen, 2006). At the same time this is not considered merely an individual practice but is also part of a collective process of selftransformation or 'being better together' that is central to spiritual approaches to alternative development (BIC, 1998; Hope \& Timmel, 2003; Agnivesh, 2003). As a result spiritual approaches affirm the practitioner's agency and their ability to transform themselves through reflecting upon, choosing and pursuing different ways of being and doing. An approach to self-understanding that emphasises practitioner creativity (Westboy, 2005; Sanderson, 2007) and "a determination to cultivate a counter-imagination to the one 'given' by the dominant infused with social hope" (Westboy, 2005 p16).

b) Self-Understanding for Orientating Practice 
Spiritual approaches call on practitioners to understand and cultivate their own conceptions of development as part of their development practice (Chile \& Simpson, 2004). In developing these counter-imaginations of development's ends and means, spiritual approaches see the practitioner's self as a resource for development practice. Practitioners' are called on to engage with their personal and collective wisdom and with spiritual and felt dimensions of knowing (Goulet, 1980) in order to answer questions such as:

- What is my conception of the good life and the good society?

- What is the good change I want to see in the world?

- Who is the human at the centre of development?

What is my relationship and responsibility to other human beings?

In doing so spiritual approaches emphasise that these are questions that cannot be solely answered by theories or critiques but require practitioners to look within themselves and develop personal answers (Chile \& Simpson, 2004). In order to do so, spiritual approaches to self-understanding highlight the role of engaging with one's own beliefs, values and virtues (Kliksberg, 2003; Loy, 2003; Lunn, 2009). The results would be personal conceptions of development that are "centred set, not bounded set"- centred on one's counter imagination of development rather than "bounded in closed orthodoxies of practice, method and fundamentalisms" (Westboy, 2005 p17). Such a process for orientating one's practice based on self-understanding would be continuous. The continuous process of understanding a self that is essentially unknowable, shifting and multiple. The continuous identification and cultivation of those beliefs and values that contribute towards a good life and good change while guarding against those that cause harm to oneself or others (Dalai Lama, 2001). 


\section{c) Self-Understanding for Engagement with Others}

While developing self-understanding is seen as important for orientating individual development practice, spiritual approaches also emphasise its role in engaging with and supporting other conceptions of development. From this perspective selfunderstanding is seen as the basis for a dialogue between practitioners and local actors regarding their development conceptions and aspirations (Muzaffar, 1999; Ver Beek, 2000; SDC, 2005). That in order for practitioners and local actors to establish relationships and build alliances, they need to be open about their different understandings and conceptions of development and the values and beliefs underpinning them (SDC, 2005 p24). This openness and dialogue is once again based on self-understanding and the practitioner's ability to reflect on and evaluate their beliefs and conceptions of development in relation to those of others.

Self-understanding is also seen as important for ethical interactions with others, as Agnivesh (2003) argues: "Paying lip service to spiritual values will not do. The emphasis must be on realizing such values in the given social, political, economic and cultural context. Spirituality is a paradigm of engagement" (ibid p37). As a result, a selfunderstanding of one's beliefs and values is the groundwork for an ethical engagement with the other which is based on doing good as well as doing no harm. As James (2010) argues - living one's virtues rather than simply trying to avoid one's vices could transform practice (ibid p22). This call is supported by several authors who have highlighted how developing self-understanding provides the fertile ground for an ethical engagement with others based on one's experiences of, beliefs in and capacity for solidarity, humility and outrage against injustice (Hope \& Timmel, 2003; Chile \& Simpson, 2004; Westboy, 2005). At the same time, other authors (Krishnamurti, 1944; Loy, 2003; Westboy, 2005) have echoed critical calls for a corresponding awareness of our harmful beliefs and behaviours in relation to others. Cultivating such awareness requires reflection on the harmful implications of our beliefs and ways of life in light of our fundamental values and personal conceptions of good change. 
The role of self-understanding as outlined above, offers a promising way forward in resolving the tension that exists between alternative development's inherent ambiguity and its necessity for definition. Self-understanding supports a constructive engagement with the practitioner's self as a resource and endorses the role of personal conceptions of development as a guide for development practice. In addition, spiritual approaches and their engagement with self-understanding indicate the potential for a more hopeful ontology that sees humans as capable of 'being better together', and practitioners of 'being the change they wish to see in the world'. Such an ontology creates space for practitioner agency and creativity in their conception and realisation of an alternative development practice orientated towards 'doing good'.

At the same time critical approaches would prove complimentary for such an engagement with self-understanding. While spiritual approaches to self-understanding focus on the importance of personal beliefs and values, critical approaches draw attention to how these relate to broader agendas, discourses and power relations. Spiritual approaches tend to focus on the practitioner's capacity for creativity and imagination while critical approaches draw attention to the boundaries and barriers that restrict agency. And while spiritual approaches focus on the practitioner's conscious self, critical approaches highlight its relational, fluid and shifting nature. The combination of these approaches within a hopeful ontology ensures that a practitioner engagement with self-understanding does not reify the self, blind practitioners to the limits of their agency and self-knowledge, or ethically isolate the practitioner from the relationships and agendas in which he or she exists. 


\subsection{Summary: The Centrality of Personal Conceptions of Development in Alternative Development Practice}

Alternative development practitioners operate in a practice context that is conceptually and morally ambiguous and personally challenging. While practitioners find themselves distanced from control over development's end and means they are at the same time increasingly implicated at the personal level in the success or failure of development initiatives and in the oppression of those they would seek to help. Within alternative development much of these challenges stem from the dominance of critical approaches and their inability to provide guidance for practitioners in developing their own understandings of development. While critical approaches are also essentially aimed at achieving good change they are limited in their ability to explore what this means through their focus on criticism and their lack of a hopeful ontology.

In contrast, the focus on self-understanding within spiritual approaches to development offers a promising way for practitioners to engage with their own conceptions of development as the foundation of an alternative development practice. This conception of self-understanding offers a new vision of the self for practitioners to consider - the self as a source of positive insights and personal strength, a self that is fluid and free to re-imagine and pursue new ways of being and doing. An approach in which practitioner's beliefs and values are seen as a resource for re-imagining their world, for changing themselves and for engaging in sincere dialogue and collaboration with others. At the same time, the critical focus on society, context and power can be seen as complimentary to the spiritual approach to the self and one's inner space. As a result, within alternative development I choose to ground my engagement with the self and personal conceptions of development within the context of spiritual approaches to self-understanding. 
Self-understanding reinforces the importance of personal conceptions of development in navigating the conceptual and moral ambiguity of alternative development practice. Personal conceptions of development can help practitioners decide what kind of change they want to be involved in, how this relates to the kind of practice they adopt and to the allies, organisations and approaches they choose to engage with. The question then is how to move from aspirations to reality, how to engage with selfunderstanding and personal conceptions of development in practice? What methods and practices are available for engaging with personal conceptions of development and how might they be employed? In the next chapter I will move from theoretical groundings to practice literature to examine how current research has engaged with these topics. 


\section{Chapter 2: Practice Research Context}

\subsection{Introduction}

Can we change the future through purposeful intervention, including collective organised action? By definition development practitioners must believe this. However faith is not enough. We need tools. These tools include theories that are tools with which to think.

(Eyben et al., 2008 p201)

In this chapter I explore development practice literature in order to identify tools with which alternative development practitioners might develop personal conceptions of development based on self-understanding. The chapter begins with a discussion of the literature revealing that a lack of engagement with the personal in development practice has led to a corresponding lack of tools for engaging with personal conceptions of development. Existing literature tends to employ either an instrumentalist approach or a critical analysis of the practitioner's self that does not engage with a self-understanding orientation. As a result, I turn to the literature surrounding personal theories of development and development practice as a means for engaging with personal conceptions of development in the form of development 'theorias'. I then move to reflective practice literature found largely outside of development studies in order to identify tools for exploring and constructing 'theorias'. The chapter concludes by examining some key considerations and limitations in the use of a reflective approach including the need for relational domains of reflection, considerations of power and limits to learning. 


\subsection{Absence of the Personal in Practice Literature}

An overview of relevant literature reveals that Chamber's call for the 'primacy of the personal' in development practice appears to have fallen on deaf ears in the academy (Fechter, 2012). This lack of engagement with the personal fundamentally undermines the exploration and construction of personal conceptions of development based on self-understanding within the field of development studies. Despite the powerful implication of the personal emerging from alternative development approaches, the development practitioner's self and its role in development practice have remained largely invisible in practice literature (Brigg, 2009). When personal values, perceptions and worldviews are given priority it is usually in relation to local actors and how to include their beliefs and values in development processes. As the first and only journal issue dedicated to the role of the personal in development practice asserts: "This situation is remarkable insofar as those involved in aid work are acutely aware of the relevance of the personal, while 'formal' development discourses and institutions tend to be anxious, silent or even hostile on the subject" (Fechter, 2012 p1387).

One notable exception to this dearth of literature are instrumentalist and critical approaches to the practitioner's self. Instrumentalist approaches seek to "understand the efficacy of the self in the development process and account for it accordingly" (ibid, p1391). These approaches ignore the agency of development practitioners and tend to "frame the personal such that aid worker's subjectivities and relationships need to be understood in order to make them operational for the aid process" (ibid, 1390). Those studies that do engage with development practice from a practitioner perspective tend to focus on reflexivity as opposed to self-understanding. Reflexivity emerged as a form of self-reflection within social studies research in the 1970s aimed at acknowledging (and mitigating) the effect of the researcher's subjectivity in research (Finlay, 2002; Dowling, 2008). Since then reflexivity has generally been associated with critical approaches to research and involves reflecting on one's identity and research practice. As with other critical approaches, reflexivity follows a "do-no-harm" 
imperative that sees the influence of the practitioner's identity, beliefs and values as potentially negative or harmful. As a result reflexivity seeks to avoid or mitigate the influence of the practitioner's behaviour, assumptions and identity by becoming aware of them and acting accordingly.

As a result, engagement with the personal and the practitioner's self in practice literature has largely been through the lenses of instrumentalism and self-critique. In particular, the lack of engagement with personal conceptions of development in the practice literature can be linked to:

a) The dominance of critical approaches to the self outlined earlier, in particular participatory methodologies and their focus on self-effacement and selfrestraint (Fechter, 2012).

b) Institutionalised development's continued focus on development as orientated exclusively towards helping impoverished or less powerful others. The result being an instrumentalist focus on development practitioner's selves in relation to processes aimed at benefiting others rather than as something important and valuable for development practitioners themselves (ibid).

c) The separation of theory and practice and of theorists and practitioners within development studies. Engagement with development concepts is restricted to theorists whose ideas are to be applied by practitioners while practitioner conceptions of development are not considered important (Reeler, 2007).

Development studies' lack of constructive engagement with the personal and with selfunderstanding is in marked contrast to other 'helping professions' such as nursing, social work and education which have established traditions for engaging with personal values and beliefs as part of their practice (Fechter, 2012). An exception to the lack of engagement with self-understanding and personal conceptions of development can be found in a debate that emerged in the mid-1990s. It is to these 
ideas that I now turn in order to explore personal theories, and practice theories, of development.

\subsection{Personal Practice Theories of Development}

In the mid 1990s an academic debate took place amongst several authors (Cooke, 1997; Blunt, 1997; Bell, 1997; Joy, 1997) which resulted in a call for personal theories of development. The debate emerged out of a search for a coherent practice theory for development practitioners and Cooke's (1997) proposal of a clinical/process consultation model as the general framework for such a theory. This clinical/process consultation approach involved practitioners adopting a similar practice theory to other helping professions with a particular focus on medical professions.

At the same time however, Cooke's model implicitly required practitioners to set aside or harmonize their own values and beliefs with those contained within the clinical/process model. This led to critiques from both Blunt (1997) and Bell (1997) who highlighted the "tyranny of methodology" (Bell, 1997 p449) and its potential to be "self-fulfilling, seeing the world in terms of itself and in terms of a deep based...ontology and epistemology" (ibid p450). This tyranny of methodology leads to development practitioners becoming imprisoned in modernist Western-scientific paradigms (such as the process consultation model) (Blunt, 1997 p348) which limit development practice (Bell, 1997).

While agreeing with Cooke's call for a theory of development practice, Joy (1997) built on the critiques of Bell and Blunt through asserting that "any theory of practice is a theory of intervention in a system about whose working there must [also] be a theory" (ibid p454). Consequently, challenging the development profession to adopt a process consultation model as its theory of practice also requires practitioners to adopt 
process consultation's conception of development's ends (ibid). Joy regarded this as highly problematic due to practitioners' different conceptualisations of development, arguing that: "There is unlikely to be a single theory of practice appropriate to all of these" (ibid). Instead Joy emphasised the need for theories of development to guide development practice, theories which draw on personal understandings of development's ends and means and engage with practitioner's values (ibid p455-456). In doing so, he asserted that:

Those of us choosing [to be involved in development assistance] need to address... questions about who we are - what is our role - how we relate, who or what we are trying to assist, to influence, to promote. Such discernment is a discipline that our training should help us develop.

(ibid p456)

What Joy proposed was the need for personal theories of development in order to develop personal theories of practice; the combination of these two theories could be considered a personal 'theoria' of development (Eikeland, 2008; Eikeland \& Nicolini, 2011; Eikeland, 2012). Theoria is one of the two ancient roots from which the modern term 'theory' is derived, the other being 'theoresis' (Eikeland, 2012). In Aristotelian philosophy 'theory' included both abstract knowledge as well as practical knowledge and could be derived from multiple ways of knowing including both distanced observation and lived experience (ibid). Theoria was concerned with theory as personal insight and actionable knowledge generated from within the individual's experience, while theoresis was knowledge attained by viewing something from a distance (ibid; Eikeland \& Nicolini, 2011). While theoria was considered a valid form of knowledge until the middle-ages, theoresis has since assumed hegemony within the academy as the only true form of knowledge (Eikeland, 2012). 
As a result, development practitioners are currently faced with an education that distances them from development by leaving its conceptualisation to theorists and its application to practitioners. I would argue that what alternative development practitioners need in order to engage with their personal conceptions of development is a practice based on theoria. Rather than theoresis's natural science approach aimed at representing and modelling from the outside, theoria can be likened to a grammar approach (Eikeland \& Nicolini, 2011). As a theory, grammar highlights the intimate relationship between the knower and the known underpinned by the fact the "we are internal to grammar [as] grammar is internal to us" (ibid p169). Theoria's grammar approach to theory is explicitly constructed from within the experience of the practitioner, aimed at making the grammar of their experience explicit and whose validity lies in its (continued) adherence to their pattern of lived experience (ibid). Like grammar, theoria is normative as well as descriptive and analytical (ibid) and can be considered a manifestation of the practitioner's theoretical and practical wisdom (Eikeland, 2008). As a result, working with theoria provides a promising tool for adopting a self-understanding approach that engages with personal experience and normative beliefs and values in order to develop personalised conceptions of development and development practice.

Within alternative development practice, theorias could be considered the combination of a practitioner's personal conception of the good and good change and their personal conception of how these should be pursued in practice. At the same time, a development theoria would also (and always does) include knowledge gained from theoresis (Eikeland, 2012). As part of theoria however, theoresis is explicitly engaged with from within the grammar of the practitioner's experience and the intimate relationship between known/knower, experience/practitioner. As a result the construction of development theorias could produce practice knowledge which "consists of fully integrated knowledge that combines learning from doing and thinking about practice with learning from other information sources" (Jarvis in Refsum, 2007 p7). Knowledge that would aid alternative development practitioners in their ability to "distinguish between right and wrong and to explain what you do and why" (Refsum, 
2007 p3). Such knowledge could prove a valuable resource for those navigating the morally and conceptually ambiguous context of alternative development practice. As a result, theorias provide a promising conceptual 'tool' for practitioners to structure their personal conceptions of development in a way that integrates their understandings of development as good change and development as practice. Having identified theoria as a promising conceptual tool, I will now explore the ways in which practitioners can construct their own theorias of development. In seeking an answer to this question I turn to the field of reflective practice as an approach for engaging with self-understanding for the creation of personal development theorias.

\subsection{Reflective Practice and Personal Development Theorias}

In the development of both personal practice theory and theoria, several authors have highlighted the role of reflective methodologies (Cooke, 1997; Eikeland \& Nicolini, 2011) while Brigg (2009) highlights that “[e]xamining developers' selves is necessarily a reflective ethical task" (ibid p1411). While reflexivity generally employs a critical focus on the self, I believe that reflective practice provides a more promising and constructive approach. Reflective practice originated from within action research and experiential learning disciplines with a focus on improving practice by reflecting on and learning from it (Fook, White \& Gardener, 2006). In doing so, reflective practice aims to identify and compare one's explicit and implicit theories of practice. Explicit theories are those that we consciously espouse and subscribe to in our professional practice while implicit theories are those that manifest themselves unconsciously in our professional practice and in how we do things (Fook \& Gardener, 2007). These theories are in turn underpinned by personal values and assumptions.

Reflective practice is essentially concerned with - "trying to put your values into practice and becoming more aware of the contradiction between what we say and what we do" (Ghaye et al. 2008 p363). Such an approach clearly resonates with a focus 
on self-understanding and the need to reflect on implicit values and beliefs in order to construct explicit theorias of development. However reflective practice and the needs of alternative development diverge in regards to both the focus and purpose of reflection. Whereas reflective practice assumes the existence of explicit practice theories which practitioners need to reflect upon and modify, alternative development practitioners are essentially concerned with reflecting on implicit values and beliefs in order to develop an explicit theoria of development. In order to overcome this limitation I believe it is useful to adopt a spiritually engaged approach to reflective practice.

Recently reflective practice has begun to engage with spirituality as a dimension of both reflection and practice (Johns, 2005; Mas Suibhne, 2009). Authors such as Beres (2004) and Hunt (2006) have explored the practice of reflection on personal spirituality and its incorporation in to the meaning making of practitoners. In particular, Hunt (2006) has highlighted the work of Wellington and Austin and their identification of transpersonal reflective practitioners who: "tend to be inner-directed and to focus on self-development and on the relationship of internal to external... [and] questions such as: "how can I integrate my personal/spiritual growth with my vocation?'” (Hunt, 2006 p6).

As a result, reflective practice's engagement with spirituality provides an opportunity for the integration of "an individual's 'inner life', including their spirituality, and the enactment of her/his working life" (ibid p8). This reflective orientation works with a self-understanding approach by shifting the focus from trying to understand one's actions in relation to one's theories/values, towards trying to understand one's conception of practice in relation to oneself. In doing so spiritual approaches broaden the scope of reflection in a way that allows practitioners to draw on life experiences rather than just practice experiences as the basis for constructing their theorias. This broad scope of reflection enables practitioners to draw on profound personal values 
and beliefs related to good change in order to inform their alternative development theorias - a focus which forms the core of my thesis research.

In addition to a spiritual orientation, both appreciative and critical reflection offer valuable reflective lenses and methods for the construction of development theorias. Appreciative reflection focuses on what works in practice and reflects upon positive experiences, beliefs and attributes (Ashdord \& Patkar, 2001). As a result, appreciative reflection seeks to identify personal strengths or positive values and beliefs through reflecting on past experiences including peak experiences and past successes (Ghaye et al. 2008 p361). This appreciative lens proves complementary to a spiritual engagement by providing a focus on analysing the positive experiences, values and beliefs related to one's conception of the good life and good change.

In contrast, critical reflection draws on reflexivity, post-modern deconstruction and critical theory in order to reflect upon the social context in which one's practice takes place (Fook, White \& Gardener, 2006). In doing so, critical reflection seeks to identify dominant power structures, power relations and discourses and examines their influence on one's professional practice and explicit and implicit values and assumptions (ibid). While a critical reflective lens may seem removed from an engagement with inner beliefs and values, its focus on knowledge construction and embodied knowledge supports a reflective practice that is more in line with the broadened scope of spiritual reflective practice (Box 3 ). This broadened understanding of reflective practice validates its role as a form of inductive, bottom-up theory building conducive to the construction of development theorias based on personal experience. Critical reflection also provides a reflective orientation which addresses the need for relational reflection (outlined later in 2.5.1) that explores one's contexts and relationships with others. 
Reflective Practice is:

i. a process (cognitive, emotional, experiential) of examining assumptions (of many different types and levels) embedded in actions and experience;

ii. a linking of these assumptions with many different origins (personal, emotional, social, cultural, historical, political);

iii. a review and re-evaluation of these according to relevant (depending on the context, purpose, etc.) criteria;

iv. a reworking of concepts and practices based on this re-evaluation.

(Fook \& Gardener, 2007 p12)

Finally, critical reflection provides a complimentary critical focus on beliefs, values and practices that can help practitioners identify and guard against the role of negative beliefs, values and actions within the context of their practice.

Taken together, a spiritual engagement with reflective practice combined with appreciative and critical reflection suggests a possible path for engaging with and creating personal theorias of development (Box 4.).

Box 4.Reflective Practice Approaches Relevant to the Construction of Theoria

\section{Reflective Practice and Development Theorias}

1. Spiritual Engagement with Reflective Practice

- Inner focused reflection

- $\quad$ Engagement with personal meaning making, beliefs and values.

- $\quad$ Broadens scope of reflection to spirituality and life experiences.

2. Appreciative Reflective Practice

- $\quad$ Provides a reflective lens for analysing positive beliefs and experiences.

- $\quad$ Provides a reflective method for generating positive beliefs from positive experiences.

3. Critical Reflective Practice

- Validates reflective practice as a form of inductive theory building.

- Supports a broadening of the scope of reflection in line with a spiritual engagement.

- Provides a relational lens of reflection that focuses on relationships with other actors and influences. 
My research will draw on this approach to engage with my own beliefs and experiences as a case study for the elaboration of a personal development theoria. The process will involve self-reflection based on self-understanding and will engage with fundamental spiritual beliefs and values in order to detail my conception of the good life and good change in the form of a development theoria. However in attempting to develop a process for the elaboration of development theorias it is first necessary to consider key challenges and limits to such a reflective approach.

\subsection{Challenges and Limits to Reflection}

While engaging with reflective practice provides a promising approach for establishing and working with development theorias it also provides a range of challenges that need to be addressed when considering such a process. In this section I examine three of the principle challenges or considerations when engaging with reflective practice for self-understanding and the construction of development theorias. The first consideration is the need for 'relational domains of reflection' i.e. reflection that focuses on ones relationship to others and broader social relationships so that reflection does not become mere navel gazing. The second consideration is the need for reflection on the role of power relations and positionality as outlined in reflexivity literature. Finally the third challenge to reflection is the limits to learning that reflective approaches face including the impossibility of transparent self-reflection and the reluctance to challenge or change one's deep seated conceptions of the world. I address each of these challenges below and elaborate on how they have shaped my research approach. 


\subsubsection{Relational Domains of Reflection}

While the personal domain of the self forms the basis for a reflective practice aimed at creating development theorias, it is important to heed Brigg's (2009) caution that:

Engaged self-reflection cannot involve solipsism for it must consider the necessarily external relations which constitute the self and bring it into existence. Encounters and exchange with others are essential to this effort, and to addressing ourselves to the ethico-political challenges of development.

(ibid p1423)

As the result, the engagement with personal development conceptions and the creation of theorias needs to take into account relational domains of reflection. These are domains in which practitioners reflect on how their personal conceptions of development shape and are shaped by their relationships with external actors and influences. In order to engage with relational domains of reflection my research employs an actor orientated approach to explore the consequence of my own and others' development theorias within my experience of development practice. The actor orientated approach (AOA) emerged in the 1970s as "a strong critique of structural and institutional types of explanations" (Long, 2003 p47). In response, AOA adopts "a theory of agency based upon the capacity of actors to process their [own], and learn from others', experiences and to act upon them", (ibid p49) and "to devise ways of coping with life even under the most extreme coercion" (Long, 2001 p16). As a result, AOA promotes reflection on practitioner agency and how the different understandings and agendas of actors (including oneself) manifest and interact in development practice. In doing so, AOA facilitates an engagement with actor theorias through an emphasis on how "meanings associated with development are produced, contested and re-worked in practice... [and] the multiple significances that the term holds for actors" (Lewis et al. in Lie, 2008). 
As a relational domain of reflection, $A O A$ focuses on the contextual role of social interfaces as "situations and places where different - and often conflicting - life worlds meet; where different local actors and interventions interact and where the different actors see their own realities and work on how to achieve certain goals they may have for themselves, which as a result shape the actual outcome of a particular intervention." (Long, 2001 p65-66). These interfaces take place in different development arenas: "spaces in which contests over issues, claims, resources, values, meanings and representations take place" (ibid p242), ranging from field visits to official donor meetings. Such social interfaces provide a useful focus for relational reflection as fleeting or more permanent intervention situations where the manifestations and interactions of different actor theorias of development can be reflected upon.

Finally, reflecting on the interaction and relationship between different actor theorias of development within particular social interfaces can provide insight into how these interactions influence development processes and outcomes (Segers et al., 2008). This can include reflection on how the understandings and practices of development interventions are shaped and re-worked according to the interpretations and agendas of different practitioners and local actors (Latour in Long 1992 p23). As a result, AOA provides the conceptual space for relational reflection on the significance of different actor development theorias for one's own and others' practice of development.

\subsubsection{Power and Reflection}

In engaging with relational domains of reflection it is important to consider the role of power and power relations as both domains and limits to reflection. While reflexivity's critical approach to the self may not be appropriate for cultivating development theorias based on self-understanding, both Feminist reflexivity (England ,1994; Rose, 1997) and hyper-self-reflexivity (Kapoor, 2004; Kindon, 2012) provide useful 
considerations for relational reflection. Feminist approaches to reflexivity emphasise the role of personal positionalities in shaping development interactions and processes (Nagar \& Geiger, 2007). These positionalities refer to the layers of socio-cultural and geopolitical determinants that shape one's identity including one's gender, class, age, race, sexuality, and nationality etc (Rose, 1997). Feminist reflexivity highlights how these different positionalities are constructed by and in turn construct different power relations between oneself and others (ibid). As a result, reflecting on positionalities offers a lens for understanding how some development theorias are privileged and others silenced according to the positionalities of those asserting them.

Kapoor's (2004) argument for hyper-self-reflexivity emphasises the inability of development practitioners to truly hear the voices of marginalized others due to their complicity in discourses which shape their perceptions and practices. In contrast to my focus on the self as a resource for constructing alternative development conceptions, hyper-self-reflexivity would argue for the influence of dominant discourses in constructing one's notion of self. For example, Cascardi (in Brigg, 2009) illustrates how "the modern subject rationalises itself and its historical emergence through 'the selfjustifying, homogeneous, and ostensibly coherent narratives of human progress, selfimprovement and growth'. One result is that... modern Western selfhood is also usually conceived of in developmentalist terms" (ibid p1419). While it may be an oversimplification to associate conceptions of linearity or personal growth with Western modernism and then with inherent harmfulness, such observations require practitioners to reflect more critically on the self as a source of theoria.

At the same time Kapoor (2004) and Kindon's (2012) engagement with the role of resistance in development interactions draws attention to a relational reflection on how local actors resist dominant development theorias in practice. This focus ties in to an $\mathrm{AOA}$ understanding of social interface as composed of multiple discourses and the need "to comprehend how dominant discourses are endorsed, transformed or challenged" including how "some actors 'vernaculise' dominant discourse in order to 
legitimise their claims" (Long, 2003 p54). Relational reflection should seek to identify these moments when actors pursue "room for manoeuvre" (ibid p55) within development projects i.e. moments when actors seek to pursue their own theorias within or by taking advantage of the theorias of others.

Finally, Kindon's (2012) more constructive use of hyper-self-reflexivity in relation to 'thirds' (Marcus, 1998) provides an additional reflective focus for exploring constructive manifestations of actor complicity in development practice. Thirds can be likened to shared concepts and understandings that manifest and facilitate interaction within social interfaces including globalised concepts such as 'human rights' and 'climate change' or more contextualised thirds such as the Treaty of Waitangi in New Zealand (Kindon, 2011 p97). Reflection on the role of thirds within development interventions can help to illustrate how differences and similarities between actor theorias emerge in relation to specific concepts and how complicity with these thirds can provide actors with 'room for manoeuvre'. As a result contributions from reflexivity provide a lens for critical reflection on the construction and mobilisation of different theorias of development with regard to power relations. At the same time, reflexivity's concern with power expands the domain for relational reflection through a focus on how actors seek room to manoeuvre within different power relations and seek to assert their own theorias including through complicity with conceptual thirds.

\subsubsection{Reflection and Limits to Learning}

Through a critique of transparent reflexivity, feminist theorists have also highlighted the limits to learning from reflection. Transparent reflexivity is the assumption that it is possible for the researcher to transparently know themselves and see perfectly and transparently their own 'landscape' of power relations i.e. the layers of positionalities that shape themselves and their perceptions of others (Rose, 1997). Transparent reflexivity has often been held up as the ideal for researchers resulting in "an 
impossible demand... to fully understand the context of his/her research rather than acknowledging that research is messy and often not fully knowable" (Kindon, 2012 p118). Critics have argued that this pursuit of transparent reflexivity can lead to endless identification of layer after layer of positionality while never becoming aware of key biases and prejudices that inform one's research (Finlay,2002). In relation to the reflective development of theorias such critiques require practitioners to acknowledge that it is impossible to construct a complete and enduring representation of their understanding of development and development practice. That implicit and possibly contradictory beliefs will remain hidden and that practitioners conceptions of development will necessarily grow, change and shift over time. As a result the construction and revision of theorias should be considered a continuous, ongoing and imperfect process.

The impossibility of transparent reflexivity is illustrated by the earlier critiques of feminist scholars regarding the failure of male critical theorists to acknowledge and address the unequal gender power relations that exist in academia (Smith, 1999). These critiques demonstrate that lack of transparency can also be related to one's avoidance of hard truths that challenge fundamental beliefs about oneself and the world. As a result, one of the biggest challenges for practitioners aiming to better understand their interpretations of themselves and their world, and to develop these through reflective practice, is their unconscious resistance to learning and changing (Von Eckhart, 1998). To illustrate this resistance it is useful to draw on personal construct theory (PCT) and its position that "people develop internal models of reality called constructs in order to explain and understand the world around them" (Celestine \& Leedom, 2007 p9). The sum of a person's different personal constructs is their personal construct system which is the person's 'truth' as they understand it (Frances, 1995; Laynton, 2009).

According to PCT when an individual's personal construct of reality is challenged they can either react by modifying that construct or by "avoiding" the challenge for 
example by rationalizing it away or undermining its validity (Walker \& Winter, 2005). As one's personal constructs shape their understanding of what to expect from reality (including their hopes and dreams) (Weiner \& Craighead, 2009), resistance to change may be strong. For example practitioners may persist in a harmfully complicit development practice despite evidence of its harmfulness because of their belief in the rightness of their practice and high expectations that their work will lead to good change in time.

Practitioners need to be aware of the tendency to avoid legitimate challenges to one's personal constructs which can limit the capacity of reflective practice to facilitate selfunderstanding and the effective use of development theorias. At the same, when the difference between one's construct system and one's experience of reality becomes too great an experience of cognitive dissonance (Remmers, 2007) tends to occur. While experiences of cognitive dissonance may be quite distressing they also offer vital opportunities for reflective learning that can generate new and important insights regarding one's conceptions of development and development practice. Becoming more vulnerable to self doubt and remaining open to cognitive dissonance can form the basis of a more effective reflective practice (ibid). In addition, the identification of cognitive dissonance and moments of avoidance can provide an important strategy in the reflective development and application of practitioners' development theorias.

\subsection{Summary: Reflective Practice for Developing an Alternative Development}

\section{Practice}

The lack of literature regarding reflective engagement with personal conceptions of development provides an opportunity for my research to contribute to alternative development practice. Despite a general lack of engagement, the literature surrounding personal practice theories and theoria present a promising opportunity to engage with personal conceptions of development. 
Theorias could provide practitioners with 'tools with which to think' and to see. Tools that help practitioners reflect upon, work through and explore new conceptions of development as the basis for alternative development practice. In order to construct theorias based on personal experiences and insights, reflective practice appears to offer a promising approach. In particular, reflective practice's recent engagement with spirituality supports a focus on self-understanding and deepens and broadens reflective practice in ways that allow practitioners to construct theoria. My research adopts such an approach and uses my personal experience as a case study for the creation of development theorias.

In attempting to construct a development theoria the literature also highlights key considerations and limits to the use of reflective practice. Critiques of transparent reflexivity remind us that theorias will always be partial and incomplete and that the process of constructing them should be considered an ongoing practice. Reflexivity literature emphasises the need for critical reflection on the relationship between the practitioner's theoria and the multiple discourses and power relations in which they are embedded. Personal construct theory supports the call for critical reflection and stresses the need to create opportunities for and work through moments of cognitive dissonance. All of these are considerations that I engage with within my research.

Multiple authors also stress the need for engaging in relational reflection as an opportunity to move beyond individual self-understanding and to examine the role of one's theorias in relation to those of others and the broader practice context. As a result, my research engages with reflective practice not only for the construction of my own development theoria but as means for considering the significance of my own and others theorias in practice. Adopting an actor orientated approach provides a useful reflective lens for exploring such concerns including how different actor theorias (including one's own) are manifest and negotiated within the social interfaces of development practice. This actor orientated approach to relational reflection is enriched by considerations of power highlighted in reflexivity literature including a 
consideration of how actors employ complicity with conceptual thirds and seek room for manoeuvre for their own development theorias. This reflective focus on power allows practitioners to consider how the interaction between different actors' theorias of development can shape the processes and outcomes of development initiatives. 


\section{Chapter 3: Personal Research Context}

\subsection{Introduction}

In this brief chapter I outline the personal context in which my research has emerged including an overview of my background, interests and personal relationship with the research.

\subsection{My Journey So Far}

In order to understand the personal context of the research and where it came from, I think it useful to provide some personal background to this investigation. I begin by framing myself as both an individual committed to well-living and good change in the form of development work and as a spiritual person drawn to understanding myself and my place in the world. Much of this investigation has been about integrating and harmonizing these two aspects of myself.

I came to the field of development and also to an awareness of the spiritual through my formative travel experiences, living and working in different countries, cultures and contexts. My interest in development emerged out of an appreciation for other ways of being and doing that I encountered during my travels. To begin with, I was not attracted to the dominant images of happiness that I was often confronted with in 'developed' countries - material wealth, a stable job and a stable life - a vision counter to that which my parents had instilled in me. Through my travels I became aware of fulfilling ways of life that were based on different aspirations and values as well as unfulfilling lives that had all the trappings of the images of 'success' and 'happiness' that I saw held in high esteem by privileged minority world peoples. This appreciation 
for other ways of life in relation to what I have termed 'dominant development' and my orientation towards the intangible and relational aspects of human happiness underpins my interest in alternative development.

As a development practitioner I am just beginning my career and am still trying to find my place practically and conceptually in the broad and often confusing and contradictory world of development. Personally I am committed to being involved in good change but I am also aware that development is an amorphous concept applied to all manner of work, much of which I would not consider 'good'. As a result, my career up until now has been largely characterized by an exploration of my understanding of development as good change and how to carry it out in practice. A search that became centred on the question of "What is development for me?"

In conducting this search, the first thing I came to realise was that for me, what made a development project good was not so much 'what' was being done but 'how' it was being done. This is a view reflected in participatory development literature which often stresses the importance of process over results, the goal of empowerment and the establishment of right relationships between insiders and outsiders (Chambers, 2007). As a result early on I engaged actively with participatory development theory and practice and sought to base my work around this approach. However, with time I also realised that 'how' something gets done depends mostly on 'why' it is being done in the first place rather than the methods, methodology or rhetoric employed.

In referring to the 'why' of development interventions I am not referring so much to the theory or organisational vision behind an initiative but rather the personal motivations and values of those involved. This belief was also reinforced by my volunteer experiences with local NGOs in South America where I often observed a clear disconnect between espoused visions and mission in relation to field practice. In my eyes then, whether a project is carried out well or not will depend on the 
objectives behind it and in turn the personal motivations, values and conception of development of those involved in the initiative. In the words of Reeler (2001 p6): "Ultimately, we have to acknowledge that it is not our methods, strategies, tools or techniques which define the core and quality of our development practice, but ourselves - our past, our present and our future, and the will we can find to face these". As a result, my engagement with the "why" of development began to focus on the role of personal beliefs, values and conceptions of development.

This was not something covered in participatory development approaches which tended to remain focused on the 'how' of development, for example by focusing on attitudes, behaviours and relationships rather than trying to understand the values and beliefs behind these (Chambers, 1997). As a result, my search for the 'good' in good change called for a return to an understanding of myself, my values, my beliefs and my conceptions of the good. In turn these investigations led me back to the importance of spiritual understandings of myself, life and, as a result, development. Through studying the relationship between development theory and spirituality in the development literature I came to the realisation that I identify strongly with spiritual interpretations of development which place humans and their spirituality at the heart of the search for good change. As a result, my engagement with spirituality has been a key reference point just as my own spirituality has become a central focus of the investigation and elaboration of my development theoria.

The reflective investigation that follows is the consequence of my personal journey so far. It is based on my search to understand myself and the good at the heart of my conception of development. As a result the personal aim of my research is to improve my development practice through a greater understanding of my conception of development as good change and what this means for me and my practice. 


\section{SECTION B: RESEARCH APPROACH}

\section{Chapter 4: Research Process and Methodology}

\subsection{Introduction}

In this chapter I outline the research approach adopted for my thesis including a description of the research process followed by the epistemology, methodology and the research methods employed. The description of my research approach builds on the insights from the previous section including the relevance of reflective practice in constructing personal theorias of development, and the importance of relational reflection in exploring one's own and others' development theorias. These considerations are reflected in the key research questions that guide my research and define my research approach:

a) How can practitioners construct personal conceptions of development to guide their alternative development practice?

b) What is the significance of an engagement with personal development theorias for one's practice?

c) What is the significance of interactions between different actor theorias of development for development initiatives, processes and outcomes?

In relation to the personal context of my research, it is important to emphasise that my research approach is rooted in my subjective experience as a novice development practitioner. As such it is an approach that is primarily concerned with my attempts to understand myself and others in terms of my development practice. My practitioner focus is outlined in the subjective description of the research process (4.2) and underlined by my epistemological concerns with constructivism, subjectivity and self- 
reflection. As a result my research methodology is based on an interpretative autoethnographic framework that employs reflective practice as a means for generating data from personal experience. Enacting this methodology has involved the use of various reflective research methods that have employed appreciative, critical and actor orientated reflective lenses. The approach has served well for constructing and reflecting on the use of development theorias and the chapter concludes with a review of its methodological strengths and weaknesses.

\subsection{The Research Process}

While the research presented in my thesis may appear logical, linear and coherent, I can assure readers that the process itself was anything but. In general it has been a deeply personal and subjective process rooted in my lived experience of the research. Conceived of as a reflective research process, it can be divided into three separate but inter-related cycles of reflection:

1) A cycle of appreciative introspective reflection aimed at interpreting my personal beliefs and values regarding development in the form of a theoria.

2) A cycle of critical reflection aimed at understanding my 'self-in-practice' and focused on an experience of cognitive dissonance that highlights the significance of development theorias for individual practice.

3) A cycle of relational reflection orientated towards the micro-political context in which I was engaged and in which the experience of cognitive dissonance occurred. This cycle employed an actor orientated lens of reflection to further explore the social interface of my practice experience and the role and relationship of different actor development theorias within an alternative development initiative. 
Of these three cycles, the second acts as the linchpin for my thesis research. It is from this experience of cognitive dissonance and its reflective analysis that my current research took form. It was this experience that caused me to return to earlier questions regarding what my conception and practice of development was, and to seek to understand how this experience had come to pass in relation to my own and other's conceptions of development. What I present in the rest of this section is an overview of the organic research process as it unfolded within the different spatial, temporal and emotional contexts that shaped it.

The story of my research began in 2011 towards the end of my first year of Master's study at Victoria University of Wellington, New Zealand. I was 29 years old, a recently returned volunteer development worker and wrestling with my understanding of the concept and practice of development. University study was once again providing a thorough deconstruction of development as generally conceived, theorised and practiced in its mainstream forms. It had also failed to provide a positive, imaginative and creative approach that moved beyond critique and explored alternatives outside of the mainstream. For me, this was an education that did not reflect the lived experience of development work with which I was familiar at a community level.

I had anticipated this situation to a certain extent and enrolled in a self-guided study course for the second half of the year. It was within this course that I began to explore alternative conceptions of development with an initial focus on participatory community development approaches. As the course progressed, my understanding of the multi-reality of a historical, lived and normative development began to take form and by the end of the course my focus had shifted from community development to spiritual approaches to alternative development. These approaches resonated with me and their focus on "being the change you want to see in the world" (Ghandi in Cohen, 2006) led me to once again question "what is the change I want to see?" This questioning led to my first cycle of reflective investigation. 
The first cycle of reflection was focused on providing an explicit understanding of my conception or theoria of development based on my understanding of 'the good' and 'good change'. The initial objective of this cycle was to develop an understanding of my key spiritual beliefs and values in order to orientate my conception and practice of development. The result was a spiritual framework that could act as the basis for the development of a personal conception of development and development practice. At this stage however, the investigation did not progress any further as the year came to an end and I began to focus on preparing for my thesis research which was to take a different orientation.

A reflective investigation of the role and importance of personal conceptions of development was not the original objective for my thesis research. Instead, my research proposal had been focused on documenting and understanding development methodologies for supporting endogenous development initiatives. These were initiatives that were locally controlled and based on local resources, institutions, priorities and conceptions of development. This research focus had emerged from an ongoing relationship with an NGO that I wanted to work for in South America and was aimed at serving four main purposes:

1) To enable me to return to South America and intern with the NGO as a first step to working with them full-time.

2) To help the NGO systematise their undocumented organisational methodology for supporting endogenous development.

3) To understand how these methodologies engaged with and supported indigenous conceptions of development in the design and implementation of development projects.

4) To allow me to get a Master's degree. 
As a result, my original thesis research aim was to understand how methodologies for supporting endogenous development engaged with and promoted indigenous conceptions of development in the planning and implementation of rural community development projects. With this objective in mind I left New Zealand for South America in March of 2012 to begin my internship and research.

I had been interning and conducting my research for around 6 months when I realised that I did not want to work for this NGO or to research their practice. During this time I had experienced an ever greater contradiction between my original understanding of the NGO and its approach and what I was seeing and experiencing in practice. This sense of contradiction culminated in the period between the $19^{\text {th }}$ and $21^{\text {st }}$ of September 2012 as an experience of cognitive dissonance characterised by deep anxiety. The experience resulted in my decision to leave the NGO and led to a shift in my research focus. I wanted to understand where this feeling had come from and why, and to explore what kind of practice I did want to be involved in. As a result, I returned to my earlier unanswered questions regarding what development meant for me as good change and as practice. I adopted a new research focus on how practitioners could answer these questions and what the consequences of the answers might be for my own and other's practice. With this shift in focus I returned to my spiritual framework and completed the first reflective cycle of my thesis by constructing a personal theoria of development.

The second cycle of reflection drew on the experience of cognitive dissonance mentioned earlier as the basis for a critical incident analysis (CIA). The objective of the $\mathrm{CIA}$ was to understand the personal and contextual sources of this contradiction and to use insights derived from the experience to further my understanding of development practice. This reflective cycle was orientated toward a situational reflection on the contradiction between the espoused and practiced development approaches of other actors and the organisation in general. The emphasis remained however on why these contradictions were significant for me and my practice. This cycle focused on the 
different situations that had given rise to the critical incident experienced and led to an examination of the role and significance of my own and others theorias of development in the practice context.

The third and final reflective cycle of my research took place during the last two months of my internship and stemmed directly from the insights and questions that had emerged in the previous cycle. I had identified the contradictions that troubled me with regard to the NGO but I wanted to understand where these had come from, what maintained them and to explore their broader consequences. Based on the experience analysed in the second cycle of reflection I had gained a sense of 'misalignment' between the objectives, priorities and practices of different actors which I decided to explore in terms of differing development theorias.

The third cycle of reflection was a more analytical approach that reflected upon the interplay between different development theorias in relation to a specific social interface of development practice. As the basis for this reflection I attempted to interpret the implicit development conceptions of different actors in relation to the explicit NGO theoria. This process of interpretation involved re-analysing earlier interview texts as well as conducting new follow up interviews in order to explore the different personal development theorias at play. In reflecting upon these I focused on their impacts on development practice while drawing on broader theoretical debates to examine their relationship with power/knowledge in the forms of discourse and complicity. The results from these different cycles of reflection were then compared and contrasted to arrive at different layers of conclusions regarding the role of personal conceptions of development in development practice. The epistemology, methodology and methods that underpinned these cycles of reflection and produced these conclusions are examined in the following sections. 


\subsection{Research Epistemology}

I begin the description of my research methodology and methods by grounding them in a constructivist research epistemology. A constructivist epistemology values subjective experience and accepts the existence of multiple realities shaped by historical and cultural norms (Cresswell, 2003). I would argue that such an epistemological standpoint is a logical orientation for an alternative development practitioner due to the need to accept and work with multiple conceptions of development. Constructivist epistemologies reject universal and objective truth claims and emphasise the subjectivity of those involved in "creating" knowledge. Instead of an external world filled with objective facts waiting to be discovered (Mottier, 2005), constructivists posit multiple social realities constructed from the individual and collective subjectivities of human beings (Long, 2003). Knowledge is interpretation rather than fact or truth, is "constructed in conformity with particular sets of fundamental beliefs and presuppositions and is fully dependant on the time, place and social position of the thinker" (Saitta \& Keene, 1990 p207).

This constructivist position supports my subjective practitioner engagement with research and the production of knowledge from a practitioner perspective. A subjective understanding of knowledge also underpins my engagement with development theorias which represent subjective constructs that explicitly draw on personal values, beliefs and conceptions of development. In relation to other development actors, an understanding of reality as multiple and socially constructed also supports my research engagement with multiple theorias of development and their manifestations in development practice.

A constructivist epistemology considers personal experience as a valid source of research data. Through its rejection of positivist binaries such as knower/known and thought/experience, a constructivist epistemology encourages the use of subjective 
experience and memory as a source of knowledge (Elliot, 1999). This is especially important for the construction of theorias that are based on the grammar of one's personal experience. This constructivist position also supports the assumption that individuals possess a reservoir of experiences and insights related to their conception of the good life and good change which they can draw on in relation to dominant development discourses. These can include individuals' subjective experiences of the spiritual including moments of connection with 'framings' greater than that of power relations such as spiritual connection or epiphany. Combined with an actor orientated understanding of people's capacity to compare, reflect upon and choose between different beliefs, experiences and discourses - my adoption of a constructivist epistemology engages with practitioner's as creative agents capable of imagining and possessing alternative theorias of development based on self-understanding.

Finally, a constructivist epistemology and its application within personal construct theory helps to broaden and deepen my understanding and use of reflective practice. PCT argues that one's personal constructs are not static but evolve and change as they are confirmed or challenged over time (Weiner \& Craighead, 2009). It is possible to 'dilate' or expand ones existing personal constructs in order to include new ideas or realisations and also to contract them in order to make them more explicit and specific (Bannister, 1962). From this epistemological standpoint, my reflective research methodology is primarily concerned with a process of expanding and contracting personal constructs related to development. In the creation of my own development theoria this process focuses on "core constructs" that "ultimately [embody] our most basic values and sense of self" (Weiner \& Craighead, 2009 p1). For me these "core constructs' are conceived of as spiritual beliefs and values which act as the focal point for 'expanding' my conception of development as good change. This understanding can then be contracted into a more detailed and practical understanding of development in the form of an explicit theoria. 
In summary, my constructivist epistemology provides the conceptual grounding for a subjective engagement with my own and others theorias of development. Such an epistemology supports an engagement with research and knowledge production from a subjective practitioner perspective based on subjective experience. More specifically a constructivist epistemology encourages the researching of my own and others subjective understandings of development in the form of theorias. In the development of these theorias a constructivist epistemology also facilitates an engagement with spiritual experience as a source of knowledge, and an engagement with spiritual beliefs and values in the form of 'core constructs'. Finally the adoption of a constructive epistemology provides a foundation for the broad and deep approach to reflective practice necessary for the construction of development theorias.

\subsection{Research Methodology}

A direct consequence of the constructivist epistemology adopted in my research is the selection of an interpretive research methodology. Interpretive methodologies are grounded in a constructivist epistemology and have an "emphasis on the analysis of constructions of meaning, of the ways people make sense of their everyday activities and surroundings" (Mottier, 2005 p4). In interpretive research "subjectivity is seen as a crucial and positive component of research" (ibid p4) and my research approach particularly focuses on my own subjectivity through an auto-ethnographic interpretive methodology.

Auto-ethnography places the researcher, as subject and knowledge interpreter, at the centre of research and "makes an explicit commitment to a self-reflective way of knowing" (Moss in Kindon, 2011 p122). My use of auto-ethnography as a methodological framework is not aimed at producing generalised theory but rather subjective knowledge that speaks to broader theory and the community of those who seek an alternative development practice. My aim has been to live my research as 
practitioner in order to learn from it and to share my learning and interpretations with others. The experience has not been merely introspective but has involved immersing myself in the lives and cultures of others. As a result it has also involved the ethnographic dimension of auto-ethnography. For example, reflecting upon the social interface of development practice requires "a detailed ethnographic understanding of everyday life and of the processes by which images, identities and social practices are shared contested and negotiated, and sometimes rejected by the various actors involved" (Long, 2003 p48). This in turn requires that "one must go where the people are already engaged in interactions, problem-solving activities or routine social practice and negotiate a role or combination of roles for his or herself as participant, observer, active collaborator and adviser" (ibid p56). These are all roles that I was able to adopt within my internship including involvement in planning and methodological development, participation in field visits and activities, and a coordinating role in the organisation's restructuring efforts.

In these ways I was able to enter into the culture of the organisation's work environment and explore its different interfaces with local partners and international donors. At the same time an auto-ethnographic understanding of my conception of development provides the standpoint from which to analyse other actor's development conceptions in practice. Working from this standpoint has allowed me to investigate the consequence of engaging with one's development theoria in practice through analysing its interrelationship with the development theorias of others and with different discourses and power relations.

In applying my auto-ethnographic framework, I have adopted a reflective practice methodology as the principle data generating approach for constructing knowledge from my subjective experience. As detailed in Chapter 2 (2.4), my reflective methodology is grounded in a spiritual engagement with reflective practice and supported by the constructivist epistemology introduced earlier. This reflective methodology consists of the three reflective cycles outlined previously and beginning 
with an appreciative reflective cycle aimed at constructing a personal development theoria based on my positive beliefs and values. The second reflective cycle involves critical reflection on an experience of cognitive dissonance and its relationship to the role and significance of personal development theorias in practice. Finally, the third cycle combines critical reflection and an actor orientated approach for a broader reflection on inter-actor relationships within the social interface of a development initiative and their consequence for development processes and outcomes.

\subsection{Methods and Techniques}

The main research methods of my investigation were employed within three reflective cycles of my research outlined above. Each cycle employed a different combination of methods for generating information including the use of reflective journaling, critical incident analysis and a qualitative mixed method approach for interpreting the development theorias of other actors. In relation to the information produced by these methods, a similar analytical approach was used involving a constructivist approach to grounded theory that combined thematic coding with a continuous comparison method for information analysis.

The first reflective cycle focused on the experience of constructing my own development theoria. In doing so, it employed iterative cycles of appreciative reflection aimed at generating a coherent theoria from personal beliefs, values and conceptions of development. The main information collection and production techniques for this cycle were the construction and use of reflective texts. This approach parallels that of transpersonal reflective practitioners who use "[a]rtefacts [reflective journals, stories of experience etc.] reflecting the transpersonal orientation [and] are introspective and often highly personal" (Hunt, 2006 p6). My use of reflective texts began with a process of information gathering that involved the re-reading and textual analysis of nine reflective journals which covered five years of my life as well as 
an incomplete spiritual autobiography which covered eight. These artefacts provided key insights that were used to draw out themes and develop categories related to my beliefs and values in the form of a spiritual beliefs and values framework. This framework in turn functioned as a new reflective text that formed the basis for successive iterative cycles of reflection and the creation of new reflective texts culminating in the final 'write up' of a personal theoria of development.

The second reflective cycle focused on relational reflection in order to explore the significance of personal development theorias for practice. This cycle centres on my use of a critical incident analysis ( $\mathrm{CIA}$ ) to understand and analyse a personal experience of cognitive dissonance and the role that my own and others development theorias played in it. Critical incident analysis (CIA) involves the investigation of a significant practice incident and its unpacking in order to understand the practitioners response and how personal and societal influences shaped it (Stewart, 2001; Gray, 2007). In the second cycle, I employed a CIA in relation to my experience of cognitive dissonance and used it to produce a narrative account of the experience which served as the main information source for the second cycle. In order to broaden the scope of my $\mathrm{ClA}$ method, I also employed elements from systematisation methodology for a more structured approach capable of analysing the lengthier experience that belied the incident.

Systematisation methodology originated in Latin America and refers to a collection of methodologies that share a common focus on the systematic reconstruction and reordering of past practice experiences in order to generate new knowledge (Holliday, 2009). This knowledge is primarily orientated to improving practice and practice theory and the methodology has many parallels with reflective practice (Morgan, 1998). To carry out this systematisation inspired CIA, I drew heavily on field journals and participant observation notes for narrative creation. The narrative generated from this information in turn served as a reflective text from which themes were identified and conclusions arrived at using the $\mathrm{ClA}$ method. 
The third and final reflective cycle employed a combination of critical reflection and AOA to analyse the interplay of different actor theorias of development within a specific social interface. This social interface was related to an ongoing alternative development initiative which I was involved with through a South American NGO. In order to support an actor orientated critical reflection, I employed a qualitative mixed method approach (Mottier, 2005) which combined a range of techniques used to elicit and interpret the different actor development theorias at play in the interface. These interpreted theorias then formed the basis for a reflective examination of the consequences and impacts of the interaction between the different actors involved in the alternative development initiative.

The information collection methods included two e-mailed surveys and 53 individual and group semi-structured interviews involving a total of 42 different participants. Research participants included 8 of the staff from the local NGO that I was involved with, aged between 30 and 55 and composed of seven men and one woman. Research participants also included indigenous community members involved with the development initiative with a total of 32 community members split evenly between men and women and aged between 16 and 60. Finally the open answer e-mail surveys were carried out with one representative from each of the NGO's two main donors, both of whom were women in their 40s.

In addition to interview and survey techniques, I also employed participant observation as part of the NGO staff to observe staff practices and uses of discourse in relation to their own and others theorias of development and documented these in the form of field notes and journal entries. Information derived from a series of participatory workshops was also vital in analysing staff development theorias and especially their interpretation of the role of community members in the development initiative. These workshops involved three separate sessions and utilised problem 
clustering techniques, problem trees and a SWOT analysis as well as lengthy group discussions and collective analysis of the workshop outputs. Finally, a literature review of documents related to the NGO was also carried out in order to generate an interpretation of the organisation's official development theoria involving the analysis of 35 official documents.

\subsubsection{Analysis Methods}

In addition to my information collection methods, I also employed a common analytical approach broadly based on grounded theory. Grounded theory is concerned with inductive theory building (Payne \& Payne, 2004), including the generation of theory from practice, and has proved complimentary to reflective practice approaches (Moore, 2002). Within the grounded theory approach: "Theory is embedded in practical situations and provides explanations of social interactions grounded in empirical data analysis" (Cresswell in Moore, 2002 p22). Such a focus is congruent with the auto-ethnographic and reflective generation of information and its analysis in terms of development theorias.

In terms of the data analysis methods themselves, my research particularly draws on grounded theory's approach to thematic categorizing based on open and axial coding and the process of continuous comparison. In grounded theory the process of data analysis usually begins with open coding which involves a reflective reading of the texts produced by the research methods in order to identify initial codes (Gibbs, 2007). This process involves "breaking down, comparing and categorizing the data" (Lockyer, 2004 p138) while axial coding involves putting "the data back together by making connections between categories identified in open coding" (ibid p138). In general, I adopted a less proceduralist approach and engaged with a constructivist focus on data analysis in line with Glasser's 'emergent design' approach (Miller \& Salkind, 2004). 
The emergent design approach places less emphasis on axial coding and more on continuous comparison for the inductive construction of theory (in my case theoria). The process involved "working back and forth between data segments and codes or categories to refine the meaning of categories as [one] proceed[s] through data" (Schwandt, 2007 p33) and involved a range of comparative research practices including (Charmaz, 2008 p472):

- Comparing data with data

- Labelling data with active, specific codes

- Selecting focused codes

- Comparing and sorting data with focused codes

- Raising telling focused codes to tentative analytic categories

- Comparing data and codes with analytic categories

- Constructing theoretical concepts from abstract categories

- Comparing category with concept

As suggested by Schwandt (2007), the process resulted in a range of data outputs including fully coded data as well as new data documents such as reflective texts. For me the comparative approach proved conducive to a reflective data analysis that involved cyclic reflection on the relationship of different codes which gave rise to broader categories and in turn new codes. Reflecting on the relationship between codes and categories also gave rise to insights that produced new reflective texts such as narratives and memos that provided new sources of reflection and emergent themes continuing and deepening the reflective process. 


\subsection{Strengths and Weaknesses of my Research Approach}

In concluding the presentation of my research approach I believe it is important to review the strengths and weaknesses of the methodology as encountered in practice. Beginning with the construction of my personal theoria of development one of the notable limitations of my methodological approach was the individual nature of the reflective methods employed. The lack of engagement with other people who know me or who are working with personal conceptions of development meant construction of my theoria was limited to my own analysis. While I agree that a self-reflective approach is the most appropriate form of engaging with the inner domain of one's personal conceptions of development, I also believe that collective reflection could benefit future investigations. A greater engagement with others in the construction of one's own theoria would also be in line with Eikeland's recommendation for the inclusion of knowledge arising from dialogue (Kirkeby, 2009).

Several challenges were also experienced in attempting to extend my reflective methodology through the use of a qualitative mixed method approach in cycle three. My focus on producing the 'thick' data necessary for interpreting individual theorias of development meant that I was unable to obtain representative data from the broader communities in which the NGO worked. Fortunately I was able to find two useful studies that complimented my narrower research focus with broader survey generated data. However in using these studies my research faced the challenge of maintaining confidentiality as referencing these reports would identify the NGO. As a result, I employed pseudonyms for the authors of the studies though this presented new ethical concerns regarding the crediting of my sources.

In terms of data collection, it soon became evident that my positionality was strongly affecting the answers being generated in community member interviews. In particular my association with the NGO as an intern meant that participants often mimicked the 
NGO's official discourse during interviews. Such responses were often inter-mixed with contradictory opinions and beliefs that appeared to represent personal opinions. This tendency of respondents to doctor interview answers was also confirmed by one of the studies mentioned earlier and in my discussion with staff members. In response to this challenge I have sought to make this weakness explicit in the corresponding analysis and results section and to incorporate these contradictions into my analysis (7.3.3).

In terms of data analysis, my combination of data from both individual and group interviews with community members has meant that I have had to weight the responses generated by groups. Such an approach is obviously fraught due to the role of micro-politics in group interviews and the potential for one member's opinions to dominate those of others and become representative (Cooke \& Kothari, 2001). In addition, the use of open rather than closed interview questions has meant that participants could supply multiple responses to a single question. As a result, individual participants may over-represent themselves in the data through frequently producing multiple responses. Both these considerations cast significant doubt over the statistical validity of the limited quantitative analysis employed in Chapter 7 of my research (7.3.3). In response I would argue that such data is indicative rather than definitive and have sought to triangulate this quantitative analysis with data contained in the studies mentioned earlier.

Finally, there was the significant challenge of drawing on the information generated from interviews and surveys to actually interpret the theorias of the other actors. As many critical researchers and practitioners have pointed out the representation of other people's conceptions of reality is a politically charged, ethically challenging and very messy and complex methodological process. Working within an interpretative research methodology I fully acknowledge that my constructions of other actors' development theorias reflect my own subjective and limited interpretations. As a result, my research does not engage with these development conceptions as objective 
representation's but as the interpretations that I arrived at based on my own subjective conceptual framework. The methodological process reflects my own struggle as a novice alternative development practitioner trying to make sense of the agendas and objectives at play in the social interface by simplifying them and rendering them comparable to my own. As a result, my auto-ethnographic engagement with others conceptions of development represents the personal challenges I faced as an alternative development practitioner seeking to make sense of my practice while working in a morally complex and conceptually ambiguous field of development where multiple actors and their conceptions of development interact. The process of interpreting the development conceptions of other actors was further complicated by the fact that some of the interviews used to construct actor theorias were not designed for that purpose. In addition the questions related to the framework used for interpreting actor theorias of development were not all applied in a single interview. This was due to the fact the framework for interpreting actor theorias of development was not defined until after I had completed the analysis of my own development theoria and had left the NGO. Such an approach clearly has its weaknesses, particularly the fact that actors were not able to respond directly to some of the questions related to their constructions of development. In terms of its strengths however this approach has allowed for the cross-checking of opinions expressed in multiple interviews while its indirectness perhaps facilitated more natural responses in comparison to abstract questioning.

\subsection{Summary: A Subjective and Reflective Approach to Researching Theorias}

While my research approach has faced challenges to its conceptualisation and implementation, I believe that it represents an innovative and effective research engagement with personal conceptions of development. Building on the focus on theorias and the need for reflective practice identified in the previous section, my research approach indicates how these can be incorporated within a reflective autoethnographic methodology. The adoption of a constructivist epistemology facilitates 
my engagement with self-understanding and spiritual beliefs as my basis for constructing theoria. This epistemology also broadens the scope for reflection in line with the needs of a spiritual engagement. Finally, the three reflective cycles of my research methodology effectively engage with the central questions guiding my research:

a) How can practitioners construct personal conceptions of development to guide their alternative development practice?

b) What is the significance of an engagement with personal development theorias for one's practice?

c) What is the significance of interactions between different actor theorias of development for development initiatives, processes and outcomes?

In addressing these questions, the three reflective cycles employ complimentary methods that extend reflection on theoria beyond myself to the role of other actors and power relations. The result of these methods and the broader methodology underpinning them are presented in the following section which describes the three reflective cycles of my investigation and discusses their results and analysis. 


\section{SECTION C: RESULTS AND ANALYSIS}

\section{Chapter 5: Constructing a Personal Theoria of Development}

\subsection{Introduction}

The three reflective cycles of my investigation began with a focus on how development practitioners could construct their own theorias of development. In relation to this objective, the first reflective cycle covers my own attempt to construct a personal theoria based on self-understanding. This cycle involved three separate reflective phases which produced three key reflective texts: a spiritual framework, my conception of development and my conception of practice. The chapter begins with a description of these different reflective phases followed by an analysis of the results of the complete cycle of reflection including critical reflections. In presenting the results I focus on synthesising an approach for the construction of development theorias that could be adopted by other practitioners. In addition, I present a brief description of the theoria developed in the process followed by a discussion and critique of the relevance of such reflective tools for practice.

\subsection{Description of the Research Process}

As mentioned earlier, the first reflective cycle of my research began in 2011 towards the end of my first year of Master's study at Victoria University of Wellington. The original aim of the research was to improve my development practice through a greater understanding of my conception of development as good change and of the 'good' in good change. In order to do so I decided to employ three separate phases of reflective investigation aimed at: 
1. Inductively constructing my personal spiritual framework and guiding values.

2. Inductively drawing out and constructing my personal conception of development through reflecting on this spiritual framework and guiding values.

3. Reflecting on personal values and my spiritual framework within the context of my conception of development in order to guide my development practice.

As my research evolved I identified the second and third phases of reflection as providing the development conception and practice dimensions of a development theoria.

\subsubsection{First Reflective Phase}

The first phase of my reflective investigation was aimed at establishing a guiding beliefs and values framework as the basis for constructing my theoria of development. In doing so I adopted a spiritual focus, drawing on my spiritual beliefs and related values as the basis for an exploration of my conception of the good and right. The phase began with a preliminary study and literature review that sought to clarify my understanding of spirituality and its dimensions. As a result, I identified three reflective domains in which my spiritual beliefs and values could be explored:

- Relationships with the self.

- Relationships with the other/s.

- Relationship with the cosmos/supernatural realm. 
These domains provided the original template for the open coding of emerging themes and concepts throughout the first phase of this reflective cycle.

After the literature review I identified my main data source and began the collection and revision of empirical data. As mentioned earlier this involved the re-reading of reflective journals kept over the last 5 years in a process which took several weeks and was focused on identifying key spiritual insights and reflections and copying them into a single book. The other major focus of reflection was an incomplete spiritual autobiography which was used to identify initial key themes for organising and analysing the insights I was collecting.

After re-reading the reflective journals and copying the relevant insights I began the central process of reflection and inductive inquiry. This process centred on separating and organising the recorded insights by their relevant theme. These themes were in turn categorised according to the spiritual domains identified earlier - relationship with myself, relationship with others and relationship with nature/cosmos (Table 2.).

Table 2. Original Themes and Categories for Reflection

\begin{tabular}{|l|l|l|}
\hline Myself & Others & Reality \\
\hline My relationship with myself & My relationship with others & My relationship with reality \\
\hline Spiritual path & Human behaviour & Tao \\
Pursuit of happiness & Ego & Basic goodness \\
Life patterns & Evolution & Beauty \\
Fear & Pursuit of happiness & Hidden/felt reality \\
Ego & Individuality and collectivity & Fvolution \\
Right behaviours & Relativity and universality & Experience/ quality \\
Trusting my heart & Relationship between self and & Appreciation \\
\hline
\end{tabular}




\begin{tabular}{|l|l|l|}
\hline Trusting myself & others & Feeling \\
Being in the now & Decisions with regards to others & Connection \\
Creating space/pace of life & & \\
\hline
\end{tabular}

The sorting of the insights by categories and themes was perhaps the most intensely reflective part of the entire investigation as it required me to read through every single insight and reflect on their significance in order to identify their appropriate theme. Such intense reflection was a very mentally and emotionally draining experience but incredibly productive and led to several revelations and changes to the organisation of themes and categories. One of the major changes was the sub-division of each of the three main categories into a) my understanding of the category (e.g. self, others etc.) and b) my understanding of right relationship with that category (Table 3.) After making the necessary changes I then began to reflect upon the different themes contained in the different categories by drawing out connections and differences.

Table 3. Revised Themes and Categories for Reflection

\begin{tabular}{|c|c|c|c|c|c|}
\hline \multicolumn{2}{|l|}{ Myself } & \multicolumn{2}{|l|}{ Others } & \multicolumn{2}{|l|}{ Cosmos } \\
\hline $\begin{array}{l}\text { My } \\
\text { understanding } \\
\text { of myself }\end{array}$ & $\begin{array}{l}\frac{\text { Right }}{\text { relationship }} \\
\underline{\text { with myself }}\end{array}$ & $\begin{array}{l}\frac{\text { My }}{\text { understanding }} \\
\underline{\text { of others }}\end{array}$ & $\begin{array}{l}\frac{\text { Right }}{\text { relationship }} \\
\underline{\text { with others }}\end{array}$ & $\begin{array}{l}\frac{\text { My }}{\text { understanding }} \\
\underline{\text { of cosmos }}\end{array}$ & $\begin{array}{l}\frac{\text { Right }}{\text { relationship }} \\
\text { with cosmos }\end{array}$ \\
\hline $\begin{array}{l}\text { Spiritual path } \\
\text { Life patterns } \\
\text { Fear } \\
\text { Ego } \\
\text { Future } \\
\text { Pursuit of } \\
\text { happiness }\end{array}$ & $\begin{array}{l}\text { Right } \\
\text { behaviours } \\
\text { Trusting my } \\
\text { heart } \\
\text { Trusting } \\
\text { myself } \\
\text { Being in the } \\
\text { now } \\
\text { Creating } \\
\text { space/pace of } \\
\text { life }\end{array}$ & $\begin{array}{l}\text { Choice } \\
\text { Human } \\
\text { potential } \\
\text { Human } \\
\text { diversity } \\
\text { Higher/lower } \\
\text { nature } \\
\text { Pursuit of } \\
\text { happiness } \\
\text { Evolution } \\
\text { Ego } \\
\text { Individuality }\end{array}$ & $\begin{array}{l}\text { Relativity / } \\
\text { universality } \\
\text { Love/compassi } \\
\text { on } \\
\text { Community } \\
\text { Connection } \\
\text { Forgiveness } \\
\text { Openness } \\
\text { Service }\end{array}$ & $\begin{array}{l}\text { Tao } \\
\text { Basic goodness } \\
\text { Beauty } \\
\text { Hidden/felt } \\
\text { reality } \\
\text { Evolution }\end{array}$ & $\begin{array}{l}\text { Faith } \\
\text { Appreciation } \\
\text { Feeling } \\
\text { Connection } \\
\text { Living in } \\
\text { nature } \\
\text { Living in the } \\
\text { now } \\
\text { Experience/ } \\
\text { quality }\end{array}$ \\
\hline
\end{tabular}




\begin{tabular}{|l|l|l|l|l|l|}
\hline & /collectivity & & & \\
\hline
\end{tabular}

The remaining themes constituted the key beliefs within my spiritual framework. In relation to values, I had originally created a specific theme for these in the category of 'myself' but during the sorting process realised that important values were present in many of the themes contained in other categories. As a result I decided to leave reflection on my values until last with the surprising emergence of many more values than my initial identification. These values were identified from themes within each category then collated and reflected upon further.

Table 4. List of Values

\begin{tabular}{|l|l|l|}
\hline \multicolumn{2}{|c|}{ Values } \\
\hline Integrity & Selflessness & Compassion \\
Foith & Humility & Dedication \\
Courage & Solidarity & Decisiveness \\
Balance & Acceptance & Equality \\
Awareness & Appreciation & Forgiveness \\
Love & Freedom & Wisdom \\
\hline
\end{tabular}

After identifying both values and spiritual beliefs I concluded the first phase of reflection with a description of my spiritual framework and values providing a short paragraph for each. These paragraphs were synthesised from the different insights grouped according to each belief or value. Finally I conducted a critical reflection on some of the possible risks inherent in subscribing to this spiritual framework as a means of identifying moral hazards and guarding against these. 


\subsubsection{Second Reflective Phase}

The second phase of the first cycle of reflection took place intermittently from the end of my university study (November 2011) until shortly after the practice experience that led to my shift in research focus (September 2012). This shift in research focus led to a renewed emphasis on constructing my development theoria which spurred my reengagement with and completion of the second reflective phase. The second phase of reflection provided the first component of my development theoria in the form of a personal conception of development.

Initially the second reflective phase carried on from its predecessor through the production of new reflective texts. These texts sought to further develop and integrate the different themes (beliefs and values) identified earlier. In doing so the second phase of reflection involved an ongoing process of 'continuous comparison' between the themes and categories contained within texts resulting in the clustering of existing themes under new codes or the emergence of new codes from comparison between themes. The process resulted in new reflective texts in the form of notes and memos as well as two longer documents - an earlier document of 18 pages and a later document of 14 pages.

In the development of the earlier document, existing beliefs and values were reflected upon with respect to my conception of the good life and good change and were compared and clustered around these new axial codes. This text incorporated a series of narratives in which new themes were embedded in relation to my understandings of humanity, human history and the good life. The main product of the text was an emergent understanding of the good life as 'well-living' based on the clustering of several new thematic categories:

- Realising our human potential 
- The spread of connection and community

- Celebrating diversity

- Seeking Harmony and Balance

The later document (14 pages) was the product of further reflection on how the values and beliefs identified in my spiritual framework could be applied to my life. The development of the text involved further reflection on the 20 values identified earlier and their comparison and clustering resulting in 8 core values. New paragraphs were then written for each of the values, synthesising the ideas contained in the value clusters that had given rise to them.

Table 5. New List of Values

\begin{tabular}{|l|l|l|}
\hline \multicolumn{2}{|c|}{ Core Values } \\
\hline Compassion & Balance & Respect \\
Integrity & Freedom & Solidarity \\
Courage & Wisdom & \\
\hline
\end{tabular}

These new values were then compared with more action orientated spiritual beliefs identified earlier including 'right behaviour', 'pursuit of happiness', 'life patterns', 'choice', 'being in the now', 'living in the now', 'trusting myself / my heart', 'creating space / achieving pace', 'future / fear' and 'connection'. The result was a new clustering of themes that further detailed my understanding of well-living through the four interrelated dimensions of:

- Being well

- Choosing well

- Doing well 
- Having well

In addition, reflecting on these dimensions of well-living along with the themes contained in earlier texts, led to the identification of three new thematic clusters related to my understanding of good change:

- Cultivating Right Understanding

- Developing Connection

- Living in the Now

Each of the dimensions related to well-living and good change were then described in detail through the elaboration of summary paragraphs related to each concept.

Following the shift in my research focus, my collection of reflective texts (including the spiritual framework) became the main resource for constructing a personal development theoria. The first step in defining my development theoria was arriving at a personal conception of development. As a result I decided to employ a conceptual framework as means of structuring my collection of increasingly coherent concepts related to good life/good change into a workable conceptualisation of development. Conceptual frameworks (CF) present key concepts, and the relationships between them, in a way that explains an overarching phenomenon or idea (Jabareen, 2009). Having struggled to inductively develop a structure for my conception of development, I decided to return to the literature (Cooke, 1997; Loy, 1997; and Pieterse, 1998) and designed a conceptual framework for guiding the process. The conceptual framework that I developed was organised around my conceptualisations of development's ends, means, actors and key elements. This framework was then used to structure the concepts contained in my reflective texts employing the use of key reflective questions to guide the process (Box 5.). 
Box 5. Conceptual Framework for my Conception of Development with Reflective Questions

1) Development's Ends

- What is my conception of the good or the good life?

- What is my conception of good change?

2) Development's Means

- How is the good life and good change to be achieved?

- How does change occur?

3) Development's Actors

- Who are the main actors involved in development?

- What are the main relationships between actors in development?

4) Developments Key Elements and Contextual Factors

- What other social, cultural, political, economic or ecological factors are central in shaping development?

5) Developments' Scope

- At what scales and in which spaces and places does development take place?

Using the CF as a reflective template and guided by the reflective questions I was able to organise the themes I had developed earlier into what I considered an appropriate structure for my conception of development. This process involved re-reading and reflecting upon the thematic categories and individual themes contained in my earlier texts and their placement and reorganisation according to the CF. The second phase of reflection concluded with a written description of each of the key concepts of my personal conception of development.

\subsubsection{Third Reflective Phase}

The third reflective phase continued on directly from the second and involved the elaboration of my personal conception of development practice as the final 
component of my development theoria. Previous reflective texts once again provided the main focus for reflection including my recently completed conception of development. A conceptual framework was once again employed to organise the themes present in these texts and was based on a modified and expanded version of the earlier CF (see Box 6.).

\section{Box 6. Conceptual Framework for my Conception of Development Practice with Reflective}

\section{$\underline{\text { Questions }}$}

1) Development Vision

- What do I see as a fulfilling way of life?

- How do I want to contribute to fulfilling ways of life? What kind of change do I want to bring about?

- Why do I want to see/contribute to this change?

- What values beliefs and assumptions underpin my vision of change?

2) Change Strategies

- How do I want to contribute to collective well-living in the form of being, choosing, doing and having well?

- What is the right way in which I want to work?

- How do I think institutionalised development initiatives should be conceived, planned and implemented?

3) Actors

- What is/are my role/s in development processes?

- How do I relate to other actors?

- What should be the role of different development actors in institutionalised development initiatives?

- What are the right relationships that should exist between development practitioners and between development practitioners and other actors in the development process?

- Who should benefit from the change?

- Who should own/drive/carry the change process?

- Who might resist or be harmed by the development approach that I seek to pursue?

4) Scale and Context

- What are the cultures religions and spiritualities that I feel drawn to and want to work with?

- What are the places, countries and/or socio-political contexts that I feel drawn to and want to work with?

- What scale of development processes do I want to be involved in?

- In what organisational/institutional context do I want to work in?

As can be seen in Box 6., my practice conception's framework employs more detailed reflective questioning which that draws on questions raised during my experience of 
cognitive dissonance and the subsequent critical incident analysis. As before, the third reflective phase concluded with a written description of the key concepts related to my conception of development practice as well as the relationship between them.

\subsection{Presentation of Results, Discussion and Critique}

Having provided a rigorous description of the research process involved in the first cycle of reflection I now turn to an analysis of the results emerging from it. The main results include a stripped down version of the process used to construct my development theoria as well as the theoria itself. The relative strengths and weaknesses of the reflective process and the reflective texts are addressed separately including their relevance and utility for other practitioners. Each of these discussions concludes with a critical analysis regarding the limitations and risks involved in promoting and/or adopting these tools.

\subsubsection{The Process}

One of the main objectives of my thesis research has been to explore a process for practitioners to develop their own conceptions of development and utilise these in practice. In relation to this objective, one of the main results of the first cycle of reflection is the methodology of the cycle itself. De-personalising this process and stripping it down to its basic elements provides a three phase and ten step approach for constructing personal development theorias based on self-understanding (Box 7.) 
Box 7. Reflective Process for Developing a Personal Development Theoria based on SelfUnderstanding

\section{Phase 1: Working from Self-Understanding}

- $\quad$ Step 1: Establish initial domains of reflection for engaging with self-understanding i.e. beliefs, values etc. in relation to what e.g. one's self, others, the world, god?

- $\quad$ Step 2: Selection and revision of sources of reflection e.g. reflective journals, autobiography, recorded dialogues, poetry, artworks etc.

- $\quad$ Step 3: Reflective inquiry - use of inductive analysis related to understandings of self e.g. thematic analysis, narrative analysis, discourse analysis etc.

- Step 4: Description and critique of understandings of self e.g. belief and value framework, narratives, poetry, artwork, critical reflection etc.

\section{Phase 2: Personal Conception of Development}

- $\quad$ Step 5: Production of reflective texts involving the continuous comparison of established understandings of self in order to develop more complex, inter-related and structured understandings e.g. memos, narratives, dialogues, artwork etc.

- $\quad$ Step 6: Development conception structuring - creation of a structure for one's personal conception of development e.g. inductively from key elements in one's reflective texts, purposively using established frameworks.

- $\quad$ Step 7: Development conception elaboration and description - using one's conception of development and related questions or cues as a reflective template for structuring selfunderstandings in relation to development.

\section{Phase 3: Personal Conception of Development Practice}

- $\quad$ Step 8: Practice conception structuring - Design and contextualisation of my conception of development practice drawing on insights from reflective texts (e.g. self-understanding descriptions, reflective texts, personal conception of development etc.) and practice experience e.g. reflecting on work experience, re-reading journals, discussions with peers etc.

- $\quad$ Step 9: Practice conception elaboration - using one's practice conception structure and related questions or cues as a reflective template for structuring one's self-understandings in relation to development practice.

- Step 10: Critical reflection on one's completed theoria of development including a critique of moral risk and potential for harmful practices or conceptions complicit in unjust power relations. [Carried out in the following sections] 


\subsubsection{Observations}

Personally I found the process outlined above a very insightful and rewarding experience characterised by its emergent and surprising nature. Most of the time I did not feel like I was simply organising things that were already known but rather discovering new understandings that were often quite unexpected. One of the most interesting examples occurred during the elaboration of my conception of development whilst making the shift from a self-orientated to an "other-orientated" application of personal values and beliefs. During this process I became of aware of two different ways of looking at my beliefs and values in relation to others - an 'inrelation-to-others' (an 'I and them') approach and an "in-relation-with-others" (a 'together with') approach. The difference is outlined in the table below which was constructed during an analysis of earlier reflective texts and their incorporation in my conception of development.

Table 6. My Conceptions of Good Change in Relation to Myself and Others

\begin{tabular}{|l|l|l|l|}
\hline $\begin{array}{l}\text { Conceptions of } \\
\text { Good Change }\end{array}$ & In relation to Myself & In relation to Others & In relation with Others \\
\hline $\begin{array}{l}\text { Developing } \\
\text { Connection }\end{array}$ & $\begin{array}{l}\text { Cultivating connection } \\
\text { with myself, others and } \\
\text { the cosmos }\end{array}$ & $\begin{array}{l}\text { Supporting others to } \\
\text { foster connections with } \\
\text { themselves, with each } \\
\text { other and with the } \\
\text { cosmos }\end{array}$ & $\begin{array}{l}\text { Collectively developing } \\
\text { connection with } \\
\text { ourselves, with each } \\
\text { other and with the } \\
\text { cosmos. }\end{array}$ \\
\hline $\begin{array}{l}\text { Cultivating Right } \\
\text { Understanding }\end{array}$ & $\begin{array}{l}\text { Developing a personal } \\
\text { understanding of myself, } \\
\text { others and the cosmos. }\end{array}$ & $\begin{array}{l}\text { Supporting others to } \\
\text { develop their own } \\
\text { understandings of } \\
\text { themselves, others and } \\
\text { the cosmos. }\end{array}$ & $\begin{array}{l}\text { Collectively developing } \\
\text { an understanding of } \\
\text { ourselves, each other and } \\
\text { the cosmos. }\end{array}$ \\
\hline Living in the Now & $\begin{array}{l}\text { Being present, letting go } \\
\text { of past and future, } \\
\text { trusting in my heart, } \\
\text { others and life, and } \\
\text { being, choosing and } \\
\text { doing in the now. }\end{array}$ & $\begin{array}{l}\text { Supporting others to be } \\
\text { in the present, let go of } \\
\text { their pasts and futures, to } \\
\text { trust in their hearts, } \\
\text { others and their lives and } \\
\text { be, choose and do in the } \\
\text { now. }\end{array}$ & $\begin{array}{l}\text { Collectively striving to be } \\
\text { present with each other, } \\
\text { to let go of our pasts and } \\
\text { futures, trust in our } \\
\text { hearts, each other and } \\
\text { our lives, and be, choose } \\
\text { and do in the now. }\end{array}$ \\
\hline
\end{tabular}


In reflecting on the distinction between these different ways of relating to others, I realised that critical approaches to alternative development tend to employ an 'inrelation-to' orientation. This predisposition seems to stem from the dominant do-noharm ethos of critical approaches which views claims of similarity, commonality or collectivity as potentially homogenising and oppressive (Kapoor, 2004). As a result, 'with' thinking by development practitioners is generally avoided.

However, in focusing on an "in-relation-to-others" (I and them) approach to my conceptions of development I encountered an ontological predisposition to paternalism in this orientation as well. The "in-relation-to" orientation tends to distance oneself from others and more importantly creates a predisposition to do things for others rather than with them. Inherent in the conception of a distanced and different ' $I$ ' doing things for 'them' is the assumption that the development practitioner is already 'developed' - is powerful, concientized, free or has attained happiness or well-being. It is because of this that the development practitioner can therefore help, facilitate or support 'others' in attaining a similar state.

I believe this conceptual relationship with others may lie at the heart of the hypocrisy encountered in many critical and alternative development approaches in general which treat less powerful others as the rightful leaders and architects of development processes while implicitly asserting their need for a 'superior' (more powerful (Chambers, 1997), 'concientized' (Freire, 2005) or free (Smith, 1999)) development practitioner to show them the way. In the words of Long (2003) such approaches:

[1]mply the idea of empowering people through strategic intervention by 'enlightened experts' who make use of 'people's science' and 'local intermediate organizations' to promote development 'from below'... Such formulations, however, do not escape the managerialist and interventionist undertones inherent in the idea of 'development'. That 
is, they tend to evoke the image of more knowledgeable and powerful outsiders helping the powerless and less discerning local folk.

(ibid p55)

Within critical approaches the response to this contradiction has generally been to reject the notion of helping itself as oppressive or misguided (Gronemeyer, 1992) or to critique our ability to help less powerful others due to our oppressive identities (Kapoor, 2004). Through the insights arrived at during the construction of my development theoria, I believe that an "in-relation-with" orientation to others may provide a more productive response to this challenge. 'With' thinking moves beyond stereotypes and dichotomies of powerless but perfectly good and wise local actors and powerful but inherently harmful and blind/deaf development practitioners to a search for collectivity, commonality and solidarity based on common goals, priorities and beliefs. Instead of doing things for others from a distance this involves doing things with others based on a feeling shared connection and understanding. At the same time, a 'with' relationship is not the same as an 'us' relationship in that a 'with' orientation signifies collective engagement as an individual with other individuals rather than the assertion of a homogenous collective (us) identity. I will return to these ideas in more detail later in my thesis; however what these insights do show is the degree to which the reflective process developed here can challenge practitioners to think through their own conceptions of development. Such an approach can provide a valuable process for challenging the dominant discourses that shape alternative development practice and could lead to creative new conceptions and counter imaginations.

\subsubsection{Critical Reflection}

In critically reflecting on the process developed in the first cycle of my research one of the first question to consider is how replicable the process is and whether doing so 
could be considered a harmful or oppressive act? To begin with it is questionable how applicable a process derived from the experience of a young(ish), spiritual, single, white, middle-class, male, New Zealander might be for practitioners of other backgrounds. In response to this concern I have attempted to strip the process back to its essential elements and to leave the application of these elements open to the interpretation of other practitioners. For example, alongside the largely textual and intellectual approaches employed in my own process I have tried to suggest other approaches based on other forms of learning, communication and interpretation including creative and artistic approaches (Box 7.). However in spite of these accommodations I accept that the widespread application of such a process would be open to deserved critiques of methodological tyranny (Bell, 1997).

The reality is that the process presented here is most likely to appeal to 'someone like me'. Someone with similar interests, motivations, values and approaches to learning and reflection. This is fine by me. My reason for exploring this process was not to create a new universal approach for constructing development theorias but rather the construction of my own personal conception of development as an example of how one might do so. Ideally I would hope that each practitioner develops their own approach to arriving at their conceptions of development and development practice.

However for training and educational purposes, I offer my experience as an example for others to consider. As a reflective learning process that I hope will become part of a large family of different methodologies, suited to different practitioners, and aimed at understanding personal conceptions of development as the basis for alternative development practice. In doing so, I believe that this process could be considered a valuable contribution given that I was unable to find existing examples within the literature. I believe that the existence of such approaches are important for the education and training of development practitioners; that while it is impossible to provide a single universal answer to the question "What is Development?" it is possible 
to provide development practitioners with the guidance and tools necessary for them to answer this question for themselves.

\subsubsection{My Theoria}

The other main result of the first reflective cycle was the construction of my personal development theoria composed my personal conception of development and development practice. While the exact details of my theoria are not pertinent to the research presented I will provide a brief description my theoria as the basis for later observations and critiques (Fig 1.).

\section{Fig 1. My Personal Theoria of Development}

\section{Personal Conception of Development}

\begin{tabular}{|c|c|}
\hline Concept & Description \\
\hline 1. Ends & $\begin{array}{l}\text { - The good - fulfilling ways of life characterised by dynamic individual and } \\
\text { collective happiness. } \\
\text { - Good change - the search for or maintenance of fulfilling ways of life in } \\
\text { their various dimensions. } \\
\text { - Development as good change focuses on relieving suffering. }\end{array}$ \\
\hline 2. Means & $\begin{array}{l}\text { - Social change is the complex, non-linear and unpredictable outcome of the } \\
\text { collective human pursuit of happiness. } \\
\text { - Development processes should be vision orientated. } \\
\text { - Development processes should be bottom-up } \\
\text { Development processes should be based on and contribute towards } \\
\text { developing human connection. }\end{array}$ \\
\hline 3. Actors & $\begin{array}{l}\text { - The main actors in development processes are individual human beings } \\
\text { involved in collective action for achieving and maintaining fulfilling ways of } \\
\text { life. } \\
\text { - Focus on human agency - human beings as defined by their ability for } \\
\text { choice. } \\
\text { - Human actors as evolutionary beings capable of choosing their nature. }\end{array}$ \\
\hline
\end{tabular}




\begin{tabular}{|l|ll|}
\hline & - & Development as a collective endeavour. \\
\hline $\begin{array}{l}\text { 4. Key Elements } \\
\text { and Contextual } \\
\text { Factors }\end{array}$ & - & Power \\
& - & Freedom \\
& - & Nature and the cosmos \\
& - & Fulfilling personal environments (Gamer, 2002) \\
\hline $\begin{array}{l}\text { 5. Scope and } \\
\text { Scale }\end{array}$ & - & Development as a multi-scalar process from the intra- and inter-personal to \\
& the international and global. \\
& - & Focus on local and community scales. \\
& - & Privileging of intra-personal scale of development. \\
\hline
\end{tabular}

\section{Personal Conception of Development Practice}

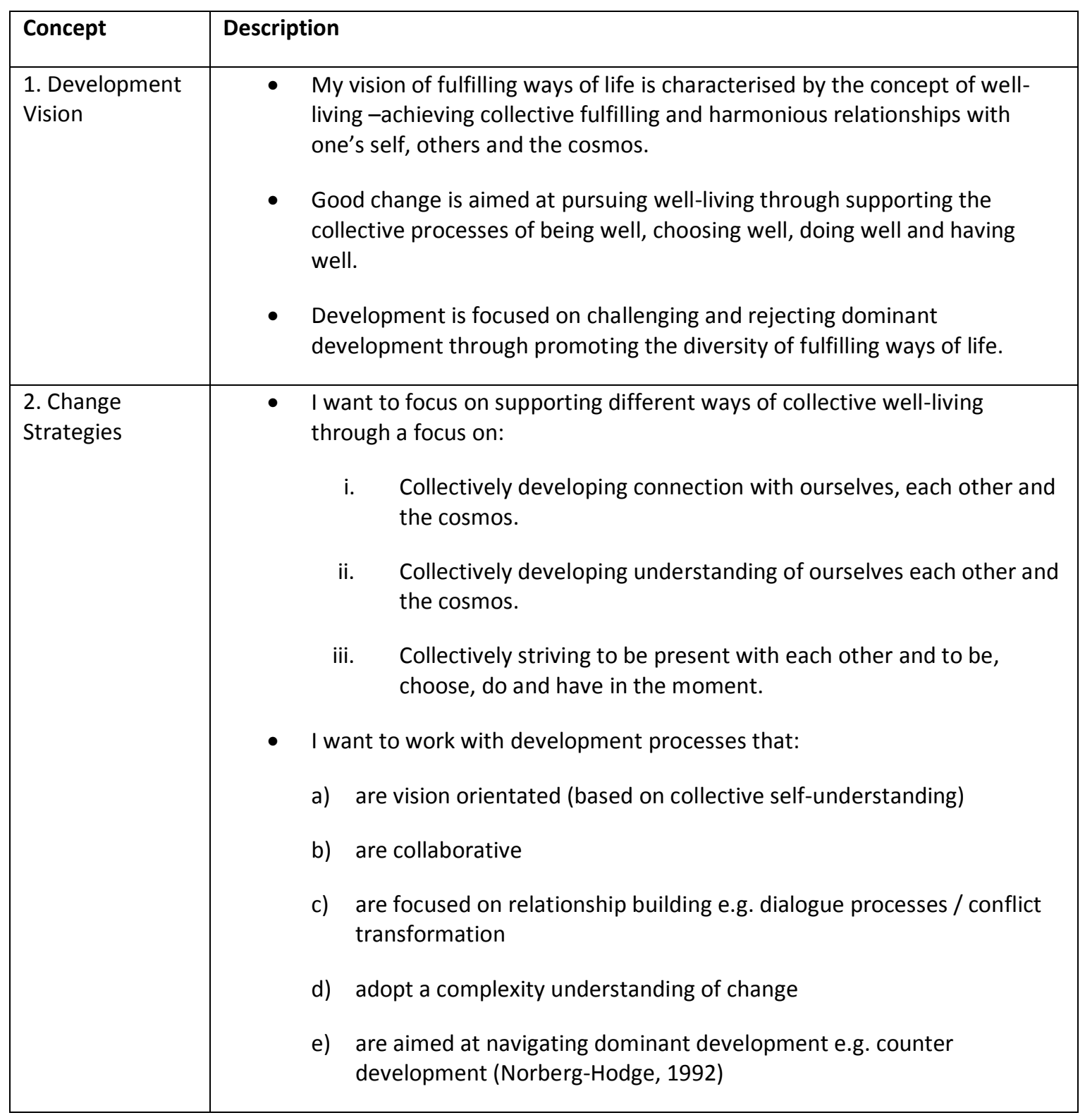




\begin{tabular}{|c|c|}
\hline & f) are aimed at creating supportive contexts \\
\hline 3. Actors & $\begin{array}{l}\text { - My role - I want to be involved in the collective design and implementation } \\
\text { of change processes at a local scale. } \\
\text { - I want to work with others rather than for others. } \\
\text { - I want to work with actors that share similar beliefs, values and goals as } \\
\text { myself. } \\
\text { - I want to work within relationships based on humility, mutual trust, } \\
\text { respect, solidarity and friendship. } \\
\text { - Development processes are collective process involving multiple actors } \\
\text { (including development practitioners) and roles should be collectively } \\
\text { decided by the main actors. } \\
\text { - Development processes should take an equity focus seeking to privilege } \\
\text { actors who have least influence, those who are suffering the most and } \\
\text { those who are most affected by the change. } \\
\text { - Non-local development practitioner/s should not be the main drivers of } \\
\text { local development processes. }\end{array}$ \\
\hline $\begin{array}{l}\text { 4. Scale and } \\
\text { Context }\end{array}$ & $\begin{array}{l}\text { - I want to focus on or privilege actions with local actors at the local scale. } \\
\text { - I am currently drawn to working within Asian cultures and with Buddhist } \\
\text { spiritualities in particular. } \\
\text { - In general I am interested in working with cultures and ways of life that } \\
\text { engage with alternative conceptions of the good life and good change in } \\
\text { relation to dominant development. } \\
\text { - I am interested in working with local organisation and community groups. }\end{array}$ \\
\hline
\end{tabular}

\subsubsection{Observations}

In examining the outputs of my reflective process I obviously do not present my development theoria as a model for others to use. Instead I want to use my development theoria as an example of the role and utility of the reflective texts produced by this process of reflection. My development theoria is both a reflective text and the product of continuous reflection on earlier reflective texts. As my reflective investigation progressed these texts became ever more complex and refined, 
beginning with the collection of spiritual insights sourced from my journals and finishing with the detailed description of my development theoria.

The process of continuous reflective comparison on themes contained within different texts led to the surprising emergence of many new individual or overarching concepts as new connections were established between existing themes from which new concepts emerged. Drawing on personal construct theory this process could be likened to the contraction and expansion of personal constructs related to my conception of development as the good life and good change. The result of this process is what I term greater inner alignment of personal constructs as inconsistencies between one's constructs related to development are resolved and a more coherent understanding of them and their inter-relationship is achieved. For me, this process led to a greater clarity regarding what I wish to do, how I should do it and why. In addition, the existence of a reflective text provides a permanent reflective touchstone that allows practitioners to re-visit and refresh their internal alignment and the complex conceptual inter-relationships that underpin it. At the same time, it is important to emphasise that these reflective texts are not set in stone and instead form the basis for further reflection and the elaboration of new and more appropriate reflective texts. In essence these reflective texts are the basis for a reflective development practice, providing the personal theory (theoria) that development practitioners can compare to their daily practice in order to modify either their actions or their understandings of development.

\subsubsection{Critical Reflection}

Taking a critical stance towards the use of reflective texts (such as my development theoria) as a guide for practice leads to a questioning of the relevance of internal practitioner alignment if it proves incompatible with or harmful to the agendas of local actors. A focus on positionality highlights the fact that my own and others concerns as 
white western males etc. may be irreconcilably different from those of non-western local actors. Indeed my priorities may in fact blind and deafen to the priorities of nonwestern local actors. Meanwhile critical approaches to complicity highlight how one's personal development theorias may be implicated in powerful and oppressive discourses that lead us to privilege oppressive knowledge systems and neglect the agendas of the subaltern. As a result, constructing personal development theorias may simply constitute the elaboration of more coherent and elegant conceptual weapons to be imposed on others.

These concerns were partially borne out during the process of constructing my conception of the good life as well-living underpinned by processes of being well, choosing well, doing well and having well. Having well was not originally in this list and it only came to my attention when I began to compare my conception of development with how it is often practiced in dominant development and by many of the world's people - having more to survive or having more in pursuit of happiness. This reflection drew my attention to the fact that my more spiritual focus privileges the intangible aspects of development at the expense of more material and corporeal development needs. This focus could perhaps be considered the privileged position of one who does not suffer from deprivation, ill-health, isolation, oppression or the threat of violence and as result neglects these needs as experienced by others.

At the same time, having more is certainly the focus of dominant development and I would argue that its focus on the world's 'have-nots' is a gross over simplification that labels the majority of the world as people who only want or need more things. The main point is that while reflective texts may embody potentially oppressive or harmful beliefs they also offer the opportunity to reflect upon these and change one's perspectives as I have done by adding 'having well' to my conception of development. Reflective texts are inherently personal texts but by making them explicit it may be possible to get them 'out in the open' and use them as instruments for dialogue with those who hold different views. The example above shows the value of reflective texts 
for considering one's own conceptions of development in relation to those of others, an approach that will be made greater use of in the second and third cycles of reflection.

\subsection{Summary: Processes for Constructing Personal Theorias of Development}

The first cycle of my reflective investigation was primarily concerned with the research question "How can practitioners construct personal conceptions of development to guide their alternative development practice?" In responding to this challenge I adopted a focus on development 'theorias' and explored a process for constructing them based on my own experience. As a result, the first reflective cycle responds directly to the research question by outlining a process that practitioners can adopt for constructing development theorias along with an example of such a theoria. However in analysing these results it is important to emphasise that the process developed here is not a blueprint but an example that other practitioners can draw on in developing their own processes. Ultimately the question of how practitioners can construct their own conceptions of development can only be answered by a family of approaches. A family of approaches that support the inner alignment of practitioners as the foundation of alternative development practice. 


\section{Chapter 6: The Role of Development Theorias in Personal Practice}

\subsection{Introduction}

While the first cycle of reflection was aimed at establishing my development theoria and providing a process for doing so based on self-understanding, the second cycle focuses on the significance of one's own and others' development theorias for one's practice. In doing so, the second cycle maintains a subjective practitioner perspective grounded in my own experience while employing critical reflection aimed at understanding my 'self-in-practice'. This critical reflection centres on the incident of cognitive dissonance that occurred during my internship with a local South American NGO and the experiences that underpinned it. In order to reflect upon this experience I employ a critical incident analysis combined with a systematisation approach to understand the cause of the incident in relation to my own and others' theorias of development. In the following sections I describe the critical reflection process before providing a summary of the results and relevant observations and critiques.

\subsection{Description of the Research Process}

\subsubsection{Overview of the Critical Incident Analysis}

As outlined above, the second reflective cycle focuses on my use of a critical incident analysis to reflect on a personal practice experience. Critical incident analysis provides a reflective method for investigating one's implicit assumptions and the role of social influences in one's practice. The specific ClA approach employed in this cycle is based on Hunt's (2006 p14-15) use of practice incidents and involves the following steps: 
1. Describe what happened

2. Make judgements (Why is it significant for you? What was good/bad, important?)

3. Analyse the event

4. Lessons learned or future action

My use of the CIA involves both a focus on the specific event as well as an unpacking of the broader experience that gave rise to it. Due to the length and complexity of the broader experience underpinning my critical incident I have included a systematisation approach for the analysis phase of my $\mathrm{ClA}$. This analytical use of a systematisation methodology involved the following steps (Morgan, 1998):

1. Establish objective of the systematisation and delimit the experience to be systematised.

2. Develop a narrative of the experience based on the main orientation or objective of the systematisation.

3. Critical reflection on the experience:

- Break down the experience into distinct elements and key factors

- Establish relationships between factors and elements e.g. cause and effect

4. Presentation of results in relation to the main objective of the systematisation.

\subsubsection{Description}

The CIA began with a description of the critical incident which provided the initial reflective text for judging the incident and orientating the analysis. After re-visiting the 
reflective diary entries that covered the experience, I developed a short narrative to describe the event outlined in Box 8.

\section{Box 8. Critical Incident Description}

\section{Description of the Critical Incident}

The critical incident described took place during my internship with a local NGO in South America. The incident occurred over a period of three days from Wednesday $19^{\text {th }}$ of September to Friday $21^{\text {st }}$ of September 2012. Prior to the event I had been interning and carrying out thesis research with the organisation for around six months and during that time had developed mixed feelings about the organisation and the prospect of working for them. However things were going well at the time when the director of the organisation offered me the opportunity to attend an international conference with him in South East Asia. In response to this invitation I developed a strong sense of unease that continued to grow as I considered whether or not to accept the invitation. At first I put this feeling down to concern over the time I had available and the demands of my thesis and internship responsibilities. As a result, I decided to decline the offer however the feeling only continued to grow and became a quite intense awareness that something was wrong characterised by feelings of anxiety, depression and disorientation. The feeling peaked on the $20^{\text {th }}$ of September and led to my decision to leave the organisation on the $21^{\text {st }}$ of September. The decision had come from the realisation that this feeling was tied to my staying with the organisation and initial reflections indicated that these feelings had been triggered by my perception of the invitation to the conference as grooming for a permanent position within the organisation.

\subsubsection{Judgement}

Based on my description of the incident I then established what had made this incident significant for me and why I wanted to investigate it further. The first reason for its significance was the strong emotional impact of the experience; the deep feeling of anxiety and disorientation that called attention to it. The second reason for the significance of the experience was its consequences for my career path and research direction. As a result, my interest in the incident also stemmed from my desire to 
understand why I had made this decision, what underpinned it, and what this meant for the future direction of my development career and practice.

\subsubsection{Analysis}

The analysis phase of my $\mathrm{CIA}$ involved examining the entire length of experience that I had had with the organisation in order to understand where this decision had come from and what led to its final manifestation. At the outset my mind was not a "tabla rasa" and my analysis initially focused on the contradiction between the organisation's vision and practice as the potential underlying reason for my decision to leave. As I began revising and reflecting upon previous journal entries, research notes and other reflective texts I also realised that a systematisation approach would prove an effective way to analyse my experience of working with the organisation. As a result my analysis adopted the four main steps described below:

1) Establishing the Objective and Scope of the Analysis

The objective of the analysis was defined by my earlier judgement of the incident and was aimed at understanding the reason why I decided to leave the organisation and what this meant for my development practice. Based on my hunch that this decision had stemmed from the contradiction between the NGO's vision and their practice I decided to focus on my entire experience with the NGO beginning with my first encounter with them and my original understanding of their vision and practice.

2) Developing a Narrative of the Experience

In order to analyse the experience I first needed to construct a narrative account of it. This process involved a review of the available 'records' that I had 
of the experience including reflective journal entries, research notes, notes from NGO meetings and workshops, and e-mails between myself and my supervisor. The elaboration of this narrative originally began with a focus on moments of contradiction encountered in the NGO's vision and practice. However I soon realised that from the very beginning of my experience with the NGO, I had been aware of this contradiction and was reminded that one of my main reasons for becoming involved with the NGO was my desire to help resolve this problem. As a result, I changed the orientation of my narrative to a focus on how my understanding of the problem of contradiction and my faith in the NGO's ability to change had shifted over time. Working with this orientation I identified key moments when my understanding of the problem or my faith in its resolution had shifted and then wrote short narratives to describe each moment.

3) Critical Reflection on the Experience

Critical reflection on the experience involved reflecting upon the narrative to identify key elements and factors and their relationship to each other and the objective of the analysis. My critical reflection of the experience began with dividing the narrative into different periods based on the moments identified earlier. Each of these periods was then analysed in order to identify key factors that could be used as a source of further reflection. The key factors identified were:

- My understanding of the problem of contradiction:

- Nature of the problem

- Cause of the problem

- Solution to the problem

- My understanding of the actors in relation to the problem of contradiction 
- My faith in the organisation to overcome the problem of contradiction

The nature of these understandings was reflected upon in each of the periods identified and the relationship between different understandings in different periods was analysed in order to identify how they had shifted over time.

4) Presentation of the Results of the Analysis

During the critical reflection process the relationship between the shifting understandings of the problem and the main objective of the analysis were identified. The analysis of each period was then written up and the emerging understanding of my decision to leave the NGO was further reflected upon to produce the written conclusions of the analysis. The conclusions of the analysis are presented in the results section of this chapter (6.3).

5) Lessons learned for future action

The final phase of my CIA was a reflection upon the significance of the insights for my understanding and practice of development. In this phase I reflected upon the conclusions of the CIA analysis in light of my own practice with a focus on the role of development theorias and a critical analysis of complicity in practice. The results from this final analysis are presented in the 'observations' and 'critical reflection' sections of this cycle (6.3.3). 


\subsection{Presentation of Results, Discussion and Critique}

\subsubsection{Critical Incident Analysis Results}

The main objective of the CIA was to provide an understanding of why I had decided to leave the NGO that I was interning with as well as the possible significance of these insights for my development practice. In order to answer these questions, I begin by presenting the results of the CIA analysis outlined earlier with regards to how my understanding of the problem of contradiction between the NGOs vision and practice shifted over time. Before continuing, it is important to mention that I do not disclose the exact name of the NGOs or the actors involved or provide details that could do so. More information regarding the actors involved in my study is provided in the third cycle.

\section{Box 9. Results of the Critical Incident Analysis}

\section{Period 1: First Encounters \\ Description}

I first encountered the NGO in February of 2010 while coming to the end of a two year period of volunteering with local Latin American NGOs. I was drawn to the NGO by its associate director who I saw as inspiring and visionary; its methodology which I saw as innovative involving the combination of participatory, emancipatory and indigenous methodologies; and its flagship project a community driven conservation area (CCA) based on local indigenous beliefs and values. I interned with the organisation from February through to May 2010 during which time I was charged with systematising the organisation's methodology which was described as existing and being practiced tacitly rather than explicitly. During this time I became aware of the contradiction between the NGO's espoused innovative methodology (according to the associate director) and the practice and capacity of the current field staff. As a result, I became interested in systematising the practice experience of the director and earlier field staff (who had led to the establishment of the conservation area) as the basis for developing an explicit practice methodology for the NGO.

Understanding of the Problem

- Nature of the Problem: Contradiction between the director's conception of the NGO practice methodology and staff practice and understandings of this methodology. Technical/ methodological problem requiring transfer of knowledge to existing staff.

- Cause: Loss of experienced staff, existing staff not familiar with the NGO methodology, lack of communication between director and staff, lack of established procedures and processes to guide staff practice.

- Solution: Systematisation of past practice experiences to develop an explicit and 


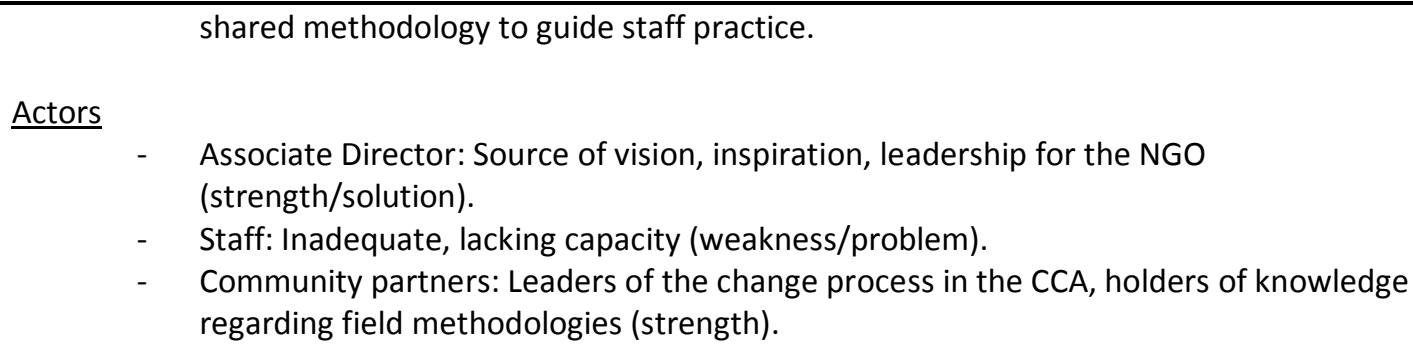

- $\quad$ Associate Director: Source of vision, inspiration, leadership for the NGO (strength/solution).

- $\quad$ Staff: Inadequate, lacking capacity (weakness/problem).

- Community partners: Leaders of the change process in the CCA, holders of knowledge regarding field methodologies (strength).

\section{Capacity for Change}

- $\quad$ Faith in a technical/methodological solution to the problem and my role in helping develop it.

- $\quad$ Faith in the director as a source of vision, knowledge and leadership.

- The CCA model as proof of the effectiveness of the NGO's practice and methodologies.

\section{Period 2: Return to the NGO}

\section{Description}

Following nearly 2 years in New Zealand I returned to the NGO to intern and carry out my Master's thesis research in March 2012. One of my main objectives for carrying out research with the NGO was the potential for my internship to result in a full time paid position with this NGO whose visions and objectives were in line with my own and whose approach I found inspiring and innovative. My Faith in the NGO was immediately shaken however through conversations with a staff member preparing to leave the organisation after a two year period working with them. Her criticisms of the NGO presented a much grimmer picture including the degree of disorganization in the NGO, the lack of communication, procedures and processes, doubts regarding the nature of the CCA and criticisms regarding the director's ability to address the need for change. While this initially led me to question my involvement in the NGO, my faith was restored by the director's recognition of many of these problems and his support for an organisational restructuring process.

\section{Understanding of the Problem}

- Nature: Broader contradiction between organisational vision and practice. Technical/ methodological in nature, requiring the development of a coherent organisational approach and procedures.

- Cause: Disorganization and lack of clear and appropriate administrative, governance and programmatic structures and processes.

- Solution: Organisational restructuring process.

Actors

- $\quad$ Associate Director: Source of vision, inspiration, leadership for the NGO (faith maintained due to support of restructuring process).

- $\quad$ Staff: Doubt regarding staff desire or capacity for organisational change.

- Community partners: Leaders of the change process in the CCA however doubts emerge regarding their relationship with the NGO (awareness of conflicts between community members and the NGO).

\section{Capacity for Change}

- $\quad$ Faith initially shaken by departing staff member criticisms but largely restored due to director support for the restructuring process and initial staff engagement with the process.

- $\quad$ Faith in the technical/methodological nature of the problem and my role in helping develop a solution. 


\section{Period 3: Restructuring}

\section{Description}

The restructuring process began towards the end of March 2012 and received official donor support in the following month. I was originally heavily involved in the process working closely with the associate director and executive director and remained actively involved until the end of August 2012. During this time my faith in the NGO and its capacity to change was tied to the progress of the restructuring and its degree of support by staff and administration. During this time I also began to increasingly question the capacity of the director to support a participatory change process in the organisation.

Understanding of the Problem

- Nature: Broader contradiction between organisational vision and practice. Technical/ methodological in nature, requiring the development of a coherent organisational approach and procedures.

- Cause: Disorganization and lack of clear and appropriate administrative, governance and programmatic structures and processes.

- Solution: Organisational restructuring process with broad staff participation.

Actors

- Associate Director: Problem as well as solution (growing doubt in the director's ability to carry out change and support a participatory change process involving all staff).

- Staff: Indicate they want to see change (growing faith in staff as key actors in the restructuring).

- Community partners: Leaders of the change process in the CCA however doubts continue regarding their relationship with the NGO (awareness of conflicts between community members and the NGO).

\section{Capacity for Change}

- Fluctuating faith in organisational capacity to change tied to the progress of the restructuring process.

- Belief in the technical/methodological nature of the problem and my role in helping develop a solution.

\section{Period 4: The Community Conservation Area Workshops}

\section{Description}

At the end of August 2012 the executive director called an impromptu meeting to discuss the problems present in the community driven conservation area (the CCA) that was the main focus of the NGO's work. My initial reaction to the meeting was one of excitement at the opportunity to get these problems out in the open and to address them as an organisation. I had been becoming increasingly aware of problems in the CCA since the beginning of the restructuring and particularly through staff interviews. As a result, I offered to facilitate a more concrete participatory analysis of these problems through a series of staff workshops carried out on the $5^{\text {th }}, 12^{\text {th }}$ and $20^{\text {th }}$ of September. The result of these workshops was a considerable shift in my understanding of the problem of contradiction between the NGOs vision and practice. I became increasingly aware of the difference between the official conception of the CCA, the staff's understanding of it and practice in it, and the role of community partners in relation to the CCA. As a result, I came to realise that the nature of the NGO's contradiction between vision and practice was not technical/methodological but more complex involving conceptual, personal and micro-political conflicts.

\section{Understanding of the Problem}

- Nature: Contradiction between NGO vision and practice. Complex, personal, conceptual, micro-political.

- Cause: Conflict between different conceptions of development and development practice highlighted in the NGO's engagement in the CCA.

- Solution: Unclear but complex, personal and profound. 
- $\quad$ Associate Director: His vision of the CCA corresponds with the official conception of the CCA but is not manifest in practice.

- $\quad$ Staff: Possess a different conception of the CCA and their role and practice within it.

- Community Partners: Their role and engagement with the CCA does not correspond with the associate director's/official conception of the CCA.

Capacity for Change

- Loss of faith in a solution to the contradiction in the NGO's work due to the complex, deeply personal and deep rooted nature of the problem.

- Loss of faith in the director's ability to change this situation.

- Realisation that while the staff do want to change, their conception of the problem and the solution are markedly different from my own.

The conclusion arrived at through my CIA was that I had lost faith in the NGO's ability to resolve the contradiction between its vision and practice due the degree of difference between the actors involved with the NGO and their conceptions of development and development practice in relation to the CCA. Underlying my former belief in a technical/ methodological solution was my somewhat paternalistic assumption that the field staff did not understand or did not 'get' the director's development vision and/or have the capacity to put it into practice. Through the CCA workshops however, I realised that field staff were in fact working from their own implicit development theorias.

During the CCA workshops, and in the absence of the associate director, staff expressed their own understandings of the problems in the CCA and the role of community members. These understandings indicated the existence of staff theorias that differed markedly from the NGO's official development vision, including:

- A perspective of the CCA as owned and run by the NGO.

- A paternalistic attitude towards community members - employer/employee, teacher/student relationship

- No mention of community management or leadership of the CCA. 
- Little to no mention of the CCA being a manifestation of traditional indigenous culture.

At the same time field staff presented a very different understanding of the community members and their motivations for being involved in the CCA. According to the staff:

- There was a lack of identification with the CCA by community members and after 10 years many community members still did not even know what the CCA was.

- There was declining participation in the CCA and its different groups.

- There was a high degree of competition and conflict between different groups within the communities of the CCA.

- The main reason for most members participating in CCA was to receive money. Many members would not participate unless paid by the NGO.

As a result I began to suspect that the community members themselves did not share the official NGO conception of the CCA espoused by the associate director.

Up until the CCA workshops my main preoccupation had been whether different actors were willing or capable of committing to the technical/ methodological process needed to resolve the contradiction between the NGOs vision and practice. Following the CCA workshop it was clear that this did not matter because even if the different actors did want to change, their conceptions of the necessary change were markedly different from each other's and from my own. This led to the realisation that it was the difference between the actors' development theorias that actually underpinned the distance between the NGO's vision and practice. That while my understanding of the CCA might correspond with that of the associate director and the NGO, it was apparent 
that it did not correspond with those of the key actors engaged directly with the CCA. Returning to the critical incident analysis, I believe it was this dawning realisation that led to my eventual loss of faith in the NGO and formed the basis for my experience of cognitive dissonance and the decision to leave the organisation.

\subsubsection{Observations}

So what is the significance of this analysis and its conclusions regarding my understanding of alternative development practice? Returning to my focus on theorias, I believe the critical incident analysis highlights the importance of development theorias, not only for the inner alignment of practitioners but also for inter-actor alignment in development practice. My CIA indicates that for development actors to work together towards a common vision (organisational or otherwise) they need to share (or experience alignment between) their development theorias. As a result, developing a collective understanding of one's own and each other's development theorias could form the basis for seeking inter-actor alignment and more effective alternative development processes. It is also possible that my prolonged engagement with a development initiative that was not suited to me was due to both my lack of clarity regarding my own development theoria combined with a focus on the official vision of the NGO rather than the theorias of different actors involved with it. As a result developing one's own development theoria and reflecting upon the theorias of potential allies could aid practitioners in deciding which alternative development initiatives they want to be involved with or are willing to support.

\subsubsection{Critical Reflection}

While I believe my CIA illustrates the importance of practitioner development theorias for inter-actor alignment, I also belief it highlights the challenge of complicity in one's 
development practice. In relation to the $\mathrm{CIA}$ it is obvious that I was complicit with the kind of development practice that I do not agree with or believe is right. On the one hand this highlights the risk of complicity when being hopeful or aspiring for something better. The risk of implicating oneself in potentially unethical or harmful situations in order to change them or in the words of Kapoor (2004 p640): working from within "the belly of the beast"

On the other hand, while the CCA workshops may have been a turning point in my decision to leave the NGO, it became apparent during the CIA that there were earlier indications that I ignored or 'avoided'. The criticisms of the departing staff member in Period 2 of the $\mathrm{CIA}$ specifically mentioned her concerns over the level of community member identification with the CCA and the paternalistic attitude of field staff. In this case I believe I 'avoided' the staff member's threat to my construction of the NGO and its work by discrediting her as a source of information. Evidence of this can be found in my e-mails and diary entries where I write her off as being in a bad space and chose to adopt a wait and see position.

My avoidance of the problems in the NGO led to my complicity in colonial continuities of development practice manifest in the treatment of indigenous community members as incapable or child like (Heron, 2007). Despite the evidence, I believe that I continued to avoid my awareness of this complicity due to my personal desire for development work (Kapoor, 2005). I saw my involvement with the NGO as the key to both my career path and my Master's research and any threat to my construction of the NGO and its worthiness was inherently a threat to the expectations generated by these beliefs. As a result it is possible that I avoided my awareness of complicity based on these desires.

Such reflections indicate the role that personal desires can play in oppressive power relations and how they can challenge our capacity to confront oppression and do what we know is right (Kapoor, 2005). At the same time, this critical reflection once again 
emphasises the importance of constructing and reflecting on one's development theoria as a means of engaging with complicity. While it may be easy to dismiss the insights of others (such as the staff member) it is less easy (existentially) to dismiss one's self as a reliable source of information. In the end it was having to make a personal choice that forced me to confront my understanding of the situation and realise it was not right for me and that I would have to go. By presenting one's key beliefs and values and making them open to reflection, development theorias could offer another instrument for reflecting on practice situations and their ethical nature.

\subsection{Summary: Development Theorias and Personal Practice}

The second cycle of my reflective investigation was primarily concerned with the research question "What is the significance of an engagement with personal development theorias for one's practice?" In order to answer this question I critically reflected upon a personal practice experience and analysed it in relation to my own and others theorias of development. The results respond to the research question by outlining the importance of inter-actor alignment for one's development practice. That it can be unproductive and potentially unethical to be involved in practice situations where one's colleagues and partners do not share the same understandings of development or development practice as oneself. Analysis of these results also suggest the significance of becoming aware of one's own and others conceptions of development as the basis for pursuing inter-actor alignment. That becoming aware of one's own and others theorias of development can form the basis for selecting the alternative development partners and initiatives that one wants to be involved with. Finally, an awareness of one's own theoria of development can also form the basis for critical reflection and an assessment of one's harmful complicity or potential for complicity within practice situations. 


\section{Chapter 7: The Significance of Actor Theorias in Development Processes}

\subsection{Introduction}

The third cycle of reflection focuses on the significance of development theorias for broader development processes and outputs. In doing so, it explores the causes and consequences of the misalignment between actor theorias identified in the previous cycle. The third reflective cycle begins by interpreting and comparing different actor theorias before moving on to an analysis of their consequences in relation to the processes and outcomes of the CCA initiative. In doing so, it employs an actor orientated approach that engages with the CCA as a permanent social interface where: "Continued interaction encourages the development of boundaries and shared expectations that shape the interaction of the participants so that over time the interface itself becomes an organized entity of interlocking relationships and intentionalities" (Long, 2003 p53). The cycle concludes with critical reflections on the role of power relations, positionalities and complicities in relation to the misalignment between actor theorias and its consequence for the CCA initiative.

\subsection{Description of the Research Process}

The third reflective cycle began with the identification of the main actors involved in the social interface of the CCA initiative. The actors identified were divided into three main groups - donors, NGO actors and community actors. In order to interpret their different theorias, data was gathered from multiple sources including:

- Staff interviews regarding the vision, mission and values of the NGO

- Staff interviews regarding the programmatic restructuring of the NGO 
- Staff, donor and community member interviews regarding their understanding of the CCA as a model

- Use of the most significant change technique with staff, donors and community members

- Official NGO documentation and descriptions of the CCA

- Official documentation from donor websites

- Existing studies of the CCA initiative

- Participant observation - recorded field notes and reflective journal entries

After gathering the data, an analysis structure for interpreting the development theorias was selected based on a simplified version of the conceptual framework employed in the first cycle of reflection. As with my personal development theoria I divided actor theorias into conceptions of development and conceptions of practice. In relation to the CCA focus these became conceptions of the CCA and conceptions of practice in the CCA (Box 10.).

\section{Box 10. Interpretive Structure for Actor CCA Theorias}

\section{Conception of the CCA}

1. Ends

- The objective of the CCA

2. Means

- What the CCA is and how it operates in order to achieve its objective

3. Actors

- Who owns/drives/carries the CCA process

- The relationship between actors in the CCA

\section{Conception of Practice in the CCA}

1. Ends

- NGO and CCA members' objectives in the CCA

2. Means

- How the NGO and CCA members achieve their objectives

- How the individual/group sees their work as contributing to either objective

- $\quad$ The part of the NGO's work that community members value most 
3. Actors

- The role of the NGO and others actors in the CCA

- $\quad$ The relationship between the NGO and other actors in the CCA

The CF was then used as a reflective template to structure the data being analysed resulting in interpretations of the different actor theorias of development. These theorias then became the main focus for critical reflection on the relationship between actor theorias and the consequence of their interactions for the development processes and outcomes of the CCA initiative.

\subsection{Presentation of Results, Discussion and Critique}

In this section I present the results emerging from my relational reflection on the role of actor development theorias in the social interface of the CCA. I begin by briefly presenting the main actors and contexts related to the CCA before examining the results of the reflective cycle in the form of my interpretation and comparison of actor theorias. I then analyse these theorias and the relationship between them in order illustrate their consequence for the CCA initiative. In doing so, I highlight how these theorias link or diverge and are manifest or suppressed within the social interface of the CCA. My analysis of the results concludes with a critical reflection on the role of power relations, positionality and complicity. Reflections that draw attention to the role of gatekeeper actors and 'constructive complicity' in the misalignment of actor theorias and its consequences for the CCA initiative.

\subsubsection{Context and Actors}

Presenting the context and actors for the third cycle of reflection proves difficult due to the constraints posed by ensuring research participant confidentiality and the 
contested nature of the CCA as a context. To avoid identifying my research participants I have limited my description of the NGO and its context while providing descriptions of actor theorias by groups instead of by individual. In addition, due to the contested and constructed nature of the CCA initiative, I am unable to present an 'objective' description of it. Instead I begin with what I consider the 'official story' based a revision of 35 official documents related to NGO.

\section{The Official Story}

As mentioned earlier the NGO and its partner communities are located in a country in the Andean region of South America. The NGO which provides the key organisational context for the research was established by the executive director as a non-profit civil society organisation in the mid-1990s and identifies itself as an Indigenous NGO. The organisation's vision is “human well-being in sustainable indigenous communities... based on their own capacities and resources and through their own local development strategies", while their mission is stated as the creation of "local capacities and grassroots strategic responses to the socio-economic, cultural, ecological and political effects of globalisation on local communities".

In pursuing its vision and mission the NGO focuses on cooperative community level engagement with indigenous organisations employing participatory processes and focusing on poverty alleviation, biodiversity management, traditional resource rights and achieving institutional and policy change. The NGO itself is composed of 13 core staff including 6 field workers and 7 administrative staff including the executive director and an associate director as well as a fluctuating number of volunteers and contract workers. The organisations structure remains relatively informal and flexible with staff organised according to the themes they work with, the roles they perform and the projects they work in. In terms of governance, the NGO has a Board of Directors composed of mostly foreign experts but which has little to no influence in the NGO's administrative affairs which are controlled exclusively by the two directors. 
In 1996 the NGO began its operations working with several neighbouring communities driven by the associate director's interest in combining global agendas related to insitu conservation, poverty reduction, food security and biodiversity. Through continued dialogue and growing community interest the process led to the establishment of the community conservation area comprising several communities with a combined population of over 5000 people. At this point the CCA was conceived of as a rights based approach to in-situ conservation founded on traditional cultural beliefs and values. Highlighted in the official documents is the significant role that the establishment of the CCA had in resolving conflicts between the different communities of the area and establishing a new sense of inter-communal unity.

In 2002 the communities and their representatives became recognised as the legal owners and administrators of the CCA and from 2002 to 2006 the inter-community governance system of the CCA was designed and established. In the mid-2000s the CCA began to be described as a new type of community led conservation model for the holistic conservation of biodiversity and related cultural traditions, knowledge and landscapes. This model remained rights focused and was aimed not only at protecting the natural environment but also the socio-cultural systems that had given rise to it in the face of external pressures driven by globalisation. The model was also founded on indigenous conceptions of territoriality and land use.

In 2006 a new focus on poverty alleviation and economic activities in the CCA emerged, focused on the establishment of inter-community micro-enterprise groups. These economic groups were assigned the dual purpose of conserving and sustainably using traditional biodiversity and cultural resources while generating income and were considered part of a solidarity economy approach. In subsequent years the CCA became increasingly referred to as a conservation-development model with a growing focus on the role of eco-tourism. More recently, official documents have begun to 
consider the rights based approach of the CCA's conservation-development model as primarily concerned with indigenous self-determination.

While the emphasis of the CCA may have changed over time, its overall aim is consistently linked to the defence of indigenous peoples against the harmful effects of globalisation. Beginning with a focus on traditional knowledge and resource rights the CCA has subsequently been associated with the defence of traditional culture, landscapes, and political rights in the form of indigenous self-determination. Another enduring dimension of the CCA is its emphasis on the cultural beliefs and values underpinning the initiative. The CCA and its governance model are said to be based on enduring cultural principles and an indigenous cosmovision with conservation efforts driven by an indigenous environmental ethic. Especially in later documents, the CCA itself is associated with a new manifestation of traditional indigenous socio-cultural relationships based on indigenous conceptions of territoriality.

Underpinning this argument is a continuing description of the communities involved in the CCA as strongly indigenous and traditional. Descriptions which tend to focus on the communities' enduring traditional beliefs and relationships with nature and each other. This emphasis includes a focus on the non-monetary values of their culture and their sense of collectivity including communal ownership and labour. The unity of community members is also emphasised and in official documents they are often referred to as a single actor - "the CCA".

\section{The Actors}

Within the social interface of the CCA initiative three main groups of actors are involved: donors, NGO actors and community actors. In relation to donors, the NGO's two principle funders were used to analyse donor theorias of the CCA and will be referred to as Donor A and Donor B. Donor A is a nationally based INGO that partners 
with local organisations and is focused on sustainable development. Donor B is an INGO which is part of an international network and also works with local partners employing a focus on rights.

In terms of NGO actors, I focus on the roles of six field workers and the NGO's two directors. These field workers include two agronomists, a tourism specialist, a women's group worker, a logistics officer/driver and a coordinator of activities in the CCA. In terms of the NGO's directors, the executive director is the one who established the NGO and acts as its legal representative, however from my experience it is clear that the associate director is the one who exercises primary leadership. It is the associate director who decides the direction of the NGO's work, its vision and approach, whose agenda dictates the work activities of staff and whose contacts provide funding for projects.

At the community level, actors are primarily divided into two groups - actors who are directly involved with the CCA (CCA members) and those who are not actively involved but occupy the same socio-geographical area associated with the CCA (community members). With regards to CCA members, they can be divided into nine different groups associated with the CCA initiative and comprise between 40 and 50 individuals in total:

- Community organisers - Coordinate and facilitate the different activities that take place in the CCA, provide the main point of contact between the NGO and the communities.

- Biodiversity guardians - Oversee conservation activities in the CCA.

- Natural products group - Conserves native plants and the knowledge associated with them, produces and sells products based on native plants.

- Traditional foods group - Maintains traditional culinary knowledge and skills, prepares meals for visitors. 
- Traditional crafts group - Maintains traditional artistic and textile skills, produces crafts for visitors to buy.

- Garden group - Grows and conserves native plants, provides inputs for the natural products group.

- Audiovisual group - Records and preserves the traditions and ways of life of the CCA's communities.

- Guides - Host and accompany tourists during their visits to the CCA.

- Home-stay tourism group - Provides overnight accommodation and a cultural immersion experience for tourists who want to stay in the CCA.

Finally, the community members who do not participate directly in the CCA inhabit the several different communities that comprise the socio-geographic boundaries of the conservation area. These are rural communities whose combined population numbers over 5000 and whose inhabitants are largely involved in traditional agricultural activities.

\subsubsection{Interpretation of Actor Theorias of the Community Conservation Area}

Having outlined the different actors whose theorias form the basis of the third cycle of reflection I now present my interpretation of these theorias. In doing so, I provide composite theorias for each group of actors including the donors, directors, field workers, CCA members and community members. These composite theorias are contrasted with one another while internal inconsistencies within the composite theorias are also addressed. 


\section{The Official NGO Theoria}

The official NGO theoria of the CCA is distinguished by its degree of conceptual complexity (Fig 2.). This conceptual complexity seems to stem from its entanglement in multiple conservation and development discourses. While the aim of the CCA model is seen broadly as conservation, its role is interpreted according to a wide range of concepts including biodiversity, development, intellectual property rights, indigenous well-being or different combinations of these. As a result, while the CCA is broadly considered a conservation or conservation development model it is also referred to as:

- A solidarity economy model

- A contact learning zone

- A gene reserve

- An alternative development model

- A sui-generis system

- An endogenous development approach

Fig 2. Official CCA Theoria of the NGO

CCA Conception

\begin{tabular}{|c|c|}
\hline Concept & Description \\
\hline 1. Ends & $\begin{array}{l}\text { The objective of the CCA: } \\
\text { - Protection and preservation of local biodiversity, landscapes, indigenous } \\
\text { culture, knowledge and livelihoods. }\end{array}$ \\
\hline 2. Means & $\begin{array}{l}\text { What the CCA is/does in order to achieve its objective: } \\
\text { - A culturally guided and rights based approach to holistic conservation and } \\
\text { development. } \\
\text { - The basic logic underlying the conservation approach is that traditional } \\
\text { indigenous culture and ways of life inherently conserve and sustainably use } \\
\text { agrobiodiversity. As a result, protecting and maintaining traditional culture, } \\
\text { resource rights and land use systems will lead to continued or strengthened } \\
\text { conservation of biodiversity and related knowledge. }\end{array}$ \\
\hline
\end{tabular}




\begin{tabular}{|l|l|}
\hline 3. Actors & $\begin{array}{l}\text { Who owns/drives/carries the CCA process } \\
-\quad \text { The CCA is community led, managed and governed. } \\
\text { - } \\
\text { Projects and initiatives that take place in the CCA are managed and } \\
\text { The CCA and its activities are identified with by all participating } \\
\text { The relationship between actors in the CCA } \\
\text { Communities are united by their identification with the CCA as their own } \\
\text { and a representation of their communities. } \\
\text { Community members are united by cultural values and beliefs that } \\
\text { emphasise reciprocity and collectivity. }\end{array}$ \\
\hline
\end{tabular}

\section{Practice Concept}

\begin{tabular}{|c|c|}
\hline Concept & Description \\
\hline 1. Ends & $\begin{array}{l}\text { NGO and CCA members' objectives in the CCA } \\
\text { - CCA members: Buen vivir = indigenous conception of development as well- } \\
\text { being and self-determined development. Protecting their traditional } \\
\text { biodiversity and related knowledge and technologies. } \\
\text { - NGO: Overarching purpose of the CCA as a model to defend the indigenous } \\
\text { communities against external threats driven by globalisation. }\end{array}$ \\
\hline 2. Means & $\begin{array}{l}\text { How the NGO and CCA members achieve their objectives } \\
\text { - CCA members: Solving problems. Pursuing political goals such as social } \\
\text { justice and having a voice in policy and decision making. Emphasising } \\
\text { traditional knowledge systems and indigenous world view, customary laws } \\
\text { and institutions. Conservation, governance and social systems based on } \\
\text { traditional culture and practices and involvement in new activities and } \\
\text { institutions based on these cultural practices. } \\
\text { NGO: Creating local capacities and grassroots strategic responses to the } \\
\text { socio-economic, cultural, ecological and political effects of globalisation. } \\
\text { Supporting new activities and institutions based on traditional practices } \\
\text { and culture. }\end{array}$ \\
\hline 3. Actors & $\begin{array}{l}\text { The role of the NGO and other actors in the CCA and relationships between them } \\
\text { - The CCA is administered by the intercommunity association. Community } \\
\text { organisers coordinate between the NGO and the communities and facilitate } \\
\text { activities in the CCA. Inter-community groups preserve agrobiodiversity and } \\
\text { culture, promote sustainable use of resources and generate income. The } \\
\text { NGO's role is unclear but seen as supportive e.g. supporting the } \\
\text { establishment of the CCA and the CCA groups, research partner etc. }\end{array}$ \\
\hline
\end{tabular}


Comparing the official theoria of the NGO with my own development theoria it is easy to see why I was attracted to working with the organisation. There exists a clear alignment between the NGO's and my own understanding of the CCA's role in combating the threats from dominant development (a.k.a. globalisation). In addition the CCA is portrayed as pursuing and promoting fulfilling ways of life in the form of the indigenous concept of well-living embodied in 'buen vivir'. This buen vivir focus also aligns with my own interest in the collective pursuit of being, doing, choosing and having well. Other areas of alignment include the community led orientation of the CCA and community member identification of the CCA as 'theirs' identifying it as a 'genuine' alternative-to-development.

\section{The Director Theoria}

The directors' theoria of development is largely dominated by the associate director's interpretation as he provided the most clear and detailed explanation of the CCA and practice related to it. This is not surprising as the associate director has been most involved in the official representation of the CCA to external audiences. At the same time however, the executive director broadly agrees with the associate director's theoria including the existence of multiple interpretations of the CCA and its overall objective of indigenous revitalisation and resistance. The only notable divergence is the executive director's belief that the CCA is not currently managed by the communities that compose it.

\section{Fig 3. Director Theoria of the CCA}

\section{CCA Concept}

\begin{tabular}{|l|l|}
\hline Concept & Description \\
\hline 1. Ends & $\begin{array}{l}\text { The objective of the CCA: } \\
\text { Provides a model that demonstrates the validity, vitality and utility of } \\
\text { traditional indigenous systems and a symbol to unite indigenous } \\
\text { communities. }\end{array}$ \\
\hline
\end{tabular}




\begin{tabular}{|c|c|}
\hline 2. Means & $\begin{array}{l}\text { What the CCA is/does in order to achieve its objective: } \\
\text { - Acknowledgement of multiple interpretations of what the CCA is and does } \\
\text { according to the different actors engaged with it including donors and } \\
\text { outside organisations, the NGO itself and the communities. } \\
\text { - Distinguishes between the CCA as community practice and the CCA as a } \\
\text { project. As community practice the CCA is seen as a new manifestation of } \\
\text { the traditional socio-cultural relationships between the indigenous } \\
\text { communities of the CCA and their members. As a project the CCA is } \\
\text { associated with a conservation-development initiative built around and } \\
\text { meant to support these indigenous socio-cultural relationships and their } \\
\text { related customs, knowledge and practices. } \\
\text { - The CCA as a conceptual and symbolic tool for the reconstitution and } \\
\text { maintenance of indigenous socio-cultural and territorial relationships. } \\
\text { Conceptually it provides a model that justifies, defends and generates } \\
\text { support for the indigenous communities, their culture and way of life. } \\
\text { Symbolically it provides the basis for uniting the different communities and } \\
\text { re-establishing inter-community socio-cultural relationships. }\end{array}$ \\
\hline 3. Actors & $\begin{array}{l}\text { Who owns/drives/carries the CCA process } \\
\text { - The indigenous communities involved in the CCA identify with it as a form } \\
\text { of territoriality that represents traditional socio-cultural relationships. They } \\
\text { identify with it as theirs. } \\
\text { - As community practice the CCA is administered by the communities } \\
\text { through their legal and traditional authorities. } \\
\text { The relationship between actors in the CCA } \\
\text { - Seen as motivated by a desire for achieving and maintaining unity and } \\
\text { traditional socio-cultural relationships focused on collectivity and } \\
\text { reciprocity. } \\
\text { - Conflicts in communities seen as originating from colonial and capitalist } \\
\text { influences. }\end{array}$ \\
\hline
\end{tabular}

Practice Concept

\begin{tabular}{|l|l|}
\hline Concept & Description \\
\hline 1. Ends & $\begin{array}{r}\text { NGO and CCA member's objectives in the CCA } \\
\text { CCA members: Revitalise and reconstitute traditional forms of inter- } \\
\text { community socio-cultural relationships and indigenous territoriality. }\end{array}$ \\
$\begin{array}{l}\text { NGO: Support the communities' objectives and help to establish an } \\
\text { indigenous territory that can sustain food and life in the face of future } \\
\text { threats. }\end{array}$ \\
\hline 2. Means & $\begin{array}{l}\text { How the NGO and CCA members achieve their objectives } \\
\text { CCA members: Revitalise and maintain traditional practices of governance, } \\
\text { conservation and development. }\end{array}$ \\
\hline
\end{tabular}




\begin{tabular}{|l|l|}
\hline & NGO: Support traditional culture and practices by: \\
$-\quad \begin{array}{l}\text { Developing new initiatives that draw on what already exists e.g. } \\
\text { practices, customary laws, knowledge etc. }\end{array}$ \\
$-\quad \begin{array}{l}\text { Working with new initiatives in a way that reinforces traditional socio- } \\
\text { cultural and territorial relationships e.g. that promote unity, collectivity } \\
\text { and reciprocity. }\end{array}$ \\
$-\quad \begin{array}{l}\text { Re-interpreting traditional culture and practices in terms of } \\
\text { conservation and development agendas in order to validate them and } \\
\text { gain the support of powerful actors and discourses. }\end{array}$ \\
\hline 3. Actors & $\begin{array}{l}\text { The role of the NGO and other actors in the CCA and relationships between them } \\
\text { Community members are seen as driving the process and the relationship } \\
\text { between the NGO and the CCA communities is based on solidarity with } \\
\text { other actors described as 'outsiders'. }\end{array}$ \\
\hline
\end{tabular}

This understanding of the directors' theoria helps to explain the conceptual complexity encountered in the official theoria of the CCA. According to the directors, one of the NGO's main roles is to re-interpret the practices and way of life of the indigenous communities in relation to conservation and development discourses. As a result, the official CCA concept is employed as a strategy for gaining support for the struggle of the indigenous communities to maintain and revitalise their cultural traditions. The explicit strategy involves inserting the CCA approach into the discourses of powerful national and global actors thereby generating endorsement and acceptance for this local struggle. However, a by-product of this strategy is the conceptual snow-balling evident in the official CCA theoria as new layers of interpretation are added to continuously broaden and maintain support for the communities' actions. At the same time, the directors' theoria still aligns with the official theoria's focus on the initiative as community led and owned and the conceptualisation of the actors as united. In addition, my own theoria is even more aligned with that of the directors' due their focus on the CCA as an indigenous struggle to promote and maintain an intercommunal alternative-to-development. 


\section{Donors' Theoria}

The donors' theoria indicates an engagement with the NGO's official theoria notably its proposal of the CCA as a conservation-development model. At the same time both donors tend to interpret the objectives of the CCA and the NGO in relation to their own institutional goals.

\section{Fig 4. Donor Theorias of the CCA}

\section{CCA Concept}

\begin{tabular}{|l|l|}
\hline Concept & Description \\
\hline 1. Ends & $\begin{array}{l}\text { The objective of the CCA: } \\
\text { Donor A: Biodiversity conservation, poverty reduction, empowerment of } \\
\text { indigenous peoples, strengthening indigenous biodiversity and cultural } \\
\text { systems. } \\
\text { Donor B: Ensure the rights of indigenous peoples to their territories, } \\
\text { cultures and livelihoods. }\end{array}$ \\
\hline 2. Means & $\begin{array}{l}\text { What the CCA is/does in order to achieve its objective: } \\
\text { Both donors identify with the CCA as a model for a culturally guided and } \\
\text { rights based approach to holistic conservation and development. }\end{array}$ \\
\hline 3. Actors & $\begin{array}{l}\text { Who owns/drives/carries the CCA process } \\
\text { Both donors focus on the CCA as driven by community commitment and } \\
\text { identification and managed by the communities themselves. }\end{array}$ \\
$\begin{array}{l}\text { Both donors identify the participating communities and their members with } \\
\text { the CCA. }\end{array}$ \\
\hline $\begin{array}{l}\text { The relationship between actors in the CCA } \\
\text { Both donors emphasise the unity of the different communities involved in } \\
\text { the CCA. }\end{array}$
\end{tabular}

Practice Concept

\begin{tabular}{|l|l|}
\hline Concept & Description \\
\hline 1. Ends & $\begin{array}{r}\text { NGO and Community objectives in the CCA } \\
\text { Community actors: Both donors associate the goals of the community } \\
\text { members with those of the CCA. }\end{array}$ \\
\hline
\end{tabular}




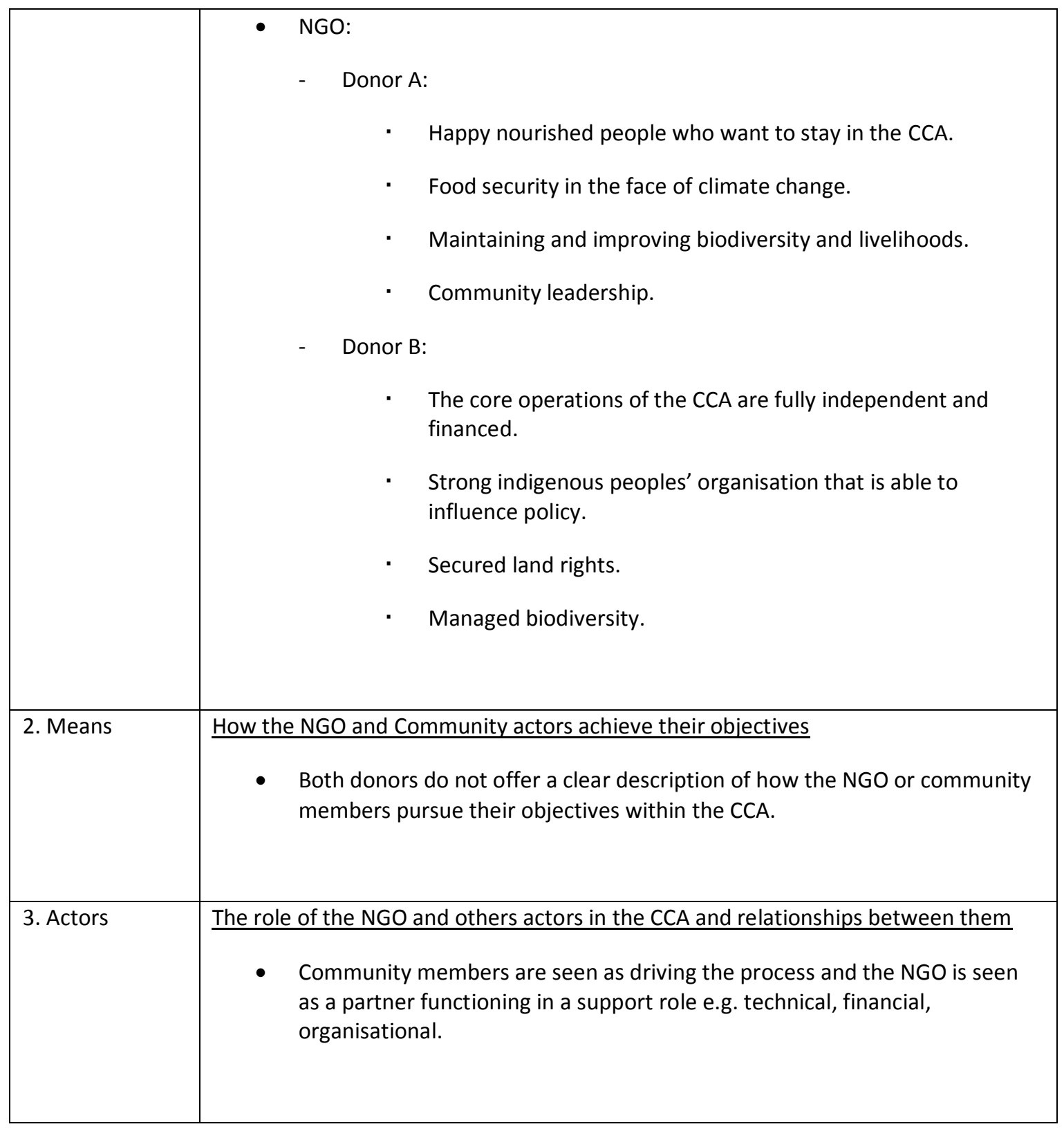

The donor theoria, official theoria and director theoria all align in terms of their emphasis of the CCA as a community owned and driven process. In addition they all emphasise the CCA as driven by the communities' priorities and based on their shared cultural beliefs, traditions and practices. Somewhat surprising is the apparent support for the director's covert agenda of supporting an indigenous struggle for maintaining traditional culture, ways of life and rights. This position suggests the donors are possibly aware of and facilitate the NGO's strategy of accessing broader support through a conservation-development discourse. 


\section{Field Worker Theorias}

While diverse, taken collectively the field worker (FW) theorias differ markedly from the similarities found in the official NGO, director and donor theorias of the CCA. Field worker theorias tend to emphasise narrower conservation focused objectives (biodiversity and cultural) for the CCA. In particular, FWs tend to tie conservation activities in the CCA to economic activities especially tourism, with the income generated from tourism projects seen as the main incentive for conservation of local biodiversity and culture. In addition there exists a deep scepticism regarding the unity of the community members and their degree of identification with, or even understanding of, the CCA and its activities. In contrast the NGO itself emerges as the key actor and the CCA is often described as the NGO's project.

\section{Fig 5. Field Worker Theorias of the CCA}

\section{CCA Concept}

\begin{tabular}{|c|c|}
\hline Concept & Description \\
\hline 1. Ends & $\begin{array}{l}\text { The objective of the CCA: } \\
\text { - All FWs share an understanding of the CCA as aimed at achieving } \\
\text { conservation of traditional biodiversity and culture though they may stress } \\
\text { one or the other. }\end{array}$ \\
\hline 2. Means & $\begin{array}{l}\text { What the CCA is/does in order to achieve its objective: } \\
\text { - All FWs share a less conceptually complex understanding of the CCA as a } \\
\text { conservation and development area - a conserved area where } \\
\text { conservation and development activities take place. } \\
\text { - The main driver for conservation in the CCA is the economic activities based } \\
\text { around tourism suggesting a conservation-tourism logic for the CCA. }\end{array}$ \\
\hline 3. Actors & $\begin{array}{l}\text { Who owns/drives/carries the CCA process } \\
\text { - All except one FW (who was unsure) believe the CCA members and } \\
\text { communities are not capable of managing the CCA themselves. } \\
\text { - Instead FWs emphasise the role of the NGO as being primarily responsible } \\
\text { for running the CCA and coordinating the activities within it. } \\
\text { - All FWs indicate the lack of a bottom-up planning and implementation } \\
\text { processes for projects in the CCA. }\end{array}$ \\
\hline
\end{tabular}




\begin{tabular}{|l|l|}
\hline $\begin{array}{l}\text { The relationship between actors in the CCA } \\
\text { All FWs associate the CCA with its different groups rather than with the } \\
\text { broader communities they come from. }\end{array}$ \\
$\begin{array}{l}\text { In interviews and workshops, FWs indicate the lack of identification with, or } \\
\text { understanding of, the CCA in the broader community as a major weakness } \\
\text { of the CCA. }\end{array}$ \\
$\begin{array}{l}\text { In workshops FWs indicated the degree of inter-group conflict that exists in } \\
\text { the communities. }\end{array}$
\end{tabular}

\section{Practice Concept}

\begin{tabular}{|c|c|}
\hline Concept & Description \\
\hline 1. Ends & $\begin{array}{l}\text { NGO and Community objectives in the CCA } \\
\text { - Community actors: All FWs indicate that the main reason that community } \\
\text { members participate in the CCA is for economic reasons while indicating } \\
\text { that other motivations are also present such as preserving traditional } \\
\text { culture and knowledge, gaining access to traditional crop varieties and } \\
\text { receiving skills training. } \\
\text { - NGO: FWs tend to associate the objectives of the CCA with the objective of } \\
\text { the NGO including: } \\
\text { - Conservation of traditional culture and knowledge } \\
\text { - Use of tourism to promote conservation } \\
\text { - Conservation and capacity building } \\
\text { - Increasing biodiversity } \\
\text { - Developing CCA autonomy } \\
\text { - Biodiversity conservation for buen vivir (indigenous well-being) }\end{array}$ \\
\hline 2. Means & $\begin{array}{l}\text { How the NGO and Community actors achieve their objectives } \\
\text { - Community actors: Participate and develop skills in, and understanding of, } \\
\text { conservation-tourism activities based on traditional culture and sustainable } \\
\text { use of resources. } \\
\text { - NGO: Provides training and continuing support for the development of } \\
\text { economic activities related to tourism, re-valuing of traditional culture and } \\
\text { knowledge, re-valuing of traditional crop varieties and biodiversity. }\end{array}$ \\
\hline 3. Actors & $\begin{array}{l}\text { The role of the NGO and other actors in the CCA and relationships between them } \\
\text { - The economic groups are the main driving force of the CCA. Economic } \\
\text { groups provide the incentive for conserving traditional biodiversity and } \\
\text { culture and encourage the sustainable use of resources. Community } \\
\text { organisers and biodiversity guardians are employed by the NGO to facilitate } \\
\text { the different CCA and conservation activities coordinated by the NGO. The } \\
\text { NGO is seen as the main actor in the CCA. }\end{array}$ \\
\hline
\end{tabular}


In comparison to the director theorias, objectives related to indigenous selfdetermination and the autonomous struggle for cultural revitalisation are never mentioned. Instead field workers seem to have combined the official discourse of the NGO theoria with their own theorias of the CCA. This belief is sustained by the majority of field workers who assert that they did not possess an official interpretation of their mission and work role and had instead adopted their own orientations based on their own understandings, roles and objectives. According to the shared logic of the FW theorias, conservation in the CCA is not driven by traditional culture but by the economic incentive of tourism related activities. In contrast to the director's portrayal of indigenous culture as resurgent and the CCA as a manifestation of this, FW narratives tend to emphasise the decline of indigenous culture and conservation practices and the CCA as providing the incentive for maintaining these practices. As a result, FW theorias tend to suggest economic motives for community participation in the CCA rather than socio-cultural or political agendas.

\section{CCA Member Theoria}

The CCA member theoria presented in this section only relates to the CCA concept as information for interpreting the practice concept was insufficient. In general, CCA member theorias seem to demonstrate multiple influences of, or alignments with, the theorias of other actors. At times this leads to contradictory interpretations of the CCA, for example while a majority associated the initiative with conservation activities only three respondents considered conservation as the main objective of the CCA. Instead the majority of respondents associate the objective of the CCA with income generation and economic activity (15). This economic focus appears to support FW interpretations of CCA members' economic motivations for involvement in the initiative. At the same time, the directors' emphasis on the CCA as a socio-cultural manifestation also appears to be endorsed by the large number of respondents (12) that focus on the goal of the CCA as inter-community organization and cooperation. 
Fig 6. CCA Member Theorias of the CCA

\section{CCA Concept}

\begin{tabular}{|c|c|}
\hline Concept & Description \\
\hline 1. Ends & $\begin{array}{l}\text { The objective of the CCA: } \\
\text { - Interpretations of the CCA's objective were diverse including: } \\
\text { - Income and economic activity (15 respondents) } \\
\text { - } \quad \text { Better organisation of the communities in working together (12) } \\
\text { - Improved quality of life (9) } \\
\text { - Increased recognition of the CCA e.g. national park status (4) } \\
\text { - } \quad \text { Conservation (3) } \\
\text { - } \quad \text { Working with agriculture (3) } \\
\text { - } \quad \text { The CCA becoming self-managed (3) } \\
\text { - } \quad \text { Expansion of the CCA and its activities (2) } \\
\text { - Preserving traditional culture (2) }\end{array}$ \\
\hline 2. Means & $\begin{array}{l}\text { What the CCA is/does in order to achieve its objective: } \\
\text { - The majority of CCA members associated the CCA with conservation in } \\
\text { some form (25) while the second largest group associated the CCA as a } \\
\text { form of community organisation (14). However there were also significant } \\
\text { differences in these interpretations: } \\
\text { - An area, space or location where communities, nature and culture are } \\
\text { present (6) } \\
\text { - An area, space or location where communities, nature and culture are } \\
\text { present and conservation activities take place (13) } \\
\text { - A community organisation (3) } \\
\text { - A community organisation involved in conservation activities (8) } \\
\text { - CCA identified with as the communities e.g. use of "we" and "our" in } \\
\text { responses (3) } \\
\text { - A conservation model (4) } \\
\text { A place to receive training (1) } \\
\text { A group that sows crops and coordinates with the NGO for } \\
\text { development (1) }\end{array}$ \\
\hline 3. Actors & $\begin{array}{l}\text { Who owns/drives/carries the CCA process } \\
\text { - In total } 14 \text { out of } 32 \text { respondents considered the CCA as managed, owned }\end{array}$ \\
\hline
\end{tabular}




\begin{tabular}{|l|l|}
\hline or driven by the communities themselves in some way, including: \\
$-\quad$ Community managed (9) \\
$-\quad$ CCA identified with as the communities themselves e.g. use of "we" \\
and "our" in responses (3) \\
$-\quad$ The CCA as a community organisation (2)
\end{tabular}

My interpretation of the contradictory perspectives expressed in the CCA member theorias is two-fold. First of all it could suggest that certain CCA members' theorias align more or less with those of the directors or the FWs. Secondly, such contradictions could represent the manoeuvring of CCA members and their use of the discourse of different actor theorias in order to access opportunities and resources associated with the CCA. This second interpretation is supported by the fact that a third of the CCA members identify the CCA as a community organisation or as community managed despite the fact that FWs acknowledge that this is not the case. As a result, I believe that many of the CCA members interviewed were simply telling me what they believed I wanted to hear as an actor associated with the NGO. This 'echoing' of other actors development theorias is perhaps even more probable due to the fact that the NGO's training of new CCA members involves imparting an official discourse of what the CCA is and does.

\section{Community Member Theorias}

In order to explore the broader perspectives of the CCA emerging from the communities located within the socio-geographical boundaries of the CCA, I now turn to existing studies conducted in these communities. These in-depth studies carried out in 2010 (Nicanor) and 2011 (Lupenz) focus on broader community member interpretations and engagements with the CCA. While I am not able to construct a theoria based on the results of these studies they do provide useful information which highlights community conceptions of the CCA and how these relate to the theorias of other actors. Significantly both studies emphasise a lack of identification with the CCA or the work of the NGO. The 2011 study indicates that only $50 \%$ of community 
members are aware of the NGO and only $31 \%$ have been involved with the CCA at some time. These statistics correspond with the results of the 2010 study which indicates that most community members believe that the CCA benefits only a few community members.

Tied to this lack of community identification with the CCA is the view held by community members that the CCA is something that the NGO does (Nicanor, 2010). The 2011 study indicates that only 11\% believe that the communities are responsible for making decisions in the CCA while the 2010 study concludes that community members participate in the CCA principally to access short-term tangible benefits. My suspicion of CCA members doctoring their answers is also supported by the 2011 study where surveys produced a range of reasons for involvement in the CCA while personal interviews revealed income as the predominant factor.

While these studies appear to contradict official and director theorias and to support the assumptions of field workers, the 2010 study suggests that community members also reject FW interpretations of the CCA. In particular the study highlights community dissatisfaction with the paternalistic and top down approaches employed by FWs and points to the common opinion that the NGO benefits more from the CCA than the communities do (Nicanor, 2010). In general both studies suggest that the majority of community members do not identify with the CCA and its long-term and primarily intangible aims be it conservation or indigenous political struggle. This is not to say that community members' conceptions of the good life and good change are only monetary and material and do not include political or cultural elements. The studies simply suggest that most community members do not associate participation in the CCA with the cultural or political elements of their conception and pursuit of the good life and good change. 


\subsubsection{Observations}

Reflecting on my interpretation and analysis of different actor theorias it is clear that a significant misalignment exists between the theorias of different actors. The main consequence of these misalignments is the fact that the CCA - as a model of rights based and community-led conservation grounded in indigenous cultural beliefs - does not exist. Even at the practical level of a conservation model, a CCA requires the active management of biodiversity by the communities themselves. In contrast my research indicates that neither the procedures, capacities or level of interest necessary for community managed conservation exist in the CCA. This is despite the fact that the NGO's CCA model has received significant policy and institutional support and has become a point of reference for other indigenous communities seeking to pursue culturally based approaches to conservation and development.

The reason for this practice outcome can be attributed to the fact that neither community actor theorias nor director theorias correspond with the official conservation objectives of the CCA. For the community actors, engagement with the CCA is primarily a means to access material benefits while the CCA initiative is considered 'something that the NGO does'. For the directors, the conservation model of the CCA is merely an interpretation of what community members are already doing and a conceptual and symbolic tool to support their efforts to reassert cultural traditions and rights. As a result, neither place significant emphasis in developing procedures and processes for managed biodiversity conservation. The only actors who do engage with the official theoria's focus on conservation are the FWs where it is applied in a top-down and paternalistic manner.

The second consequence of the misalignment between actor theorias is the failure of the directors' strategy for using the CCA as a vehicle for the communities' cultural and political struggles. This failure can be seen as resulting from the fact that neither FWs 
nor community actors engage with the directors' theoria of the CCA. FWs do not share the focus on indigenous self-determination, cultural revitalisation or solidarity relationships that are evident in the directors' theoria. In addition, it appears the community actors themselves do not identify with the CCA, or its associated activities, as a manifestation of their cultural and political struggle. In summary, an examination of the misalignment between actor theorias reveals that the main outcome of the CCA in practice is the realisation of a collection of conservation and development projects built around a tourism incentive that primarily attracts community members through the opportunity to access short term tangible benefits (Nicanor, 2010).

\subsubsection{Critical Reflection}

So how has the illusion of the CCA as a community-led conservation and development model continued to exist for over a decade? What has maintained it and how has the CCA as a development process persisted despite the profound misalignment between actor theorias? In seeking to answer these questions I employ a final critical reflection on the role of power relations and 'constructive complicity' in creating and maintaining the misalignments between actor theorias which underpin the CCA 'mirage'.

The relationships between actors engaged in the social interface of the CCA emerge within layers of unequal power relations that establish certain actor positionalities. These positionalities include the role of gatekeeper actors who control the access of other actors to the benefits or resources they seek. At the same time, those who act as gatekeepers are often subject to the power of their own gatekeepers. For example, community actors are subject to the power of field workers in order to access the benefits of projects, while field workers are subject to the directors who control their salaries, and the directors and their ambitions are subject to the role of donors as the gatekeepers of funding and strategic support. These unequal power relations and 
attempts by actors to negotiate them maintain the misalignment of actor theorias that underpins the illusion of the CCA.

In the case of the directors, and especially the associate director, an "emperor has no clothes" scenario seems to exist. In this situation neither field workers or community actors appear willing to draw attention to the absence of the CCA as interpreted by the associate director or as represented in official documentation. At the same time the director theoria of the CCA is maintained by a form of unconscious and unintentional paternalism (UUP) associated with their relatively powerful position. According to Khader (2011), UPP is "a type of paternalism in which one party unjustifiably substitutes her judgment for another's because of difficulty distinguishing her desires for the other from the other's good" (ibid p742). This unconscious and unintentional paternalism is manifest in the directors' over-identification with the community actors, and the directors' assumption that their own agenda and conception of the CCA represents that of the community actors.

While paternalism in the case of the directors may be unconscious, a more typical form of paternalism is present in the relationship between field workers and community actors. As demonstrated in their theorias, field workers are aware of the differences between the official NGO theoria that they are working with and the conceptions and objectives of the community actors. In response to this they consciously seek to impose their interpretation of the official theoria of the CCA on community actors for the good of the actors themselves. Misalignment is then maintained by FW attempts to make community actors conform to their 'superior' theoria coupled with the continued resistance of community actors to this imposition.

At the same time, it is possible to interpret the conscious paternalism of the field workers as the consequence of their own experience of paternalism vis-a-vis the directors. In this case, the directors (and the associate director in particular) 
consciously impose their vision of the CCA on field workers who are forced to reconcile this theoria with the practice situations they encounter including the resistance of community members. As a result, they arrive at their own theorias of the CCA as a means of reconciling the official theoria and imposing it in practice. In summary, one of the main causes for the continued misalignment that underpins the illusion of the CCA is the imposition of different theorias of the CCA and the efforts of actors to resist or adapt to these theorias.

Another reason why the mirage of the CCA is maintained is the role of desire and 'constructive complicity'. From this perspective the broad concept of the CCA acts as a symbolic "third" (Marcus, 1998) that facilitates the efforts of individual actors to pursue their own desires and theorias. According to Kindon's (2012) interpretation, 'thirds' act as shared conceptual reference points that facilitate productive relationships between different actors involved in development processes (ibid p114115). In the case of the CCA, this third has facilitated 'productive' relationships in the sense that it has enabled different actors to inter-act and pursue their own agendas and desires despite possessing markedly different development theorias. Building on Kindon's work this situation has led to a form of 'constructive complicity' that has maintained the official representation of the CCA despite obvious contradictions.

Authors working with complicity have tended to focus on its unconscious manifestation in relation to dominant discourses or thirds, however in the case of the CCA this constructive complicity has been largely conscious and active. The NGO's directors have actively used the official theoria of the CCA as a means to achieve complicity with official donor discourse and access funding and strategic support for their own covert theoria of the CCA. Field workers also pursue active complicity through 'echoing' the official theoria of the CCA while pursuing their own theorias. More interesting to consider is why FWs fail to engage with the director theoria of the CCA and instead tend to re-interpret and incorporate the official CCA theoria in their practice. Possible reasons may include the apparent similarity between the two 
discourses which employ similar concepts and elements but with different aims. For example, the official theoria sees indigenous culture and self-determination as the means for achieving conservation while the director theoria sees conservation (discourse) as a means for supporting indigenous culture and self-determination. The result may be conceptual confusion for field workers, an assumption reinforced by my experience in the NGO with many staff emphasising the lack of communication and the need for a common conceptual language (Personal communication, 2012). As mentioned earlier, it is also likely that FWs have formulated their own theorias based on their field experience working with community actors who themselves are not interested in the CCA as a vehicle for indigenous struggle. It may also simply be that FWs do not share the objectives, beliefs and values of the directors. Either way it appears that field workers maintain complicity in the CCA as a conceptual third in order to facilitate their field work, remain in favour with the directors and guarantee their livelihoods.

Finally CCA members also pursue active complicity with the concept of the CCA in order to gain access to the benefits provided by projects carried out in the CCA. In doing so, CCA members usually 'echo' a field worker version of the official theoria as FWs provide the main point of contact between the community actors and the NGO. As a result, the official representation of the CCA is maintained through processes and relationships of conscious constructive complicity. This complicity maintains the social interface of the CCA initiative and is used by actors to pursue their own theorias, agendas and desires. Constructive complicity also provides actors occupying less powerful positionalities with 'room for manoeuvre'. While gate keeper actors may have the ability to impose their theorias and make final decisions, complicity in the CCA concept allows less powerful actors to pursue their own theorias under the guise of a dominant discourse. 


\subsection{Summary: Theorias and Alternative Development Initiatives}

The third cycle of my reflective investigation was primarily concerned with the research question "What is the significance of interactions between different actor theorias of development for development initiatives, processes and outcomes?" In the third cycle I have responded to this question by demonstrating the consequence of inter-actor misalignment for development initiatives. Using the CCA as an example I have shown how misalignment between actor theorias can result in "social constructions of success" (Rap, 2006) that do not correspond with practice experiences. Analysis of the results indicates how the combination of different actor theorias and unequal power relations led to a 'mirage' of the CCA as an indigenous conservation-development model. The results indicate the importance of inter-actor alignment for alternative development processes and outcomes. That for actors to work towards alternative conceptions of development they need shared understandings of their objectives and how they aim to achieve these in practice. 


\section{SECTION D: FINAL REFLECTIONS}

\section{Chapter 8: Reflecting on Research Implications}

\subsection{Introduction}

In this chapter I draw together key insights and conclusion from the different reflective cycles of my investigation in order to speak back to my own practice, to alternative development practice in general and to alternative development theory. The results and analysis from the previous section have demonstrated the potential for constructing personal conceptions of development in the form of theorias and indicated their significance for individual practice and alternative development initiatives. In this chapter I reflect on the implications of these results for my own and others' practice and for alternative development theory in general by drawing attention to the concept of alignment. In terms of my own practice I examine how the research process has helped me to achieve greater inner-alignment and the consequences of this for my understanding of my development practice. In reflecting on the implications of my research for alternative development practice, I explore how inner alignment can help practitioners to assess and pursue inter-actor alignment as the basis for an alternative development practice. I conclude with reflections on the theoretical implications of an alignment approach within the broader framework of alternative development and in relation to dominant critical approaches.

\subsection{Personal Implications of the Research}

In line with Hunt's interpretation of reflective practice, my reflective investigation has helped me to be able say "this is where I am now; this is how I got here; and these are 
some of the reasons why I think/feel/act as I do" (Hunt, 2006 p1). The implication of this research experience could be characterised as the achievement of greater inner alignment regarding my beliefs, values and conceptions of development and development practice.

In terms of "how I got here" the investigation has helped me to reflect on "my journey so far' (3.2) - on that which I have learned about myself, my place in the world and my relationship with others. The experience has allowed me to reconnect with my spirituality and re-visit past insights and implicit understandings by returning to my reflective journals and providing space to explore the relationship between my values, beliefs and aspirations. This same process has also helped me to re-connect with past practice experiences and lessons learned.

Reflecting on my past experiences and personal beliefs has also helped me to understand some of the reasons "why I think/feel/act as I do". In the context of my practice experience this has meant understanding why I decided to leave the NGO and why I believed this was the right thing to do. By reflecting on my development theoria I can see how I was originally drawn to the NGO due to its espoused support of fulfilling ways of life that corresponded with my own focus on being, choosing, doing and having well. I can also see how the practice experience that I encountered in the NGO contradicted my values of solidarity and integrity as well as my orientation towards locally controlled and owned development processes. Finally I can see how the development theorias manifest in the practices of others in the CCA proved too distant from my own and led to my decision to leave.

In terms of "where I am now" the process of inner alignment embodied in my research has resulted in greater alignment between my personal beliefs and values, my conception of development and my practice orientation. This alignment has been made explicit in the form of a written development theoria that I can return to and 
reflect upon in terms of my career. The process has also brought a greater degree of clarity regarding what I want to do in relation to the complex, ethically challenging, and conceptually ambiguous world of alternative development. For the first time I have a guiding vision of what development is for me. A conception based on the pursuit of fulfilling ways of life and characterised by my involvement in processes and practices of well-living including being, choosing, doing and having well. As a result my research experience and its process of inner-alignment also have profound implications for "where I might be going to next".

\subsection{Implications for Alternative Development Practice}

My research experience has shown that practice is personal and that the personal is practical. Based on this insight the main practice implication of my research is the need for inter-actor alignment in development processes. As evidence of this, my research clearly illustrates how the misalignment of personal conceptions of development can shape development processes and outcomes. The case in point being that a decade long alternative development initiative effectively does not exist. This in turn supports my earlier analysis of the need for tools and processes that can aid alternative development practitioners in engaging with their own and other's conceptions of development.

In responding to this challenge, my research provides an example of an approach that could aid practitioners in reflecting upon their own and others conceptions of development in the form of development theorias (Box 7.). The process employs an innovative use of reflective practice based on self-understanding and the identification of the key personal beliefs and values underpinning one's concept of development. As outlined in the previous section such a process can facilitate inner-alignment regarding one's understanding of development, however I also believe that such inner-alignment can provide the basis for the inter-actor alignment required in alternative 
development practice. In other words, by helping practitioners answer the question "What is development for me?" - theorias can also help practitioners to identify who they want to work with and what kinds of alternatives-to-development they want to be involved in. In doing so, practitioner development theorias could serve as a reference point, a reflective touchstone, for assessing one's own and others' practice.

The reflective use of personal theorias could also provide the basis for a reflective development practice that could be used to continuously assess one's alignment with other actors. Theorias could provide the personalised 'theoretical' reference point needed for a reflective development practice and which development studies itself cannot provide (Joy, 1997). A reflective practice based on theoria would draw on selfunderstanding and could help practitioners "to understand our own intentions, values and visions and prepare us to work in challenging field where our ethics and morals may be tested". As well as assessing one's alignment with other actors, continuous reflection could also facilitate the revision and reconstruction of one's own theoria as a means of maintaining or deepening inner alignment.

A reflective development practice focused on inter-actor alignment would also need to engage with relational reflection. Relational reflection could help practitioners assess the viability of practice situations by reflecting on the level of inter-actor alignment that exists between the different actors involved in initiatives. Critical reflective approaches could prove complimentary to this approach including the practice of hyper-self-reflexivity advocated by Spivak (1988) and Kapoor (2004) and modified by Kindon (2012). Techniques from hyper-self-reflexivity could be applied to an analysis of different actor theorias providing a focus on the manifestations of complicity in the different social interfaces of one's practice. In doing so, development theorias could provide a reflective lens for examining the development conceptions of other actors and exploring how development theorias and power relations are shaping development processes. 
On the other hand, a reflective engagement with development theorias and alignment could also benefit dominant critical approaches to alternative development practice. The construction of personal theorias could be adopted as a strategy for 'unlearning' (Spivak, 1988) necessary to bring about new counter-practices based on nonoppressive values and beliefs. The adoption of theorias based on positive beliefs, values and aspirations could also help critical approaches move beyond undoing-harm to a more constructive engagement with doing-good. Such an approach also supports aspects of creativity often missing in critical practices with theorias being "used by practitioners for interrogating their own activity and exploring new ways of doing, saying, and being" (Eikeland \& Nicolini, 2011 p170).

One of the main obstacles to such an approach might be the resistance of practitioners to engage with themselves at such an intimate level (Eyben et al., 2008). In response I would argue that it is this very same level of self-reflection and disclosure that alternative development practitioners often expect from local actors (Reeler, 2007). At the very least then, professional integrity requires alternative development practitioners to be open to these same processes. As a result, "daring to intervene" (Gibson-Graham, 2005 p6) also requires the "courage to use self-understanding" (Lushaba, 2009 p57) a process that involves not only recognising and guarding against one's vices, but also identifying and cultivating one's virtues (James, 2010). In this sense, self-reflection based on self-understanding does not need to be a process of self-rejection or punishment but can instead be enlightening and affirming as my research indicates.

My final reflection on the construction and use of development theorias is that they are not only a beneficial means for inter-actor alignment but also an ends of alternative development practice. As mentioned earlier, the reflective process of creating one's development theoria can be considered a process of internal alignment. Such a process involves the establishment of greater coherency between ones values and beliefs and their alignment in relation to the concept of development. From a 
spiritual approach to development, this process could be considered as "putting one's inner house in order" (Schumacher, 1989) as the basis for "being the change we want to see in the world" (Ghandi in Cohen, 2006). From this perspective developing and continuing to develop one's conception and practice of development can be considered an end in itself. The end being self-transformation as part of collective human transformation - being better people together in order to bring about a better world.

\subsection{Implications for Alternative Development Theory}

Drawing on the implications of inner and inter-actor alignment, my research also speaks to alternative development theory by exploring the potential for an alignment based approach to alternative development. This alignment based approach would challenge dominant critical approaches to engage with personal conceptions of development, self-understanding and actor creativity. By overcoming the limitations of critical approaches, I believe that an alignment approach could offer a new form of alternative development practice: A development practice that no longer avoids the question of "What is development?" but consciously seeks to answer this question at a personal level. Such a practice would value the self and engage with practitioners' beliefs, hopes and aspirations as part of development. This would be a practice which acknowledges that development is not value neutral, and that practitioners need to make value decisions about the kinds of change processes they want to be involved in. Recognising that practitioners do not and should not act as value-free vessels for others' change processes; this kind of practice would aim for sincere and open development dialogues rather than self-neutral facilitation. Drawing on the insights from my research experience and related literature I believe that three elements would be essential for developing an alignment based approach: an 'in-relation-with' orientation, seeking alignment, and pursuing positive complicity. 
The foundation of an alignment based approach would be the 'in-relation-with' orientation to other actors outlined in Chapter 5 (5.3.2). This would be in contrast to the 'in-relation-to' (I and them) orientation common in critical approaches. As outlined earlier the 'in-relation-to' orientation tends to distance practitioners from others by emphasising the individual subjectivity of the practitioner leading to a tendency to do things for others rather than with them. Even when couched in the language of 'facilitating' or 'supporting', this distanced way of relating to others still implies that the practitioner is in some way superior - more developed or already free, happy, wealthy or self-aware. In contrast, an 'in-relation-with' approach to others is fundamentally based on humility. This humility is not based on 'disempowering' oneself (Chambers, 1997) but instead accepting that practitioners, like the others they work with, are imperfect beings in pursuit of happiness and good change in their lives (Kumar, 2003). That both practitioners and 'others' are more and less powerful, happy and unhappy, wise and foolish, capable of helping and harming (Chatteton, Fuller \& Routledge, 2007). As a result, an alignment approach to alternative development would be based on a collective pursuit of change founded on a collective awareness of shared imperfections, challenges, values and aspirations. Development initiatives based on alignment would not be designed to benefit only local actors or outside practitioners but instead both according to their shared understanding and pursuit of development (ibid). As a result, an 'in-relation-with' orientation fosters relationships where the practitioner is faithful to the other and faithful to oneself (Sanderson, 2009 p127).

Another key dimension of an alignment approach is seeking alignment rather than assuming it. The risk posed by unconscious unintentional paternalism (UUP) highlights the need to seek and assess alignment rather than trying to cultivate it within the context of unequal power relations. As demonstrated by Khader (2011) and my own experience, assuming alignment or attempting to 'apply' it in one's relationships with others without an awareness of one's positionality can lead to the echoing of practitioner's own theorias of development back at them. As a result, achieving alignment should be based on finding like minded actors with whom one can re-work 
or co-construct shared objectives and conceptions of development. A process that is based on the mutual self-understanding of the actors involved.

In order to pursue alignment, practitioners and other actors must first have an understanding of what they are pursuing as the basis for identifying who they are seeking to work with. For practitioners, this requires an understanding of one's own conception of development (for example one's theoria) in order to assess one's compatibility with other actors and practice situations. Such an awareness is equally important for not misunderstanding the theoria's, objectives and aspirations of other actors (Khader, 2011). By reflecting on one's own theoria practitioners can anticipate how they might misinterpret other actors by prioritising opinions that correspond with their own theorias or 'avoiding' those that do not. As the means for assessing interactor alignment will most likely be sincere and continuous dialogue, the ability to hear others and speak one's own conceptions of development will be vital.

Finally, in relation to the need to hear and see others, Khader stresses the role of "loving attention" (Khader, 2012) in mitigating unconscious unintentional paternalism. Loving attention is "the active search for otherness and particularity... an approach that dwells on the otherness of the other and lets that otherness be" (Ruddick in Khader, 2012 p744). This orientation towards others is echoed in Lu Kun's affirmation that: "Regarding others like the self, while realising that others are not necessarily like self, is comprehension" (Zeldin, 1994). In other words 'loving attention' is necessary to maintain a 'with' orientation to one's work with others that appreciates diversity rather than an 'us' approach that assumes homogeneity. While it is impossible to transparently see, hear or know others, practicing loving attention can help practitioners avoid the projection of their hopes and aspirations on to others.

A final key dimension of an alignment approach is a re-engagement with the concept of complicity as positive and active. Critical approaches often take a deterministic 
approach to complicity that sees powerful practitioners as conditioned and constrained by their inherent complicity in oppressive discourses. However as Gunaratnam (2003) and Kindon (2012) have pointed out, complicity is not necessarily a harmful or deterministic phenomenon, but can also be employed by actors as the conceptual basis for cooperative endeavours. In some cases, it can be seen as essential for a foundation for trust, solidarity and action.

An alignment approach to complicity would argue we can and should seek complicity in affirmative actions and practices, particularly where they engage with discourses of resistance, possibility and hope that align with practitioners' own development conceptions. Self-understanding and the definition of personal conceptions of development once again play a key role in pursuing constructive complicity. For example, reflecting on personal theorias can help practitioners align their practice with broader agendas, movements and constructive discourses. These constructive discourses would represent one's interpretation of patterns of 'good change' (such as the spread of women's rights) that exist in dialectical tension with harmful patterns of human history (such as colonial continuities (Heron, 2007)). At the same time through constructing their own counter-imaginations of development as good change, practitioners can also contribute towards the construction of new "demotic discourses (literally of-the-people) that offer alternative more locally rooted points of view" (Long, 2003).

In both instances, a hopeful and constructive complicity should be free to engage with new framings beyond discourse and power from which hope, inspiration and meaning can be drawn. As a result constructive complicity should acknowledge that "religiously or spiritually based approaches can provide an awareness of a frame of reference larger or deeper than the visible material world and thereby offer new possibilities for response" (Harper \& Clancy, 1999 p78). This in turn will require a hopeful ontology capable of appreciating the latent, the beautiful and the wonderful in order to envision and pursue new possibilities. 
In light of these key elements, as well as earlier insights, the potential characteristics of an alignment based approach to alternative development could be identified as:

- Self-understanding - Developing understanding of one's own conceptions of development and development practice, based on an awareness of one's beliefs and values, as the basis for seeking alignment with other actors.

- Open and ongoing dialogue - As the basis for seeking and assessing alignment between different actors involved in development initiatives.

- Relationship building - Building relationships of solidarity, trust and mutual understanding as the basis for development processes.

- Continuous critical reflection - Continuous critical reflection on the role of power in the relationships between actors and comparing actors theorias with their words and deeds in order to address complicity or echoing.

In terms of practice, such an alignment based approach would involve:

- Individually and/or collectively cultivating internal alignment and a personal understanding of development and development practice.

- Seeking out allies, organisations, colleagues and work environments that align with one's conception of development and engaging in development processes with these.

- Seeking complicity with affirmative and hopeful counter discourses, movements and agendas that align with one's own conception of development.

Finally, before concluding this section it is important to address potential critiques or weaknesses of an alignment based approach for alternative development. Through critically reflecting on the alignment approach presented here, I have identified four 
main concerns: exclusivity, the limits of privilege, the risk of universalism and the rejection of critical approaches.

With regard to the first concern, there is the risk that an alignment approach could lead to exclusivity where actors or groups of actors avoid working with each other due to strict adherence to their own conceptions and practices of development. Such a situation could breed alternative fundamentalisms and a patchwork of competing or conflicting development approaches. In order to address the risk of exclusivity it is essential that practitioners' conceptions of development (e.g. theorias) are "centred set, not bounded set" (Westboy, 2005 p17).

Personal conceptions of development should be centred in practitioners' core beliefs, values and conceptions of the good life rather than bounded by orthodoxies of methodology or aesthetics. Working with centred conceptions of development means alignment should be established based on why allies are carrying out a development processes rather than the details of how this actually happens or what exactly it results in. At the same time, it is important to remember that actors' conceptions of development are not static and there is always the possibility that conflicting conceptions of development may grow closer over time. This potential for emerging alignment underpins the need for continuous relationship building and dialogue in an alignment based approach as: "Only by taking alternative conceptions of social change, selfhood and the good life seriously can we respect differences and open ourselves to different professional and personal futures" (Brigg, 2009 p1423).

The second potential critique of an alignment approach is the privileged perspective that underlies it. One of the main implications evident in my investigation of interactor alignment was the importance of 'walking away' from development initiatives that are not aligned with one's conception of development. This is the response that I chose in relation to the local NGO with which I was working and its community 
conservation initiative. However it is a response that may not be available to other practitioners who do not occupy a political, economic or socio-cultural positioning that provides them the freedom to 'walk away'. An example of this may include community based workers who cannot or do not want to leave their communities or local NGOs who have to share a development arena with other organisations.

In response, I would argue that this research has been adopted from a privileged practitioner perspective and therefore offers insights and experiences that are more relevant to practitioners who share these privileges. On the other hand, a broader application of this alignment approach might also be possible. In attempting to extend the alignment approach to less privileged or more engaged practitioners, I believe that it would be most valuable when initiating one's involvement in a development initiative. Once within a development initiative and lacking the freedom to extract oneself, the situation would then become more complex. While I maintain my argument that there are degrees of misalignment that should not be tolerated by practitioners dedicated to good change it is also possible that lesser degrees of misalignment could remain workable. Lesser degrees of misalignment could still involve cooperation between actors such as forms of collective resistance or temporary alliances and selective cooperation. As mentioned earlier, personal theorias of development also do not remain static and there is always the possibility that continued relationship and dialogue will foster the co-construction of new collective theorias that both promote and represent, emergent inter-actor alignment. However, working within a context of misalignment will require practitioners' to determine how flexible they are willing to be in terms of their personal conception of development and development practice and where they draw the line. In doing so, working with a value centred conception of development would again be beneficial as would assessing the degree of harm that the misalignment might cause and the degree of hope one has in this misalignment improving. 
The third critique that I will address in relation to my proposal of an alignment based approach is the risk of universalism. Alternative development approaches are fundamentally opposed to universalised conceptions or totalising discourses of development. However, in proposing an alignment based approach to alternative development I risk imposing a new universal conception of how alternative development should be conceived and practiced.

On the one hand I could respond to this critique by employing a relativist stance and positioning my conception of alternative development alongside a range of others who possess equal claims. However in doing so I would be ignoring a central contradiction in alternative development theory - the fact that while denying universality, alternative development itself offers an implicit universal framework (see Table 1.). I would argue that this contradiction of alternative development actually represents a strength, in that it responds to critiques of relativity by proposing a "pluralisation of the universal" (Nakano, 2007 p73). In doing so it seeks to replace the totalising discourse of dominant development and its assertion of one way of life based on modernity, with a discourse of "a world where many worlds fit" (Habermann \& Ziai, 2007 p223).

The contribution of an alignment approach to this discourse includes its promotion of an ontology of possibility found in different alternative development approaches including spiritual approaches to development. The benefit of an alignment approach to alternative development practice is that it answers Santos's call for an approach that links different initiatives rather than prescribing a single theory for them to follow (Santos, 1999 p126). In linking different alternative development initiatives the alignment approach does not prescribe overarching normative guidelines for cooperation but instead proposes a process of collectively arriving at these through self-reflection and seeking alignment. As a result, an alignment approach could provide a means for linking different approaches, initiatives and practitioners within the broader framework and discourse of alternative development. 
Finally, my description of an alignment approach could be criticised for rejecting the benefits of critical approaches. In response, I would argue that the two approaches are in fact complementary in nature; a complementarity that is highlighted in their shared engagement with the concept of complicity. While critical approaches promote awareness of one's unconscious implications in harmful discourses, an alignment approach adds a focus on consciously pursuing more affirmative and hopeful forms of complicity including those advocated by Gunaratnam (2003) and Kindon (2012).

Insights from my research suggest that constructive complicity in contextualised thirds (such as the CCA concept) can act to 'cover up' misalignment between actor theorias in ways that still facilitate 'productive' relationships but limit the achievement of alternative development goals. Such situations can lead to an "Emperor has no clothes" scenario where social constructions of success do not correspond to the practice situations encountered (Rap, 2006). Such situations indicate the need for an 'aligned complicity' where contextualised thirds exist as the manifestation of interactor alignment (rather than a covering over of misalignment) and facilitate productive relationships based on shared development conceptions and objectives.

To achieve such 'aligned complicity' it is important for practitioners be involved in "thinking-through-complicity" (Kindon, 2012) together. In doing so practitioners can identify which forms of complicity are based on shared goals and understandings and seek to develop complicity as affinity (ibid) in the form of relationships of solidarity, mutual trust and respect. Forms of 'thinking-through-complicity' (Kindon 2012) can also contribute to achieving the foundation of humility necessary for the 'in-relationwith' orientation of an alignment approach. 


\subsection{Concluding Reflections}

An alignment approach to alternative development based on pursuing complicity, seeking alignment and an 'in-relation-with' orientation to others, distinguishes itself by the fact that it pursues inter-actor alignment towards possibilities and alternatives. In this sense, pursuing an alignment approach to alternative development is perhaps more difficult than adopting a critical or resistance approach. While resisting may require only limited alignment with other actors against particular threats, seeking alignment involves building relationships and understandings that move actors toward alternatives based on shared visions, values and aspirations. While alignment towards alternatives will necessarily involve the rejection of shared thirds such as 'dominant development' or 'racism' etc., their rejection and/or deconstruction should always be carried out in relation to the alternative conception of development being constructed or pursued. As a result an alignment approach involves moving beyond networks of resistance to networks of alliance based on shared values, beliefs and hopes for the future. Doing so will require forging relationships built on a re-working of the affirmation that:

If you come only to help me, you can go back home. But if we consider each other's struggles as part of our own struggles for alternatives then maybe we can work together.

(Based on a quote from an aboriginal activist in Habermann \& Zai, 2007 p222)

Such an approach may appear daunting but it is a journey that each practitioner can begin from within their own practice by engaging with their personal conceptions of development. 


\section{REFERENCES}

Agnivesh, A. (2003) A Spiritual Vision for the Dialogue of Religions, Development, 46 (4), 35-38.

Agostino, A. (2007) Post-development - Unveiling clues for a possible future. In (Ed) Ziai, A. Exploring Post-development - Theory and practice, problems and perspectives. Oxon: Routledge.

Alkire, S. (2006) Religion and Development. In D. A. Clark (Ed.), Elgar Companion to Development Studies (pp. 502-510). UK: Edward Elgar Publishing Limited.

Ashdord, G. \& Patkar, S. (2001) The Positive Path. Canada: IISD Publishing

Bahai International Community (1998) Valuing Spirituality in Development. Paper presented at 'The World Faiths and Development Dialogue', London, UK.

Bannister, D. (1962) Personal construct theory: A summary and experimental paradigm, Acta Psychologica, 20, 104-120.

Baudot, B. (Ed.) (2003) Candles in the Dark: A New Spirit for a Plural World. Washington: University of Washington Press. 
Bell, S. (1997) Not in isolation: the necessity of systemic heuristic devices in all development practice, Public Administration \& Development, 17 (5), 449-452.

Beres, L. (2004) A Reflective Journey: Spirituality and Postmodern Practice, New Scholarship in the Human Services. Retrieved from http://www.ucalgary.ca/currents/files/currents/v3n1_beres.pdf.

Blunt, P. Prisoners of the paradigm: process consultants and 'clinical' development practitioners, Public Administration \& Development, 17 (3), 341-349.

Boog, B. (2003) The Emancipatory Character of Action Research, its History and the Present State of the Art. Journal of Community \& Applied Social Psychology, 13, 426438.

Brigg, M. (2009) The Developer's Self: a non-deterministic Foucauldian frame, Third World Quarterly, 30 (8), 1411-1426.

Carmen, R. (1996) Autonomous Development: Humanizing the Landscape. London: Zed.

Chambers, R. (1995) NGOs and development: the primacy of the personal, IDS Working Paper Series, 14, 1-13.

Chambers, R. (1997) Whose Reality Counts? Putting the First Last. London: Intermediate Technology Publications. 
Chambers, R. (2007) From PRA to PLA and Pluralism: Practice and Theory. IDS Working Paper 286.

Charmaz, K. (2008) Reconstructing Grounded Theory. In (Eds.) Alasuutari, P., Bickman, L. \& Brannen, J., The SAGE Handbook of Social Research Methods. London: Sage Publications.

Chatteton, P., Fuller, D., \& Routledge, P. (2007) Relating Action to Activism: Theoretical and Methodological Reflections. In (Eds.) Kindon, S., Pain, R. \& Kesby, M., Participatory Action Research Approches and Methods: Connecting People. Oxon: Routledge.

Chile, L. \& Simpson, G. (2004) Spirituality and community development: Exploring the link between the individual and the collective. Community Development Journal, 39 (4), 318-331.

Cohen, A. (2006) Be the change, Tikkun, 21, 60-61.

Cooke, B. (1997) From process consultation to a clinical model of development practice, Public Administration \& Development, 17 (3), 325-340.

Cooke, B. \& Kothari, U. (2001) Participation: the new tyranny? New York: Zed Books.

Cresswell, J. (2003) Research Design - Qualitative, Quantitative and Mixed Method Approaches. USA: Sage Publications. 
Dag Hammarskjöld Foundation (1975) What Now? Another Development. Retrieved from http://www.dhf.uu.se/pdffiler/75 what now.pdf.

Dalai Lama XIV (2001) Ethics for the New Millennium. New York: Riverhead Books.

Deranty, J. (2010) Critical Theory. In Encyclopedia of Political Theory. SAGE

Publications. Retrieved from http://www.sage-

ereference.com/view/politicaltheory/n109.xml.

De Silva, G.V.S. (Ed.) (1988) Towards a Theory of Rural Development. Progressive Publishers.

De Vries, P. (2007) Don't Compromise Your Desire for Development! A Lacanian/Deleuzian Rethinking of theAnti-Politics Machine. Third World Quarterly, 28 (1), 25-43.

Dowling, M. (2008) Reflexivity. In The Sage Encyclopedia of Qualitative Research Methods. SAGE Publications. Retrieved from http://www.sageereference.com/research/Article n377.html.

Doyle, T. (2005) Environmental Movements In Majority And Minority Worlds: A Global Perspective. NJ: Rutgers University Press. 
Eikeland, O. (2008) The ways of Aristotle - Aristotelian Phrónêsis, Aristotelian philosophyof dialogue, and action research. Bern: Peter Lang Publishers.

Eikeland, O. (2012) Action Research - Applied Research, Intervention Research, Collaborative Research, Practitioner Research, or Praxis Research?, International Journal of Action Research, 8 (1), 9-44.

Eikeland, O. \& Nicolini, D. (2011) Turning practically: broadening the horizon, Journal of Organizational Change Management, 24 (2), 164-174.

Elliot, C. (1999) Locating the energy for change: an introduction to appreciative inquiry. Winnipeg: IISD

England, K. (1994) Getting Personal: Reflexivity, Positionality and Feminist Research. Women in the Field, 46 (1), 80-89

Escobar, A. (1995) Encountering development: the making and unmaking of the Third World. Princeton, NJ: Princeton University Press.

Escobar, A. (1995b) Imagining a post-development era. In (Ed.) Crush, J. Power of development. London: Routledge, pp. 211-227.

Escobar, A. (2000) Beyond the Search for a Paradigm? Post-Development and beyond, Development, 43 (4), 11-14. 
Escobar, A. (2004) Other Worlds Are (Already) Possible: Self-organisation, Complexity, and Post-capitalist Cultures. In (Eds.) Sen, J., Anand, A., Escobar, A. and Waterman, P., World Social Forum: Challenging Empires. New Delhi: The Viveka Foundation.

Escobar, A. (2007) 'Post-development' as concept and social practice. In (Ed) Ziai, A. Exploring Post-development - Theory and practice, problems and perspectives. Oxon: Routledge.

Esteva, G. \& Prakash, M. S. (1996) Grassroots Post-Modernism: Beyond Human Rights, the Individual Self, the Global Economy, New York: Peter Lang.

Fasenfest, D. (2006) Critical Sociology. In 21st Century Sociology. SAGE Publications. Retrieved from http://www.sage-ereference.com/view/sociology/n60.xml.

Fechter, A. (2012) The Personal and the Professional: Aid workers' relationships and values in the development process. Third World Quarterly, 33 (8), 1387-1404.

Finlay, L. (2002) Negotiating the swamp: The opportunity and challenge of reflexivity in research practice, Qualitative Research, 2 (2), 209-230.

Flora, C.B. \& Flora, J.L. (2006) The Sociology of Development. In 21st Century Sociology. SAGE Publications. Retrieved from http://www.sageereference.com/view/sociology/n50.xml. 
Fook, J., White, S. \& Gardener, F. (2006) Critical Reflection in Health and Social Care. UK: Open University Press.

Fook, J. \& Gardener, F. (2007) Practising Critical Reflection - A Resource Handbook. UK: Open University Press.

Fortin, J.R. (2002) Benedictine spirituality: A basis for revaluating modern development trends. In (Ed.) Baudot, B.S., Candles In The Dark - A new spirit for a plural world. Seattle: UWP.

Freidman, J. (1992) Empowerment: the Politics of Alternative Development. Cambridge: Blackwell

Frances, M. (1995) Organizational change and personal mythology, Personnel Review, $24(4), 58-68$.

Freire, P. (2005) Pedagogy of the Oppressed. New York: The Continuum International Publishing Group.

Gamer, R.E. (2002) Development Reflecting Human Values. In (Ed.) Baudot, B.S., Candles In The Dark - A new spirit for a plural world. Seattle: UWP.

Ghaye, T., Melander-Wikman, A., Kisare, M., Chambers, P., Bergmark, U., Kostenius, C. \& Lillyman, S. (2008) Participatory and appreciative action and reflection (PAAR) democratizing reflective practices, Reflective Practice, 9 (4), 361-397. 
Gibbs, G.R. (2007) Analyzing Qualitative Data. London: Sage Publications.

Gibson-Graham, J.K. (2005) Surplus possibilities: postdevelopment and community economies, Singapore Journal of Tropical Geography, 26 (1), 4-26.

Goulet, D. (1975) The Cruel Choice. New York: Atheneum Paperback.

Goulet, D. (1980) Development Experts: The One-Eyed Giants, Worid Development, 8, 481-489.

Goulet, D. (1997) Development ethics: a new discipline. International Journal of Social Economics, 24, (11), 1160-1171.

Gray, D.E. (2007) Facilitating management learning: Developing critical reflection through reflective tools, Management Learning, 38 (5), 495-517.

Gronemeyer, M. (1992) Helping. In (Ed) Sachs, W., The Development Dictionary - A guide to knowledge as power. London: Zed Books.

Gunaratnam, Y (2003) Researching Race and Ethnicity: methods, knowledge and power. London: Sage. 
Habermann, F. \& Ziai, A. (2007) Development, internationalism and social movements A view from the North. In (Ed) Ziai, A. Exploring Post-development - Theory and practice, problems and perspectives. Oxon: Routledge.

Harper, S. \& Clancy, K. (1999) 'The Way to Do Is to Be': Exploring the Interface between Values and Research, Gender and Development, 7 (1), 73-80.

Henderson, H. (1991) Paradigms in Progress. Indianapolis: Knowledge Systems.

Heron, B. (2007) Desire for Development: Whiteness, gender and the helping imperative. Waterloo: Wilfred Laurier University Press.

Hickey, S. \& Mohan, G. (Eds.) (2004) Participation - From Tyranny to Transformation: Exploring New Approaches to Participation in Development. London: Zed Books

Holliday, O.J. (2009) La sistematización de experiencias y las corrientes innovadoras del pensamiento Latinoamericano, Dialogo de Saberes, 3, 118-129.

Hope, A. \& Timmel, S. (2003) A Kenyan Experience for Faith-Based Transformative Action, Development, 46 (4), 93-99.

Hunt, C. (2006) A step too far? Mythopoesis, spirituality and professional reflective practice. Paper presented at 'Professional Lifelong Learning: Beyond Reflective Practice', Leeds. 
International Foundation for Development Alternatives (1980) Building Blocks for Alternative Development Strategies - A progress Report from the Third System Project, IFDA Dossier 17.

Jabareen, Y. (2009) Building a Conceptual Framework: Philosophy, Definitions, and Procedure, International Journal of Qualitative Methods 2009, 8 (4), 49-62.

James, R. (2010) Vices and Virtues in Capacity Development by International NGOs, IDS Bulletin, 41 (3), 13-24.

Joans, P.S. (2000) Why is it alright to do development 'over there' but not 'here'? Changing vocabularies and common strategies of inclusion across the 'First' and 'Third' Worlds. Observations, 32, (2), 237-241.

Johns, C. (2005) Balancing the winds. Reflective Practice, 6 (1), 67-84.

Joy, L. (1997) Developing a development practice - A commentary in response to Cooke, Public Administration \& Development, 17 (5), 453-477.

Kapoor, I. (2004) Hyper-Self-Reflexive Development? Spivak on Representing the Third World 'Other', Third World Quarterly, 25 (4), 627-647.

Kapoor, I. (2005) Participatory Development, Complicity and Desire, Third World Quarterly, 26 (8), 1203-1220. 
Kapra, F. (1982) The Turning Point. London: Bantam.

Kavanagh, J. \& Mander, J. (Eds.) (2004) Alternatives to Economic Development. San Francisco: Berret-Koehler Publishing.

Kesby, M. (2007) Spatialising participatory approaches: geography's contribution to a mature debate, Environment \& Planning A, 39 (12), 2813-2831.

Khader, S.J. (2011) Beyond Inadvertent Ventriloquism: Caring Virtues for Antipaternalist Development Practice, Hypatia, 26 (4), 742-761.

Kiely, R. (1999) The last refuge of the noble savage? A critical assessment of postdevelopment theory, The European Journal of Development Research, 11 (1), 30-55.

Kindon, S. (2012). 'Thinking-through-Complicity' with Te Iwi o Ngāti Hauiti: Towards a Critical Use of Participatory Video for Research (Doctoral thesis), University of Waikato, New Zealand.

Kippler, C. (2010) Exploring Post-Development: Politics, the State and Emancipation. POLIS Journal, 3, 1-38.

Kirkeby, O.F. (2009) Olav Eikeland (2008): The Ways of Aristotle. Aristotelian phrónêsis, Aristotelian Philosophy of Dialogue, and Action Research, International Journal of Action Research, 5 (1), 144-151. 
Kliksberg, B. (2003) Facing the Inequalities of Development: Some lessons from Judaism and Christianity, Development, 46 (4), 57-63.

Korten, D. C. (1990) Getting to the 21st Century: Voluntary Action and the Global Agenda. West Hartford: Kumarian Press.

Korten, D. (2007) The Great Turning: From Empire to Earth Community. San Francisco: Berrett-Koehler Publishers.

Kothari, M. (2006) An agenda for thinking about 'race' in development, Progress in Development Studies, 6, (1), 9-23.

Krishnamurti, J. (1944) Living in an Insane World. Fifth Talk in The Oak Grove. Retrieved from http://www.jkrishnamurti.org/krishnamurti-teachings/viewtext.php?tid=173\&chid=4529.

Kumar, S. (2003) Development and Religion: Cultivating a sense of the sacred, Development, 46 (4), 15-21.

Latouche, S. (1992) Standard of Living. In (Ed) Sachs, W., The Development Dictionary A guide to knowledge as power. London: Zed Books.

Laynton, R. (2009) Mysticism, Madness and Mania. Retrieved from http://www.scribd.com/doc/32793162/Mysticism-Madness-and-Mania-Full-Editionan-Exploration-of-Experiences-of-God-and-Mental-Disorder. 
Lepenies, P.H. (2008) An Inquiry into the Roots of the Modern Concept of Development. Contributions to the History of Concepts, 4, 202-225.

Lie, J.H.S. (2008) Post-Development Theory and the Discourse-Agency Conundrum. Social Analysis, 52 (3), 118-137.

Lockyer, S. (2004) Coding Qualitative Data. In (Eds.) Lewis-Beck, M.S., Bryman, A. \& Futing Liao, T., The SAGE Encyclopedia of Social Science Research Methods. London: Sage Publications.

Long, N. (1992) From paradigm lost to paradigm regained. The case for an actor oriented sociology of development. In (Eds) Long, N. \& Long, A., Battlefields of Knowledge: The Interlocking of Theory and Practice in Social Research and Development. London: Routledge.

Long, N. (2001) The case for an actor-oriented sociology of development. London: Routledge.

Long, N. (2003) An Actor-oriented Approach to Development Intervention. In (Ed.) Cruz, D.A., Rural Life Improvement in Asia. Tokyo: Asian Productivity Organization.

Loy, D.R. (2003) The Poverty of Development: Buddhist reflections. Development, 46 (4), 15-21. 
Lunn, J. (2009) The Role of Religion, Spirituality and Faith in Development: a critical theory approach, Third World Quarterly, 30 (5), 937-951.

Lupenz, M. (2011) Pseudonym for a study carried out on the CCA by a European researcher.

Lushaba, L.S. (2009) Development as modernity, modernity as development. Dakar: CODESRIA

Marcus, G. (1998) Ethnography through Thick and Thin. Princeton: Princeton University Press.

Mas Suibhne (2009) 'Wrestle to be the man philosophy wished to make you': Marcus Aurelius, reflective practitioner, Reflective Practice, 10 (4), 429-436.

Mathews, S. (2007) What, then, should we do? Insights and experiences of a Senegalese NGO. In (Ed) Ziai, A. Exploring Post-development - Theory and practice, problems and perspectives. Oxon: Routledge.

Max-Neef, M. (1991) Human Scale Development. USA: Apex Press.

McGregor, A. (2009) New Possibilities? Shifts in Post-Development Theory and Practice, Geography Compass, 3(5), 1688-1702. 
Mehmet, O. (1996) Westernizing the Third World. Humanomics, 12, (3), 37-55.

Mesbahuddin, T. (2010) Religion in Development : An Islamic Model Emerging in Bangladesh, Journal of South Asian Development, 5 (2), 221-241.

Miller, D.C. \& Salkind, N.J. (2004) Handbook of Research Design \& Social Measurement. London: Sage Publications.

Mitlin, D., Hickey, S. \& Bebbington, A. (2008) Introduction: Can NGOs Make a Difference? The Challenge of Development Alternatives. In (Eds.) Mitlin, D., Hickey, S. \& Bebbington, A. London: Zed Books.

Moore, A.B. (2002) Community development practice: theory in action. Journal of the Community Development Society, 33(1), 20-32.

Morgan, M.L. (1998). Búsquedas Teóricas y Epistemológicas desde la práctica de la Sistematización. Paper presented at 'Seminario Latinoamericano de Sistematización de Prácticas de Animación Sociocultural y Participación Ciudadana en América Latina', Medellín. Retrieved from http://unpan1.un.org/intradoc/groups/public/documents/icap/unpan033084.pdf

Mottier, V. (2005) The Interpretive Turn: History, Memory, and Storage in Qualitative Research, Forum: Qualitative Social Research, 6 (2), 1-10. 
Muzaffar, C. (1999) From Human Rights to Human Dignity. In (Ed.) Van Ness, P., Debating Human Rights: Critical Essays from the United States and Asia. London: Routledge.

Muzhou, P. (2005) Enemies of Civilization: Attitudes toward Foreigners in Ancient Mesopotamia, Egypt, and China. NY: SUNY Press.

Nabudere, D. W. (1997) Beyond Modernization and Development, or Why the Poor Reject Development. Geografiska Annaler. Series B, Human Geography, 79, (4), 203215.

Nagar, R. \& Geiger, S. (2007) Reflexivity and Positionality in Feminist Fieldwork Revisited. In (Eds) Tickell, A. \& Sheppard, E., Politics and Practice in Economic Geography (p267-278). London: Sage.

Nerfin, M. (1986) Neither Prince nor Merchant: Citizen - An Introduction to the Third System Approach. (Eds) Ahooja-Patel, K., Drabek, A.G. \& Nerfin, M. World Economy in Transition. Oxford: Oxford University Press.

Nicanor, L. (2010) Pseudonym for a study carried out on the CCA by a South American researcher.

Norberg-Hodge, H. (1992) Ancient Furtures - Learning from Ladakh. San Francisco: Sierra Club Books. 
Nuten, C.A. \& Leedom, D. (2007) Deductive Sensemaking Principles Using Personal Constructs of the Field Commanders. Paper presented at 'The 12th International Command \& Control Research and Technology Symposium', Newport. Retrieved from http://www.dodccrp.org/events/12th ICCRTS/CD/html/papers/213.pdf.

Oakley, P. \& Marsden, D. (1985) Approaches to participation in rural development. Geneva: ILO Publications.

Parfitt, T. (2004) The Ambiguity of Participation: A Qualified Defence of Participatory Development, Third World Quarterly, 25 (3), 537-556.

Parpart, J. (2000) Rethinking Participatory Empowerment, Gender and Development: The PRA approach, Research Centre on Development and International Relations Working Paper No. 92.

Payne, G. \& Payne, J. (2004) Key Concepts in Social Research. London: Sage Publications.

Pieterse, J.N. (1998) My Paradigm or Yours? Alternative Development, PostDevelopment, Reflexive Development. Development and Change, 29, 343-373.

Pieterse, J. (2000) After post-development. Third World Quarterly, 21 (2), 175-191. 
Poutanen, S. \& Kovalainen, A. (2009) Critical Theory. In Encyclopedia of Case Study Research. SAGE Publications. Retrieved from http://www.sageereference.com/view/casestudy/n97.xml.

Radcliffe, S. \& Laurie, N. (2006) Culture and development: taking culture seriously in development for Andean indigenous people, Environment and Planning D: Society and Space, 24, 231-248.

Rahman, M.A. (1993) People's self development: perspectives on participatory action research. London: Zed Books.

Rap, E. (2006). The Success of a Policy Model: Irrigation Management Transfer in Mexico, Journal Of Development Studies, 42 (8), 1301-1324.

Reeler, D. (2001) Unlearning - facing up to the real challenge of learning. Cape Town: Community Development Resource Association (CDRA).

Reeler, D. (2007) A Theory of Social Change and Implications for Practice, Planning, Monitoring and Evaluation. Cape Town : Community Development Resource Association (CDRA).

Refsum, G. (2007) Personal Theory Towards a Model of Knowledge Development for Design Practitioners, Nordes, 2, 1-10. Retrieved from http://www.nordes.org/opj/index.php/n13/article/view/165/148 
Remmers, G. (2007) The Spectrum of Endogenous Development: In search of a conceptual red line. In (Eds) Haverkort, B. \& Rist, S., Endogenous Development and Biocultural Diversity. Netherlands: Compas/CDE.

Rist, G. (2007) Development as a Buzzword. Development in Practice, 17 (4/5), 485491.

Rose, G. (1997) Situating knowledges: positionality, reflexivity and other tactics, Progress in Human Geography, 21 (3), 305-320

Sanderson, E. (2007) The Challenge of Placing Spirituality within Geographies of Development, Geography Compass, 1 (3), 389-404.

Sanderson, E. (2009) Emotional engagement in the context of development and spirituality research, Emotion, Space and Society, 5, 122-130.

Santos, B. (1999) On Oppositional Postmodernism. In (Eds) R. Munck and D. O'Hearn, Critical Development Theory: Contributions to a New Paradigm. London and New York: Zed Books.

Saitta, D.J. \& Keene, A.S. (1990) Politics and surplus flow in prehistoric communal societies. In (Ed.) Upham, S., The Evolution of Political Systems. Caimbridge: CUP.

Schumacher, E.F. (1989) Small Is Beautiful: Economics as if People Mattered. New York: Harper \& Row Publishers. 
Schwandt, T.A. (2007) The SAGE Dictionary of Qualitative Inquiry. London: Sage Publications.

SDC (2005) Role and Significance of Religion and Spirituality in Development Cooperation. Switzerland: Holenstein, A.

Segers, K., Dessein, J., Nyssen, J., Haile, M. \& Deckers, J. (2008) Developers and farmers intertwining interventions: the case of rainwater harvesting and food-for-work in Degua Temben, Tigray, Ethiopia, International Journal of Agricultural Sustainability, 6 (3), 173-182.

Sen, J., Anand, A., Escobar, A., and Waterman, P. (eds) (2004) World social forum: challenging empires. New Delhi: The Viveka Foundation

Shahid Alam, M. (2003) Articulating group differences: A variety of autocentrisms. Science \& Society, 67, (2), 205-217

Sheth, D. L. (1987) Alternative Development as Political Practice, Alternatives, 12 (2), 155-71.

Shiva, V. (1993) Monocultures of the Mind. Penang: Zed Books.

Singh, B. (2007) Integration of Spirituality with Community Development For Peace (Master's Thesis). Paññāsāstra University, Cambodia. 
Spivak, G. (1988) Can the subaltern speak? In (Eds) Nelson, C. \& Grossberg, L., Marxism and Interpretation of Culture. Chicago: University of Illinois Press.

Stenberg, S.J. (2006) Liberation Theology and Liberatory Pedagogies: Renewing the Dialogue, College English, 68 (3), 271-290.

Stewart, M. (2001) Encouraging reflective practice, an introduction to a range of strategies, JMU Learning Issues Press, 4-7.

Tauli-Corpuz, V., Enkiwe-Abayao, L. \& de Chavez, R. (Eds) (2010) Indigenous Peoples' Self-Determined Development. Baguio City, Philippines: Tebtebba Foundation.

Taylor, V. E. (2010) Critical Theory. In Encyclopedia of Identity. SAGE Publications. Retrieved from www.sage-ereference.com/view/identity/n56.xml.

Thomas, A. (2004) The Study of Development. Paper prepared for DSA Annual Conference, Church House, London.

Tuhiwai Smith, L. (1999) Decolonizing Methodologies. London, UK: Zed Books.

United Nations Office on Crime and Drugs (2005) Alternative Development: A Global Thematic Evaluation. Vienna: United Nations Publications 
Ver Beek, K.A. (2000) Spirituality: a development taboo, Development in Practice, 10 (1), 31-43.

Von Eckhart, B. (1998) Introspection, psychology of. In Craig, E. (Ed.), Routledge Encyclopedia of Philosophy. London: Routledge.

Walker, B.M. \& Winter, D.A. (2005) Kellian invalidation, attachment and the construct of 'control'. In (Eds.) Winter, D. \& Viney, L., Personal Construct Psychotherapy: Advances in Theory, Practice and Research. London: Whurr Publishers.

Weiner, I.B. \& Craighead, E. (2009) Personal Construct Theory. In (Eds.) Weiner, I.B. \& Craighead, E., The Corsini Encyclopedia of Psychology. New Jersey: John Wiley \& Sons.

Westboy, P. (2005) Flirting with Spirituality within Community Development Practice. Paper presented at 'Flirting with Spirituality', Maleny, Queensland.

Zeldin, T. (1994) An intimate History of Humanity. New York: Harper Collins

Ziai, A. (2007) Development discourse and its critics - An introduction to postdevelopment. In (Ed) Ziai, A., Exploring Post-development - Theory and practice, problems and perspectives. Oxon: Routledge. 